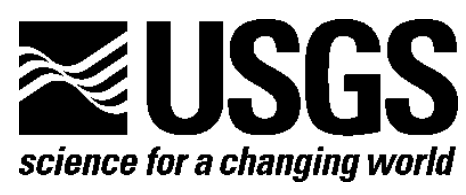

Prepared in cooperation with California Geological Survey

\title{
2018 U.S. Geological Survey-California Geological Survey Fault-Imaging Surveys Across the Hollywood and Santa Monica Faults, Los Angeles County, California
}

By Rufus D. Catchings, Janis Hernandez, Mark R. Goldman, Joanne H. Chan, Robert R. Sickler, Brian Olson, and Coyn J. Criley 


\section{U.S. Department of the Interior \\ DAVID BERNHARDT, Secretary}

\section{U.S. Geological Survey James F. Reilly II, Director}

U.S. Geological Survey, Reston, Virginia: 2020

For more information on the USGS-the Federal source for science about the Earth, its natural and living resources, natural hazards, and the environment-visit http://www.usgs.gov/ or call 1-888-ASK-USGS (1-888-275-8747).

For an overview of USGS information products, including maps, imagery, and publications, visit http://store.usgs.gov/.

To order USGS information products, visit http://store.usgs.gov/.

Any use of trade, firm, or product names is for descriptive purposes only and does not imply endorsement by the U.S. Government.

Although this information product, for the most part, is in the public domain, it also may contain copyrighted materials as noted in the text. Permission to reproduce copyrighted items must be secured from the copyright owner.

Suggested citation:

Catchings, R.D., Hernandez, J., Goldman, M.R., Chan, J.H., Sickler, R.R., Olson, B., and Criley, C.J., 2020, 2018 U.S. Geological Survey-California Geological Survey fault-imaging surveys across the Hollywood and Santa Monica Faults, Los Angeles County, California: U.S. Geological Survey Open-File Report 2020-1049, 42 p., https://doi.org/10.3133/ofr20201049.

Associated data for this publication:

Goldman, M.R., Catchings, R.D., Chan, J.H., Sickler, R.R., Criley, C.C., Hernandez, J.L., and Olson, B., 2020, Data release for the 2018 U.S. Geological Survey-California Geological Survey fault-imaging surveys across the Hollywood and Santa Monica Faults, Los Angeles County, California: U.S. Geological Survey data release, https://doi.org/10.5066/P9ENA8D4. 


\section{Acknowledgments}

Partial funding for this work was provided by the California Geological Survey (CGS). We thank CGS for identifying and securing the investigative fault sites. We thank Deshawn Brown, Michael DeFrisco, Erik Frost, Maxime Mareschal, Gordon Seitz, Brian Swanson, and Christopher Tran of the California Geological Survey for assistance in acquiring the data for this report. We thank the First Presbyterian Church of Hollywood, the City of Los Angeles, and the City of Beverly Hills for access. We thank Yong-Gang Li of the University of Southern California, and Walter Mooney of the U.S. Geological Survey (USGS), for reviewing the manuscript.

We thank the following USGS scientists: Kerri Gefeke, Dan Langermann, Belle Philibosian, and Ali Pickering; we also thank USGS volunteers Joseph Catchings, Shirley Imsand, Richard Philibosian, and Nathan Suits, for assistance in acquiring the data for this report. We thank Shane Detweiler, Mike Diggles, and Taryn Lindquist (all USGS) for editing and formatting and reviewing. 


\section{Contents}

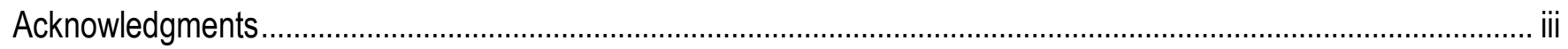

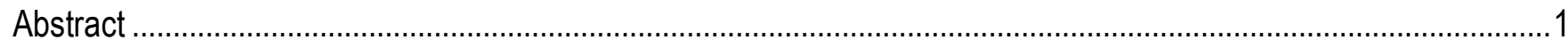

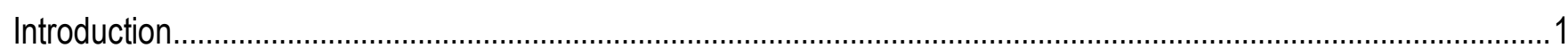

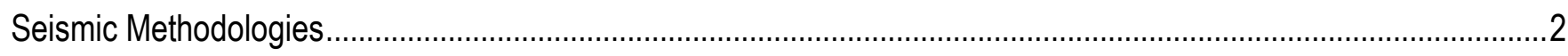

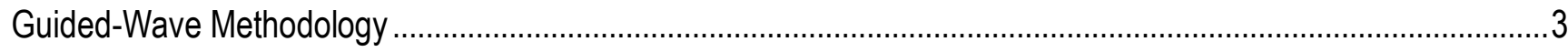

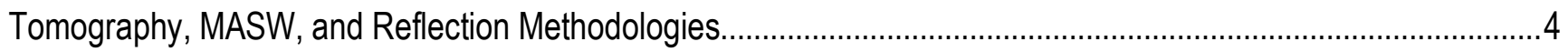

Hollywood Fault Data Acquisition and Profiles........................................................................................

Hollywood Fault Profile HW1 …………....................................................................................................

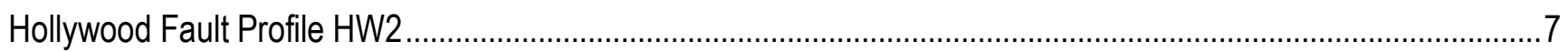

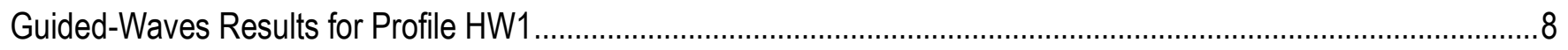

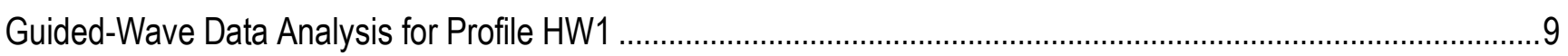

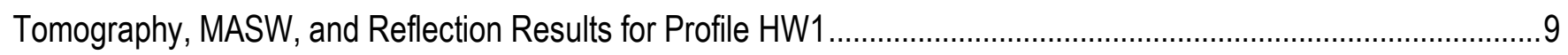

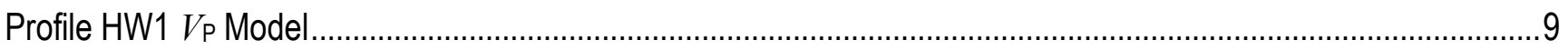

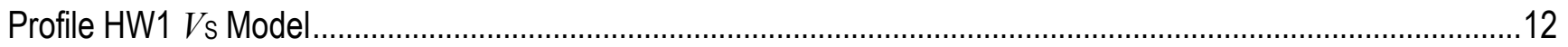

Profile HW1 VP/Vs Ratios, Tomography Model.......................................................................................13

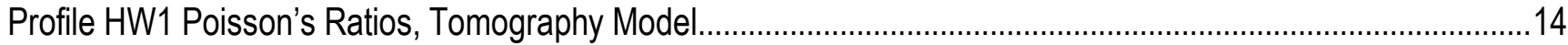

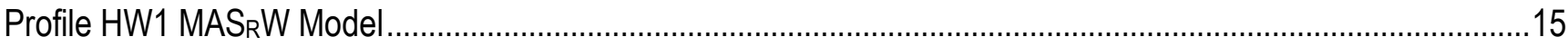

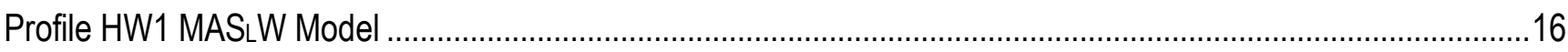

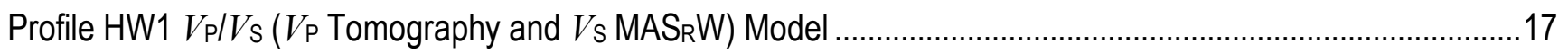

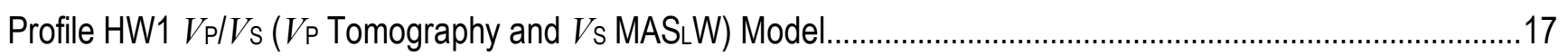

Profile HW1 P-Wave Reflection Stack .......................................................................................................

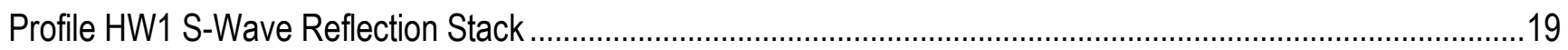

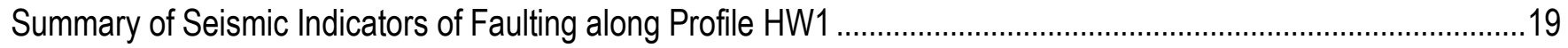

Guided-Wave Results for Profile HW2

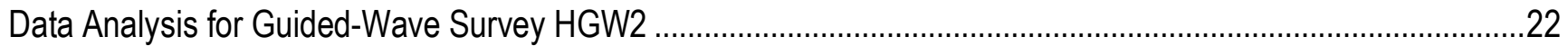

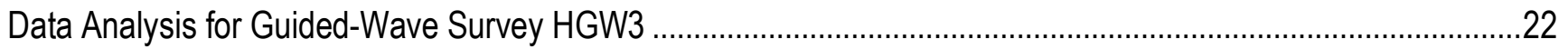

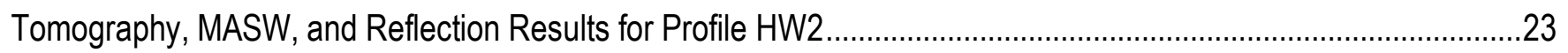

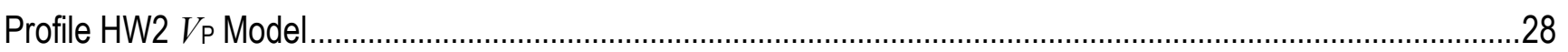

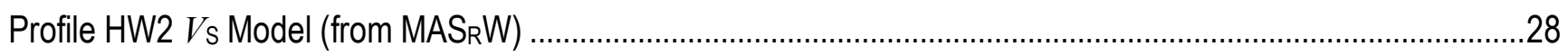

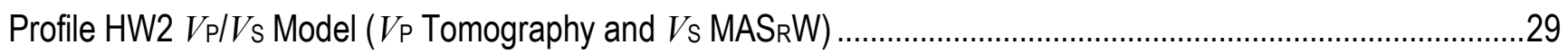

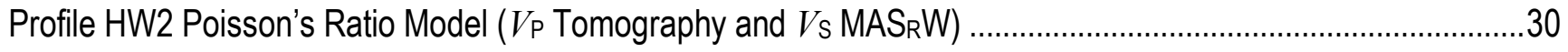

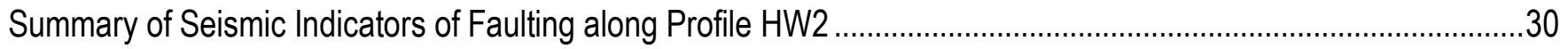

Summary of Observations, Hollywood Fault .................................................................................................

Santa Monica Fault Data Acquisition (Beverly Hills) ...........................................................................................

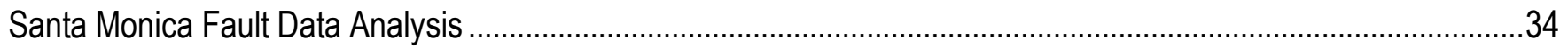

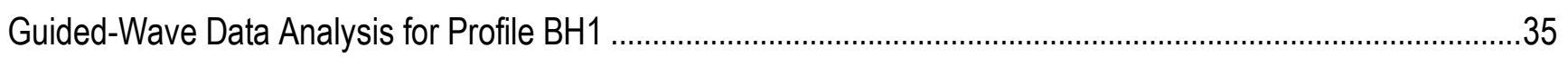


Beverly Hills Profile BH2 Guided-Waves

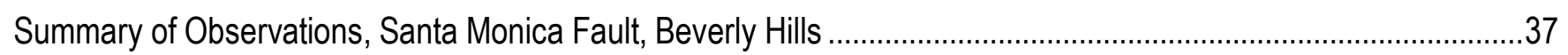

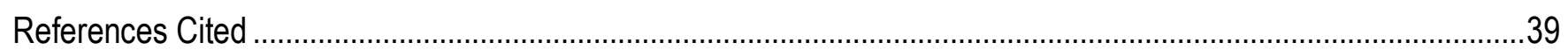

Figures

Figure 1. Mosaic of Google Earth images of the greater Los Angeles area, showing locations of the Hollywood Fault, Santa Monica Fault, and other faults.

Figure 2. Google Earth image of study area along Hollywood Fault ...............................................................

Figure 3. Google Earth image of Hollywood Fault study area near Profile HW1 .................................................

Figure 4. Google Earth image of Hollywood Fault study area near Profile HW2 ..............................................

Figure 5. Stacked guided-wave shot gathers for Profile HW1 .......................................................................

Figure 6. Plot of peak ground velocity (PGV) of guided waves for each recording channel along Profile HW1; and plot of time of arrival of corresponding PGV values.....................................................................11

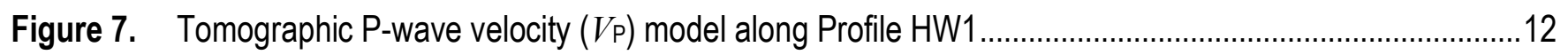

Figure 8. Tomographic S-wave velocity $(V \mathrm{~s})$ model along Profile HW1 ........................................................13

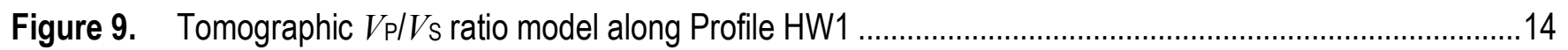

Figure 10. Tomographic Poisson's ratio model along Profile HW1. ..................................................................

Figure 11. S-wave velocity $\left(V_{\mathrm{s}}\right)$ model inferred from Rayleigh waves. ................................................................16

Figure 12. S-wave velocity $\left(V_{\mathrm{s}}\right)$ model inferred from Love waves....................................................................17

Figure 13. $V_{\mathrm{P}} / V_{\mathrm{S}}$ ratio model along Profile $\mathrm{HW} 1$ derived from a combination of our $V_{\mathrm{P}}$ tomography model and our $M A S_{R} W V_{S}$ model. 18

Figure 14. Poisson's ratio model along Profile HW1 derived from combination of our $V_{\mathrm{P}}$ tomography model and our MASLW $V$ S model.

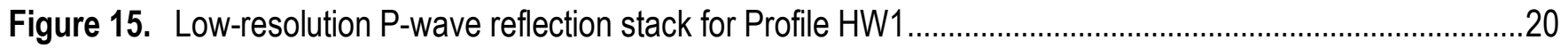

Figure 16. Low-resolution S-wave reflection stack for Profile HW1 ....................................................................

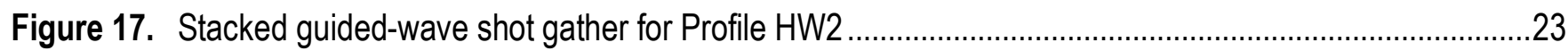

Figure 18. Plot of peak ground velocities (PGV) of guided waves for each recording channel along part of Profile HW2, and plot of travel times from SP1 to Profile HW2 ................................................................24

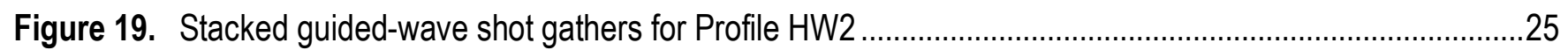

Figure 20. Plot of all peak ground velocities (PGV) of guided waves for each recording channel along part of Profile HW2, and travel times of PGV values; plot of PGV of guided waves along part of Profile HW2, and travel times of PGV values.

Figure 21. In-line P-wave shot gather along Profile HW2, south of Yucca Street.................................................28

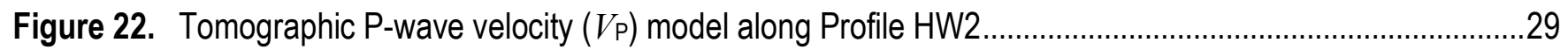

Figure 23. S-wave velocity $\left(V_{\mathrm{s}}\right)$ model along Profile HW2

Figure 24. $V_{\mathrm{P}} / V_{\mathrm{S}}$ ratio model along Profile $\mathrm{HW} 2$, derived from combination of our $V_{\mathrm{P}}$ tomography model and our MASRW $V_{\mathrm{S}}$ model.

Figure 25. Poisson's ratio model along Profile HW1, derived from combination of our $V_{\mathrm{P}}$ tomography model and our MASRW $V_{\mathrm{S}}$ model saturated zone between two faults. Locations of nearby streets are shown. Abbreviation: $\mathrm{m}$, meter(s). 
Figure 26. Google Earth image of Santa Monica Fault in our study area in Beverly Hills..

Figure 27. Stacked guided-wave shot gather for BHGW1 seismic survey

Figure 28. Plot of peak ground velocity (PGV) of guided waves for each recording channel along BHGW1 survey. and plot of time of arrival of corresponding PGV values

Figure 29. Stacked guided-wave shot gather for Profile $\mathrm{BH} 2$.

Figure 30. Plot of peak ground velocity (PGV) of guided waves for recording channels along BHGW2 survey. and plot of time of arrival of corresponding PGV values.

\section{Conversion Factors}

International System of Units to U.S. customary units

\begin{tabular}{|c|c|c|}
\hline Multiply & By & To obtain \\
\hline \multicolumn{3}{|c|}{ Length } \\
\hline centimeter $(\mathrm{cm})$ & 0.3937 & inch (in.) \\
\hline millimeter (mm) & 0.03937 & inch (in.) \\
\hline meter $(\mathrm{m})$ & 3.281 & foot $(\mathrm{ft})$ \\
\hline kilometer $(\mathrm{km})$ & 0.6214 & mile (mi) \\
\hline \multicolumn{3}{|c|}{ Flow rate } \\
\hline meter per second $(\mathrm{m} / \mathrm{s})$ & 3.281 & foot per second (ft/s) \\
\hline \multicolumn{3}{|c|}{ Mass } \\
\hline kilogram $(\mathrm{kg})$ & 2.205 & pound avoirdupois $(\mathrm{lb})$ \\
\hline
\end{tabular}

\section{Abbreviations}

1-D one dimensional

2-D two dimensional

AGC automatic gain control

AWD accelerated weight drop

CGS California Geological Survey

HGW1 Hollywood guided-wave survey 1

HGW2 Hollywood guided-wave survey 2

HGW3 Hollywood guided-wave survey 3

HRR1 Hollywood refraction-reflection survey 1

HRR2 Hollywood refraction-reflection survey 2

HW1 Hollywood seismic profile 1 (P-wave survey)

HW2 Hollywood seismic profile 2 (S-wave survey)

HW3 Hollywood seismic profile 3 (P-wave survey)

$\mathrm{Hz} \quad$ hertz

MASW multichannel analysis of surface waves

MAS $_{\mathrm{L}} \mathrm{W} \quad$ MASW for Love waves

$\mathrm{MAS}_{\mathrm{R}} \mathrm{W} \quad \mathrm{MASW}$ for Rayleigh waves

PGV peak ground velocity

$V_{\mathrm{P}} \quad$ P-wave or compressional-wave velocity

$V_{\mathrm{P}} / V_{\mathrm{S}}$ ratio ratio of $\mathrm{P}$-wave velocity to S-wave velocity

$V_{\mathrm{S}} \quad$ S-wave or shear-wave velocity

USGS U.S. Geological Survey

UTC coordinated universal time 


\section{U.S. Geological Survey-California Geological Survey Fault-Imaging Surveys Across the Hollywood and Santa Monica Faults, Los Angeles County, California}

By Rufus D. Catchings, ${ }^{1}$ Janis Hernandez, ${ }^{2}$ Mark R. Goldman, ${ }^{1}$ Joanne H. Chan, ${ }^{1}$ Robert R. Sickler, ${ }^{1}$ Brian Olson, ${ }^{2}$ and Coyn J. Criley 1

\section{Abstract}

We acquired multiple types of seismic data across the Hollywood Fault in Hollywood, Calif., and the Santa Monica Fault in Beverly Hills, Calif., in May and June 2018. On the basis of our data, we infer near-surface locations of various traces of these faults.

From two separate profiles across the Hollywood Fault, we evaluated multiple seismic datasets and models, including guided-wave data, tomographic $V_{\mathrm{P}}$ data, tomographic $V_{\mathrm{S}}$ data, $V_{\mathrm{P}} / V_{\mathrm{S}}$ and Poisson's ratio models derived from tomographic $V_{\mathrm{P}}$ and $V_{\mathrm{S}}$ data, Rayleigh-wave-based $V_{\mathrm{S}}$ models, Love-wave-based $V_{\mathrm{S}}$ models, $V_{\mathrm{P}} / V_{\mathrm{s}}$ and Poisson's ratio models (derived from combinations of tomographic-based $V_{\mathrm{P}}$ and surface-wave-based $V_{\mathrm{S}}$ models), P-wave reflection images, and S-wave reflection images. All of these data and models can be used to delineate near-surface faulting, and the data consistently infer near-surface fault traces of the Hollywood Fault in the same locations. Importantly, the combined data indicate more than one near-surface fault trace of the Hollywood Fault. Between North Bronson and North Gower Avenues, evidence exists for a near-surface trace of the Hollywood Fault slightly south of Carlos Avenue. Farther west, along Argyle Avenue, our data contain high levels of cultural noise, but we interpret near-surface faulting slightly south of the intersection of Carlos and Argyle Avenues and between Carlos Avenue and Yucca Street.

For the Santa Monica Fault in Beverly Hills, we acquired guided-wave data only along Lasky Drive between Moreno Drive and South Santa Monica Boulevard, owing to limited access permissions. However, we used two separate source locations to generate the guided-wave data (SP1 and SP2). The data from more distant source location (relative to the recording array, SP1) were noisy, but on the basis of those data, we infer near-surface faulting at several locations along Lasky Drive, with concentrated near-surface faulting slightly south of the intersection of Lasky Drive and Charleville Boulevard. Guided-wave data generated at the closer source location (relative to recording array, SP2) more clearly show evidence for distributed near-surface faulting at several locations along Lasky Drive, with concentrated faulting near the intersection of Lasky Drive and Charleville Boulevard.

Although the seismic surveys across both faults provide strong evidence for the locations of near-surface fault traces, the seismic data provide little or no information about the rupture history of the fault traces.

\section{Introduction}

In May and June 2018, the U.S. Geological Survey (USGS) and the California Geological Survey (CGS) jointly conducted a series of seismic investigations in Los Angeles County, Calif., that

\footnotetext{
${ }^{1}$ U.S. Geological Survey

${ }^{2}$ California Geological Survey
} 
were aimed at locating near-surface traces of the Hollywood Fault in Hollywood, Calif., and the Santa Monica Fault in Beverly Hills, Calif. (fig. 1). For the Hollywood Fault, we acquired four seismic surveys along two transects, from which we evaluated five types of seismic data, as well as multiple data combinations that can be used to evaluate near-surface faulting. We used active sources to generate body waves, surface waves, and guided waves, and from those data, we evaluated (1) P-wave velocities $\left(V_{\mathrm{P}}\right)$, S-wave velocities $\left(V_{\mathrm{S}}\right)$, and their ratios using tomography, (2) S-wave velocities $\left(V_{\mathrm{S}}\right)$ using multichannel analysis of surface waves (MASW) on Rayleigh and Love waves, (3) peak ground velocities (PGV) of guided waves, (4) reflection images, and (5) combinations of those data. For the Santa Monica Fault, we acquired two guided-wave seismic surveys along Laskey Drive, from which we evaluated PGV of guided waves. In this report, we present images, models, and interpretations for the acquired data.

\section{Seismic Methodologies}

Faulting produces physical effects in the shallow subsurface that can be observed using multiple seismic-imaging methods. Although various types of seismic data can be affected differently by nearsurface faulting, those effects generally occur within the fault zone at the same locations. As a result, using multiple seismic datasets can provide greater confidence in the locations of near-surface faults.

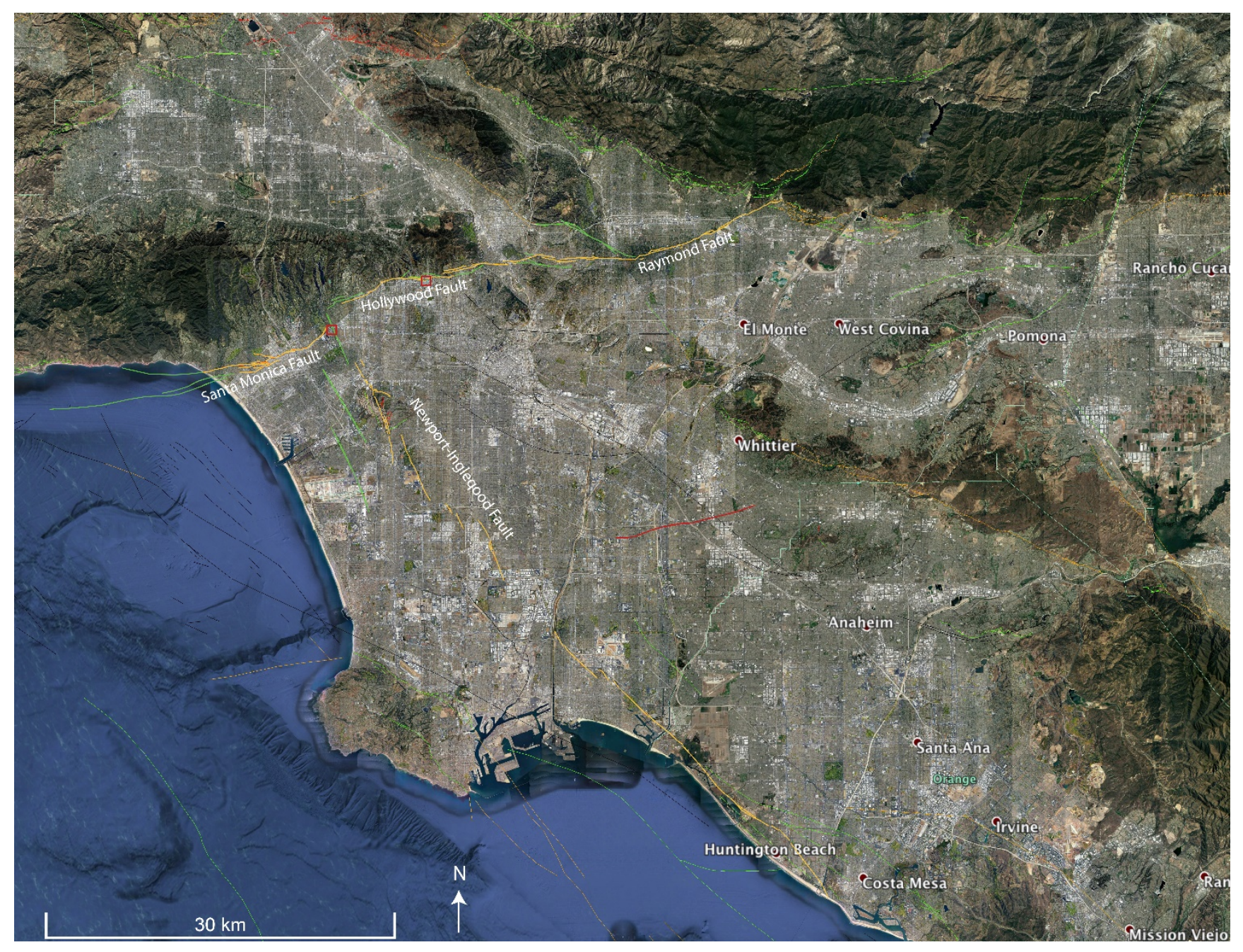

Figure 1. Mosaic of Google Earth images of the greater Los Angeles area, showing locations of the Hollywood Fault, Santa Monica Fault, and other faults. Small red rectangles indicate locations of Hollywood and Beverly Hills seismic profiles. Red lines show locations of historic faulting. Abbreviation: km, kilometer(s). 
Here, we briefly describe some of these effects and how they relate to the seismic methods used in this investigation.

Shearing during the faulting process reduces the rigidity of faulted rocks and materials. As a result, both $\mathrm{P}$ - and $\mathrm{S}$-wave velocities ( $V_{\mathrm{P}}$ and $V_{\mathrm{S}}$, respectively) decrease within fault zones relative to the surrounding rock mass. Empirical studies using laboratory data (Wang and others, 1978), active-source refraction data (Healy and Peake, 1975; Mooney and Luetgert, 1982; Mooney and Ginzburg, 1986; Jarchow and others, 1994; Catchings and others, 1998, 2002, 2008, 2009, 2014, 2016; Catchings, 1999), seismic-velocity logs (Boness and Zoback, 2004 ), earthquake-source data (Mayer-Rosa, 1973; Aki and Lee, 1976; Thurber, 1983; Eberhart-Phillips, 1990; Thurber and Atre, 1993; Thurber and others, 1995; Eberhart-Phillips and Michael, 1998), and guided-wave data (Leary and others, 1987; Li and Vidale, 1996; Li and others, 2000, 2007; Korneev and others, 2003; Li and others, 2014; Catchings and others, 2016) show a significant reduction (as much as 50\%) in seismic velocities within fault zones.

These reductions in $V_{\mathrm{P}}$ and $V_{\mathrm{S}}$ that are due to faulting typically are seen in velocity models as near-vertical zones of low seismic velocities. However, in the shallow subsurface, low-velocity fault zones can be obscured in $V_{\mathrm{P}}$ models because of the presence of near-surface groundwater, which causes $V_{\mathrm{P}}$ in fault zones to increase, rather than decrease. In the shallow subsurface, $V_{\mathrm{S}}$, which is strongly affected by the shear modulus, is typically more affected by faulting than $V_{\mathrm{P}}$, which is strongly affected by the bulk modulus and the presence of groundwater. As a result, the ratios of $V_{\mathrm{P}}$ to $V_{\mathrm{S}}$ can be unusually high in fault zones, and such high ratios typically are highly diagnostic of near-surface faulting (Catchings and others, 2014).

Where present, stratigraphic layers can be vertically offset by near-surface faulting, particularly for reverse and normal faulting. Seismic-refraction tomography is a highly useful method for identifying such vertical offsets, particularly when different rock types are juxtaposed across faults. Seismicreflection imaging is another particularly useful seismic method for identifying such vertical offsets when subhorizontally layered strata is present in the shallow subsurface. However, small vertical offsets may not be seen in the near-surface at the resolutions of many seismic-reflection surveys, particularly when faulting produces little vertical offset.

Guided waves (see below) can also be highly diagnostic of near-surface faulting when a fault trace can be identified in at least one location along its length. Collectively, these methods have been shown to be highly diagnostic of near-surface faulting.

\section{Guided-Wave Methodology}

With respect to seismic-wave propagation, low-velocity fault zones can be considered as wave guides that channel seismic energy. A number of studies have documented the wave-guide effect and the seismic energy that travels along and within the fault zones. This seismic energy is referred to as faultzone-guided waves or fault-zone-trapped waves (Cormier and Spudich, 1984; Li and Leary, 1990; Li and others, 1990, 1997, 2000; Hough and others, 1994; Huang and others, 1995; Ben-Zion, 1998; Jahnke and others, 2002; Rovelli and others, 2002; Ben-Zion and others, 2003; Malin and others, 2006; Li and others, 2014). Fault-zone-guided waves travel exclusively within low-velocity fault zones, and once the seismic energy enters the fault zone, high-amplitude seismic energy results from coherent multiple reflections at the boundaries between low-velocity fault zones and higher velocity wall rocks (Cormier and Spudich, 1984; Leary and others, 1987; Li and Leary, 1990; Li and Vidale, 1996).

Propagation of the seismic waves in fault zones is somewhat similar to optical-fiber light transmission. The amplitudes of fault-zone-guided waves are typically much larger, and the velocities are much lower, than body waves that travel outside of the fault zone (Cormier and Spudich, 1984; Spudich and Olson, 2001; Fohrmann and others, 2004; Ellsworth and Malin, 2011). Numerical studies have shown that highamplitude guided waves are generated and propagate within fault zones only when the source is located within, or very close to, the fault zone ( $\mathrm{Li}$ and Leary, 1990; Li and Vidale, 1996; Ben-Zion, 1998; Ingel 
and others, 2002) or when the source underlies a fault zone that extends only to shallow depths (Fohrmann and others, 2004). Thus, for most crustal faults, guided waves propagate only along faults that are continuous between the seismic source and the observation point, as a discontinuous fault prevents lateral propagation of guided waves beyond the endpoint of the fault (Li and Vidale, 1996; Jahnke and others, 2002). Thus, the presence, continuity, and connectivity of faults can be inferred from the presence or absence of guided waves along faults (Catchings and others, 2016).

Guided waves have been identified in most studies on the basis of their relatively low-velocity, high-amplitude waveforms that have dispersive wavetrains, which are recorded on a series of seismographs deployed across or along a fault zone. The waveforms can be forward-modeled to estimate physical properties of the fault zone, including geometry, Q (attenuation), velocities, and temporal changes in velocity (Li and others, 2014, 2016). Furthermore, the locations of stations that record the high-amplitude waveforms and long time durations can be used to infer the overall maximum width of a fault zone, but this method is not ideal for locating individual fault traces within the overall fault zone.

In our study, we use peak amplitude (peak ground velocity [PGV]) of fault-zone-guided waves (Catchings and others, 2013, 2016) to more precisely locate individual fault traces within the overall fault zone. Because fault zones can be kilometers in width and can consist of multiple traces, evaluation of PGV is more effective in locating individual traces. For our present study, we identify guided waves as high-amplitude seismic waves that arrive later than the body waves (either $V_{\mathrm{P}}$ or $V_{\mathrm{S}}$ ) and are narrowly confined to a set of stations. Guided waves can be measured on either vertical- or horizontal-component sensors (Malin and others, 1996), but in our present study, we use only data from horizontal-component sensors.

\section{Tomography, MASW, and Reflection Methodologies}

To develop seismic images, we also used seismic-refraction tomography, multichannel analysis of surface waves (MASW), and seismic-reflection processing techniques in this study. We developed Pand S-wave seismic-refraction tomography models using first-arrival travel times and the modeling code of Hole (1992). The nonlinear travel-time-tomography method by Hole (1992) uses a finite-difference algorithm to solve the eikonal equation in computing first-arrival travel times from the source to the receiver, and the model is updated in iterative steps using backprojection. Because P- and S-wave geophones and their respective shots were colocated approximately every 2 meters $(\mathrm{m})$, we parameterized both our $V_{\mathrm{P}}$ and $V_{\mathrm{S}}$ models using 2-m horizontal (x) and vertical (z) intervals. For the tomographic inversions, we used 1-D starting models developed from shot-gather modeling that assumed similar but differing vertical variations in velocity. All starting models produced similar final velocity models, having velocities that generally differed by less than 5 percent at any given location in the final models. The geometrical setup of the seismic profile allowed us to use reciprocal shot and geophone (receiver) pairs to determine travel times. First arrivals were measured at nearly every geophone ( 89) for each shot point (89) along the profile, totaling nearly 7,900 first arrivals for the $\mathrm{P}$ waves and for $\mathrm{S}$ waves. Although most first arrivals could be measured on most shot gathers, for some less energetic shots, we used reciprocal travel times from the more energetic shots to ensure travel-time consistency.

We developed Rayleigh- and Love-wave $V_{\mathrm{S}}$ models using a version of the MASW method (Park and others, 1999) that was developed by Hayashi and Suzuki (2004) and Hayashi (2008) and is available in the Geometrics 2D SeisImager software package. For MASW analysis, the SeisImager algorithm constructs common midpoint correlations to develop 1-D dispersion curves and 1-D $V_{\mathrm{S}}$ models for each shot point along the seismic profiles, and, by laterally combining those $V_{\mathrm{S}}$ models, a 2-D $V_{\mathrm{S}}$ model can be developed for each seismic profile. Although the MASW method can be applied to Rayleigh- and Love-wave (surface wave) data, the MASW method was originally applied to Rayleigh waves (Xia and others, 1999) and is generally referred to as the MASW method in the scientific literature. However, the 
method is sometimes referred to as the $\mathrm{MAS}_{\mathrm{R}} \mathrm{W}$ method (Yong and other, 2013). The MASW method also has been applied to Love waves and has been referred to as the MALW method (Yuan, 2011; Xia and others, 2012; Catchings and others, 2017) or the MAS $\mathrm{L}_{\mathrm{L}} \mathrm{W}$ method (Yong and others, 2013). In this report, we use the $\mathrm{MAS}_{\mathrm{R}} \mathrm{W}$ and $\mathrm{MAS}_{\mathrm{L}} \mathrm{W}$ descriptors to differentiate between the MASW method when applied to Rayleigh and Love waves, respectively.

In seismic-reflection data processing, we followed procedures similar to those outlined by Brouwer and Helbig (1998). Processing steps included geometry installation, independent trace editing, timing corrections, automatic gain control (AGC), band-pass filtering, surgical muting of refractions, surface waves and airwaves, velocity analysis (tomographic and 1-D velocities), elevation static corrections and normal moveout correction (using refraction-tomography velocities), stretch muting, common-depth point stacking, and poststack AGC and band-pass filtering. We attempted to stack both the P-and S-wave reflection data to look for variations in the resolution of the images.

\section{Hollywood Fault Data Acquisition and Profiles}

We acquired seismic data along profiles in Hollywood between May 23, 2018, and June 1, 2018. Data were acquired in several stages, with the data being recorded along the following two transects: (1) Profile HW1, which consisted of a 178-m-long, north-south-trending, linear profile (within a parking lot) located north of Hollywood Boulevard and about 80 m east of North Gower Street (fig. 2), and (2) Profile HW2, a 370-m-long, north-south-trending, linear profile along North Argyle Avenue, between Hollywood Boulevard and Franklin Avenue (fig. 3).

\section{Hollywood Fault Profile HW1}

Profile HW1 originated on the north side of Hollywood Boulevard and ended in the courtyard of the First Presbyterian Church of Hollywood. We conducted several types of seismic investigations along Profile HW1. The first seismic investigation was a guided-wave survey (HGW1), whereby the recording array was perpendicularly offset from the seismic source, which was generated by a 227-kilogram $(\mathrm{kg})$ (500-pound [lb]) accelerated weight drop (AWD). We used 157 individual "shots" at the same physical location (SP1), and the individual "shots" were stacked to form a single shot gather containing faultzone-guided waves. Generally, the seismic source must be within or near a fault trace to generate guided waves, and so, accordingly, we placed SP1 within a known trace of the Hollywood Fault that had been previously investigated by core-boring and cone-penetration-testing (CPT) transects (Ninyo and Moore, 2015a, b).

The second seismic survey (HRR1) along Profile HW1 used active P-wave seismic sources (227$\mathrm{kg}$ AWD shots and 3.6-kg hammer shots) that were in line with the recording array. Both seismic sources generated seismic energy when an AWD or hammer vertically struck a steel plate on the ground surface. The recording array consisted of 89 vertical-component sensors that were spaced $2 \mathrm{~m}$ apart. For the HRR1 seismic survey, we recorded P-wave refraction, P-wave reflection, and Rayleigh-wave data that were evaluated for evidence of faulting. In acquiring the P-wave data, we generated seismic shots at locations coincident with the 89 sensors. We used two stacked AWD shots at each of the southernmost 70 shot points, and four stacked hammer shots for each of the northernmost 19 shots, which were largely within the church courtyard.

The third seismic survey (HRR2) along Profile HW1 used active S-wave sources that were in line with the recording array. We generated the seismic sources by horizontally striking a 3.6-kg hammer against an aluminum block that was tethered to the ground surface. The recording array consisted of 89 horizontal-component sensors that were spaced $2 \mathrm{~m}$ apart. For the HRR2 survey, we recorded S-wave refraction, S-wave reflection, and Love-wave data that were evaluated for evidence of faulting. In acquiring the S-wave data, we generated seismic shots at 78 (of 89) shot-point locations that 


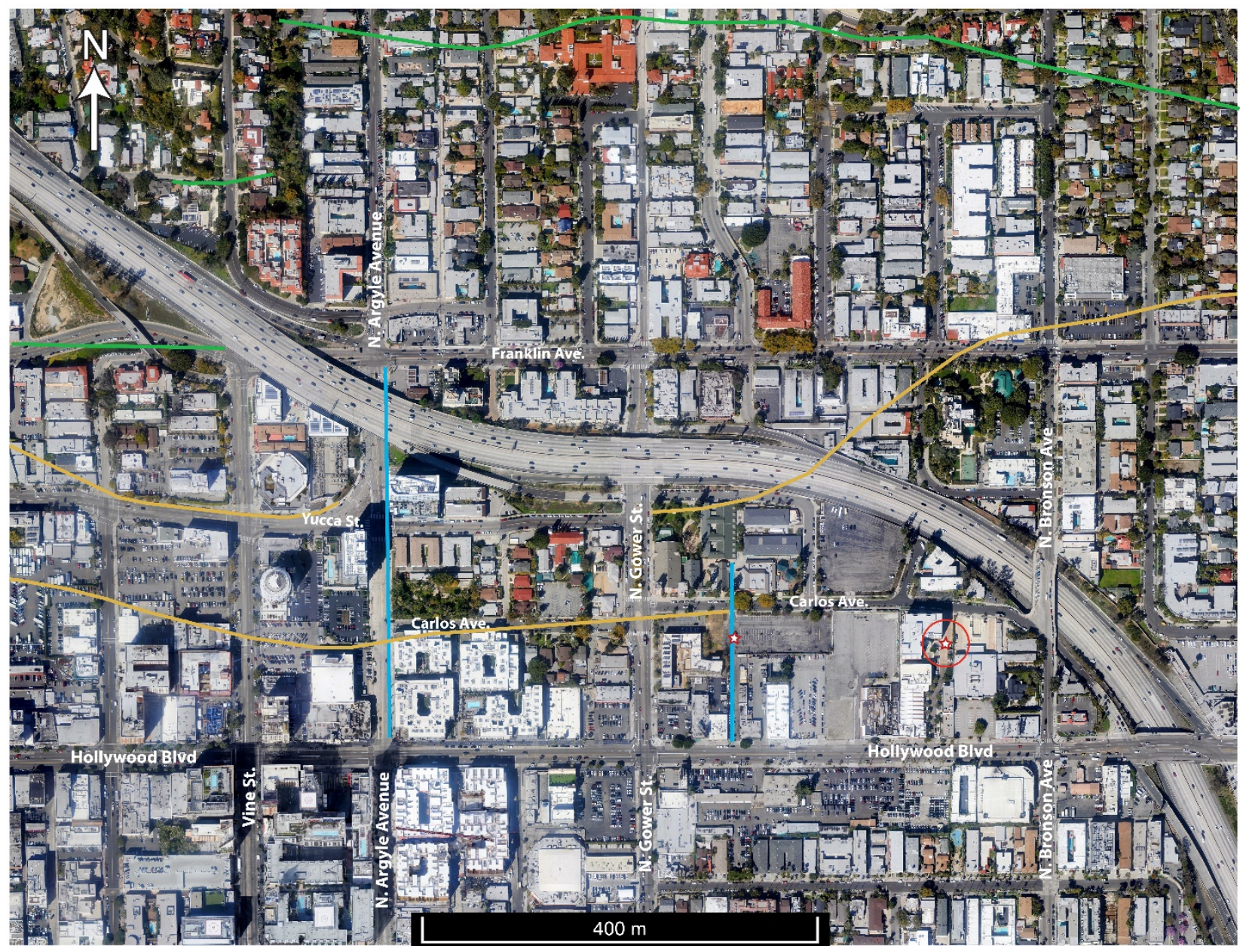

Figure 2. Google Earth image of study area along Hollywood Fault (yellow lines). Green lines show inferred location of faults of undetermined age. Blue lines show locations of seismic profiles: HW1 is shorter, eastern profile; HW2 is longer, western profile. Red stars show locations of shot points used to generate guided waves: SP2, star along profile HW1; SP1, circled star. Abbreviation: m, meter(s).

were coincident with horizontal-component sensors. Most of the unused shot-point locations were within the courtyard of the First Presbyterian Church of Hollywood, where the ground was covered with cement. To avoid damaging the cement, we chose not to have sources at sensor numbers 66,69 , and 81 to 89 . We used four stacked hammer-block shots for each shot point.

We used three types of recording systems along Profile HW1. For in-line, P- and Rayleigh-wave seismic imaging, we used Mark Products 4.5-hertz (Hz), vertical-component sensors (geophones) that were attached to a refraction cable. For in-line, S- and Love-wave seismic imaging, we used Mark Products $4.5-\mathrm{Hz}$, horizontal-component sensors that were attached to the same refraction cable. For both types of sensors, the refraction cable was attached to two 60-channel Geometrics RX60 Strataview seismographs. For both the P- and S-wave surveys, we used a sampling rate of 0.5 milliseconds (ms), and data were recorded for 2 seconds (s). For guided-wave recording along Profile HW1, at each recording site, we used two stand-alone, Reftek RT-125 (Texan) seismographs that were attached to Sercel $4.5-\mathrm{Hz}, 3-$ component $\mathrm{L}-28$ sensors, and we used a sampling rate of $0.5 \mathrm{~ms}$ and a recording length of $3 \mathrm{~s}$. 


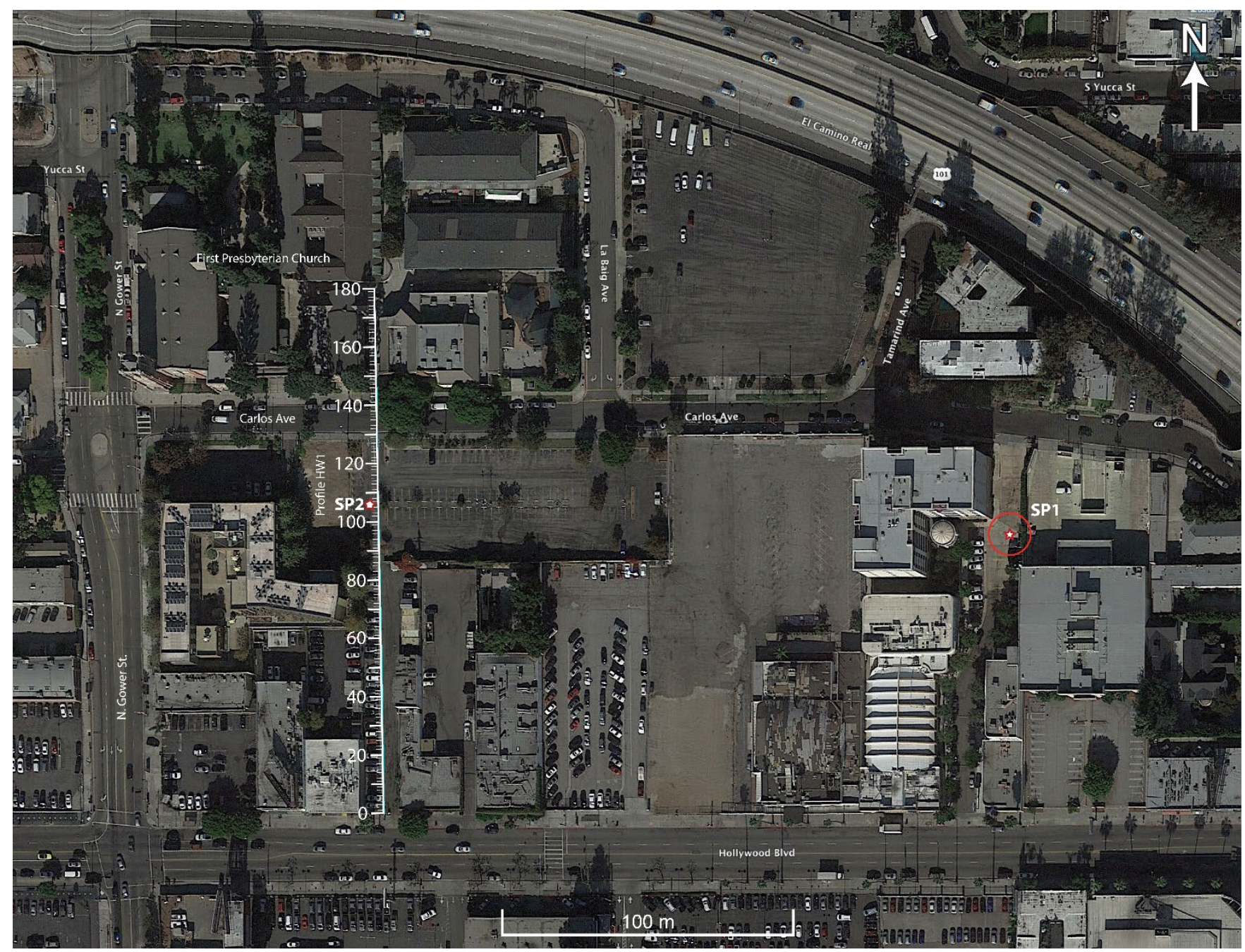

Figure 3. Google Earth image of Hollywood Fault study area near Profile HW1, showing distance scale (in meters [m]) along Profile HW1 and locations of shot points SP1 and SP2 (red stars). SP1 is located at the nearsurface fault trace, as determined by a core-boring and cone-penetration-testing (CPT) transect; SP2 is located at the near-surface trace of Hollywood Fault, as indicated by peak ground velocity of guided waves.

\section{Hollywood Fault Profile HW2}

Profile HW2 extended along the east side of North Argyle Avenue from Hollywood Boulevard to Franklin Avenue, crossing Yucca Street and Highway 101 near the north end of the profile (fig. 4). As with Profile HW1, we conducted several types of seismic investigations along Profile HW2 or parts of it. The first seismic survey along Profile HW2 was a guided-wave survey (HWG2), from which guidedwave data were acquired. The second seismic survey was an in-line P-wave survey (HRR3), from which reflection, refraction, and $\mathrm{MAS}_{\mathrm{R}} \mathrm{W}$ (multichannel analysis of surface waves, Rayleigh waves) data were acquired. The third seismic survey was an S-wave survey (HRR4), from which we attempted to acquire reflection, refraction, and $\mathrm{MAS}_{\mathrm{L}} \mathrm{W}$ (multichannel analysis of surface waves, Love waves) data; however, we recorded only $13 \mathrm{~S}$-wave shots for the HRR4 survey because our S-wave seismic sources were too weak to overcome the traffic noise along North Argyle Avenue. As a result, we did not process data for the third (HRR4) survey.

For the HRR3 in-line seismic survey, we deployed 66 channels, using 3-m spacing between each channel and having a total profile length of $195 \mathrm{~m}$. The actively recording profile extended only from 


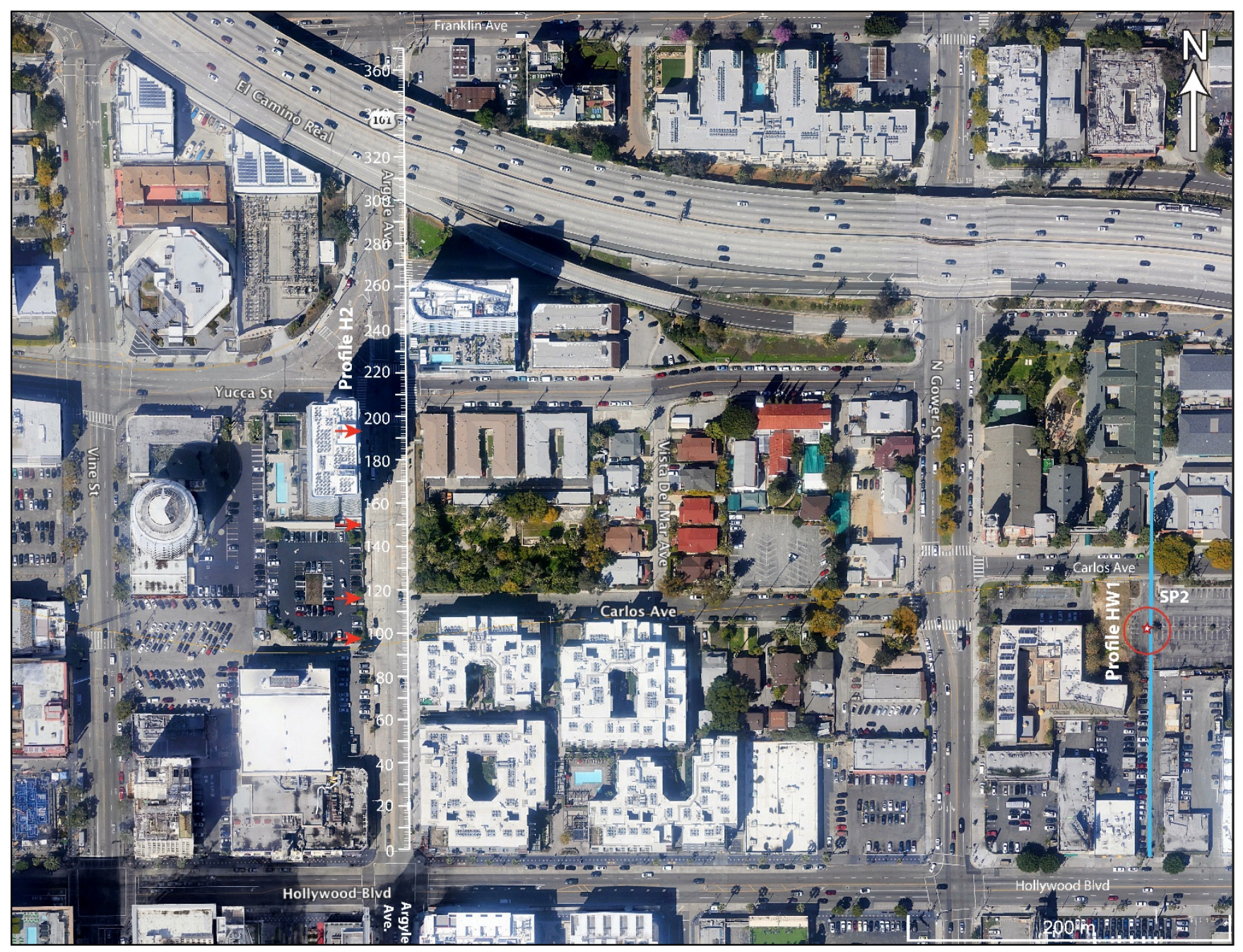

Figure 4. Google Earth image of Hollywood Fault study area near Profile HW2, showing distance scale (in meters [m]) along Profile HW2 (North Argyle Avenue) and location of SP2 (circled red star). Red arrows along North Argyle Avenue denote two zones of probable faulting, as indicated by seismic data. SP2 is located at the nearsurface trace of Hollywood Fault, as indicated by peak ground velocity of guided waves.

Hollywood Boulevard to Yucca Street (fig. 4). We used a 227-kg AWD to generate P- and Rayleighwave seismic energy along the profile, and a shot point was colocated with every active channel except three of them that had obstructions that prevented the use of the AWD. The P- (and Rayleigh-) wave data were recorded using two Geometrics RX-60 seismographs that were attached to refraction cables and Sercel 4.5-Hz, single-component (vertical) sensors.

\section{Guided-Waves Results for Profile HW1}

The guided-wave seismic survey (HGW1) along Profile HW1 was conducted on the night of May 24, 2018. Although we deployed 89 sensors that were spaced at 2-m intervals, ten of the sensors experienced instrumental failure. The seismic source for the HGW1 survey was located about $215 \mathrm{~m}$ east of the recording array and approximately $100 \mathrm{~m}$ west of North Bronson Avenue, between Carlos Avenue to the north and Hollywood Boulevard to the south (fig. 3). To record guided waves with less cultural noise, we generated seismic sources (157 AWD shots) in the evening hours of May 24, 2018, beginning at about 18:06:11 (local time) and continuing until 18:57:40. The resulting data contained clear arrivals and strong guided-wave energy. 


\section{Guided-Wave Data Analysis for Profile HW1}

Guided waves generated during the HGW1 survey were identifiable as high-amplitude arrivals following the shear-wave arrivals (figs. $5 A, B$ ). As a result, we evaluated PGV on the seismic traces only for the part of the seismic record at and following the S-wave first arrival. We correlated the PGV of the guided waves and the travel times to differentiate the guided waves from other possible strong arrivals (figs. 6A, $B$ ). The data show that the highest PGV values, which are expected at fault traces, arrived at the recording array at about $1,200 \mathrm{~ms}(1.2 \mathrm{~s})$, and, because the source was approximately $215 \mathrm{~m}$ from the recording array, we determined that the guided waves traveled (on average) at about $180 \mathrm{~m} / \mathrm{s}$. The earliest shear waves arrived at the recording array at about $800 \mathrm{~ms}(0.8 \mathrm{~s})$, suggesting an average $V_{\mathrm{S}}$ of about $270 \mathrm{~m} / \mathrm{s}$. Thus, the guided waves traveled at about 67 percent of the velocity of the shear waves, consistent with velocities expected of guided waves.

Because guided waves travel exclusively within fault zones as high-amplitude arrivals, the physical location of near-surface fault traces can be inferred from guided waves (fig. 6A), with the highest amplitudes occurring at the near-surface trace. Our analysis of the PGV of guided waves along Profile HW1 shows a prominent peak between channels 48 and 66 (meters 94-110) of the recording array, with the highest peak concentrated at channel 54 (meter 106) of Profile HW1. Although the highest PGV value occurs at channel 54, relatively high values also occur between channels 50 and 60 (meters 98-118), suggesting a wider fault zone at slightly greater depths. PGV values are appreciably lower to the north and south of the apparent fault zone (channels 48-66, meters 94-110), but an asymmetry is present in PGV values, whereby values to the south are higher than those to the north. We interpret this asymmetry to indicate either a near-surface southward dip of the fault zone or some additional deeper fault traces to the south of meter 106 of the seismic profile.

Our inferred fault location is also consistent with disruptions in lithology identified in previous borehole measurements (Group Delta, 2015). However, Group Delta (2015) interpreted this change in lithology as arising from a shallow-depth paleochannel at that location. We suggest, however, that a paleochannel cannot account for the presence of guided waves, the observed travel-time delay of the guided waves, or the discrete high PGV values at meter 106. As discussed below, a paleochannel also cannot account for other seismic anomalies observed at that location. Thus, we suggest that the lithology change and the high PGV values result from near-surface faulting near meter 106 of Profile HW1 .

In addition to the high PGV values at the apparent near-surface fault zone (meter 106), a zone of relatively higher PGV values is present between channels 1 and 18 (fig. 6A). Although this zone has high PGV values that would be expected of a deeper fault zone, the timing of the high PGV values (fig. $6 B$ ) suggests that they are not generated by guided waves. Instead, we suggest that this zone of high PGV values may be caused by seismic energy generated by the subway system (Metro Red Line), which is located beneath Hollywood Boulevard. With respect to guided waves, a subway system would be somewhat analogous to a fault zone, whereby high-amplitude seismic and sound waves that are generated within the subway bore by moving trains would be trapped and would propagate within the subway bore.

\section{Tomography, MASW, and Reflection Results for Profile HW1}

For the in-line active-source surveys along Profile HW1, we evaluated $V_{\mathrm{P}}, V_{\mathrm{S}}, V_{\mathrm{P}} / V_{\mathrm{S}}$ ratios, and Poisson's ratios, using $V_{\mathrm{P}}$ derived from tomography and $V_{\mathrm{S}}$ derived from several methods. We also evaluated $V_{\mathrm{P}}$ and $V_{\mathrm{S}}$ reflection images.

\section{Profile HW1 $V_{\mathrm{P}}$ Model}

Along Profile HW1, our tomography model (fig. 7) shows that $V_{\mathrm{P}}$ ranges from about $300 \mathrm{~m} / \mathrm{s}$ (at the surface) to $2,800 \mathrm{~m} / \mathrm{s}$ (at $\sim 50 \mathrm{~m}$ depth). In the shallow subsurface, a change in the depth of the 

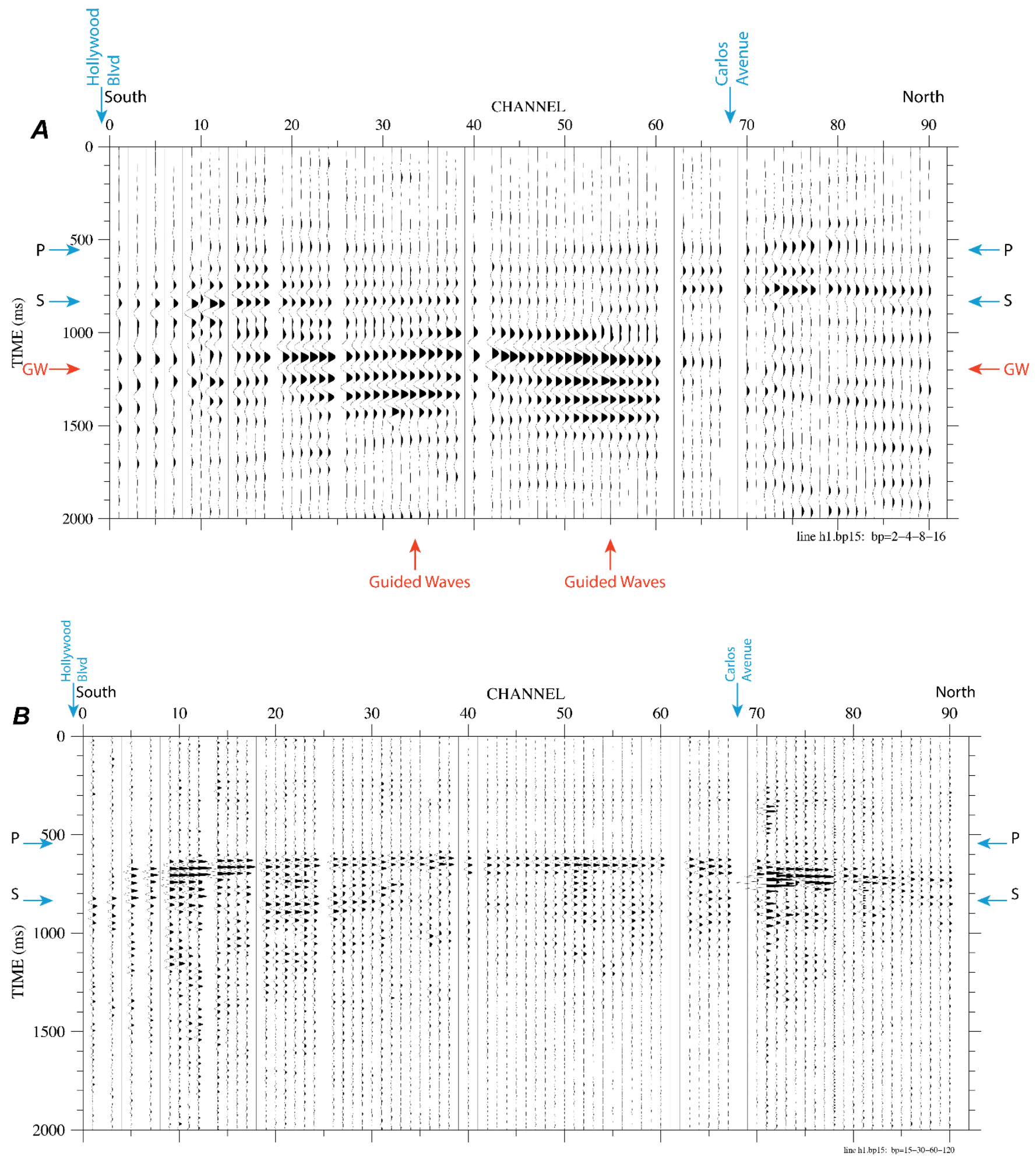

Figure 5. A, Stacked guided-wave shot gather for Profile HW1 (guided-wave survey HGW1). Source is located at SP1; recording array is located along Profile HW1. P waves (P), S waves (S), and guided waves (GW) are labeled on shot gather. Data were band-pass filtered between 2 and $16 \mathrm{~Hz}$. B, Same shot gather as in $A$, but filtered between 15 and $120 \mathrm{~Hz}$ (note that only P-waves and partial S-waves are prominent at higher frequencies). Locations of nearby streets are shown. Other abbreviation: ms, millisecond(s). 

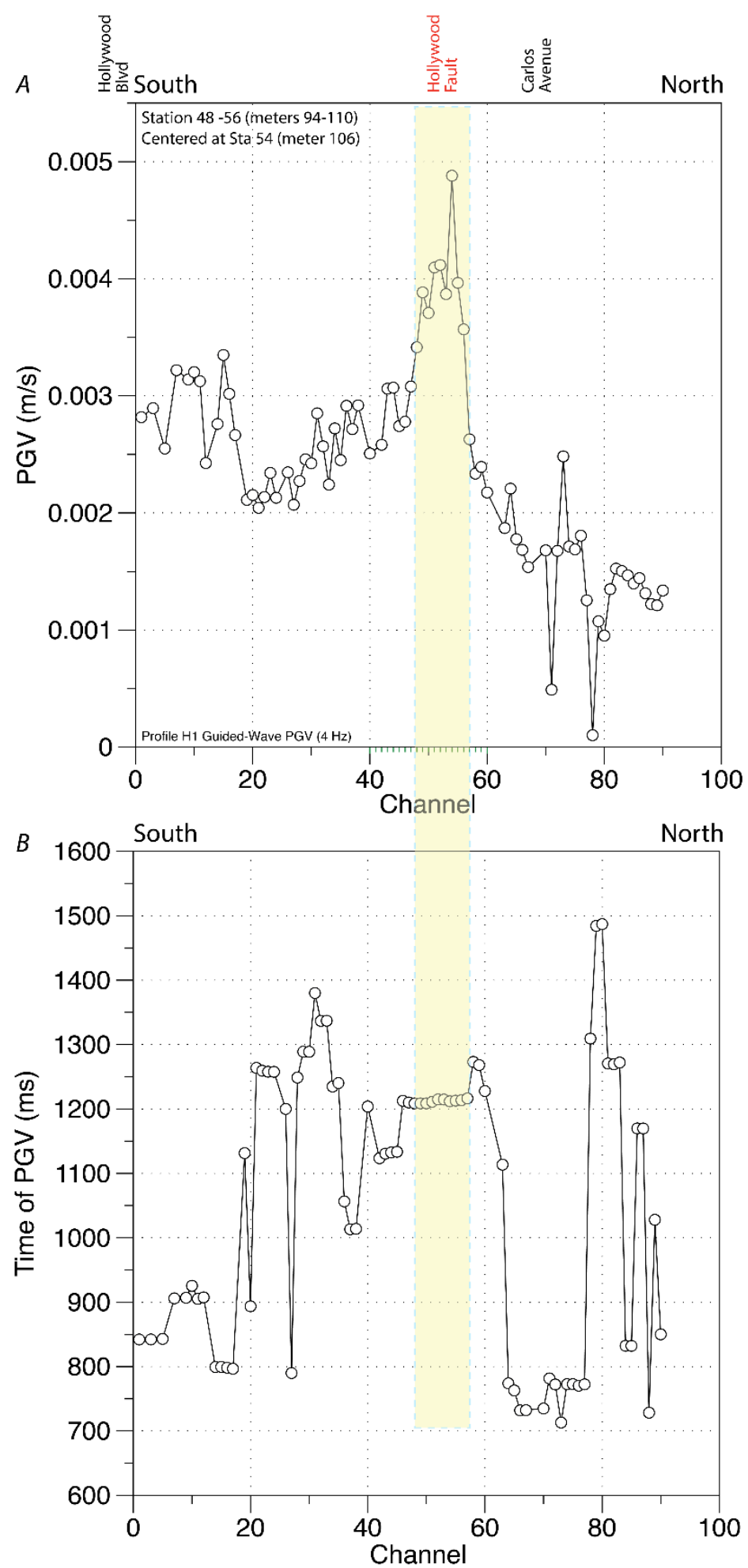

Figure 6. A, Plot of peak ground velocity (PGV) of guided waves for each recording channel along Profile HW1; highest PGV values (yellow shading) are concentrated between channels 48 and 56 , and highest PGV value is at channel 54 (meter 106). B, Plot of time of arrival of corresponding PGV values shown in $A$; highest PGV values coincide with delayed phases that arrive at about $1,200 \mathrm{~ms}$. As can be seen from shot gather (see fig. $5 \mathrm{~A}$ ), these delayed phases correlate with guided waves; zones of high PGV of guided waves are expected within near-surface fault zones. Locations of nearby streets are shown. Other abbreviations: $\mathrm{m}$, meter(s); ms, millisecond(s); s, second(s). 


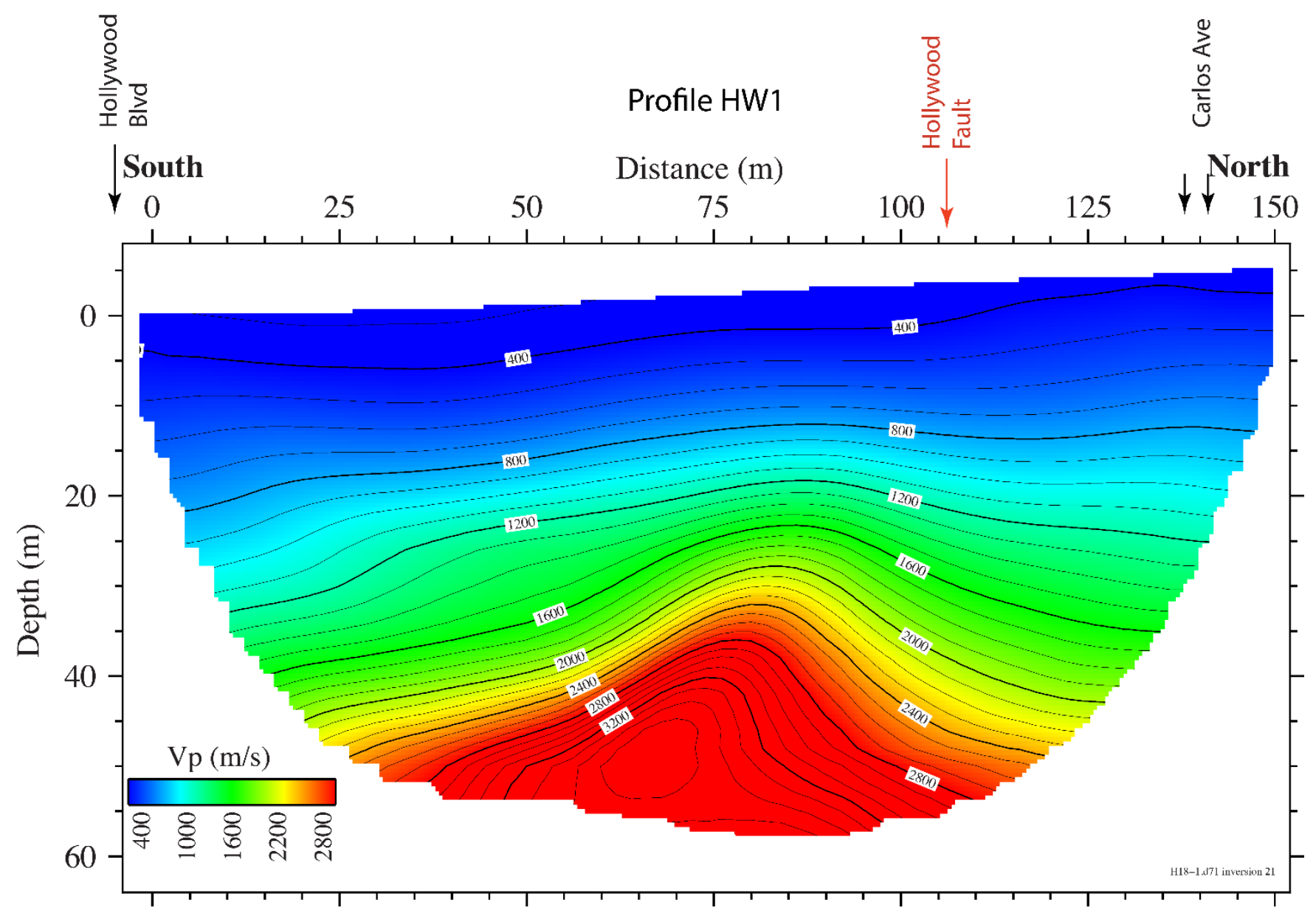

Figure 7. Tomographic P-wave velocity $\left(V_{\mathrm{P}}\right)$ model along Profile HW1, showing locations of nearby streets. Near-surface location of Hollywood Fault at meter 106 (as inferred by guided waves) correlates with sharp change in depth of $400-\mathrm{m} / \mathrm{s}$ velocity contour. At about $20 \mathrm{~m}$ depth, slightly south of inferred surface trace of Hollywood Fault, there is a zone of high velocities, especially velocities higher than about $1,500 \mathrm{~m} / \mathrm{s}$, which is consistent with a fault that acts as a groundwater barrier. Other abbreviations: $m$, meter(s); s, second(s).

400-m/s velocity contour is observed near meter 106 of the seismic profile, suggesting a lateral change in material properties there. This shallow change in materials overlies a deeper, dome-shaped set of velocity contours, suggesting a continuous change in velocities from the near-surface to the base of our velocity model. For $V_{\mathrm{P}}$ values in excess of $1,500 \mathrm{~m} / \mathrm{s}$, the apex of the dome is located at meter 90 at about 20-m depth. Overall, the dome-shaped structure dips to the south. We have observed such domelike velocity structures elsewhere where groundwater saturation, which typically has $V_{\mathrm{P}}$ of 1,500 $\mathrm{m} / \mathrm{s}$ in sediments, abruptly changes across faults. Such structures typically result from ponding of groundwater against faults that act as ground-water barriers. However, ponding typically occurs on the topographically upslope side of faults, unless water flows parallel to the fault or over the top of a fault that does not reach the surface (Catchings and others 2014). We suggest that the approximate depth to the top of groundwater along Profile HW1 is indicated by the $1,500-\mathrm{m} / \mathrm{s}$ velocity contour.

\section{Profile HW1 $V_{s}$ Model}

Our tomographic $V_{\mathrm{S}}$ model (fig. 8) shows that shear-wave velocities $\left(V_{\mathrm{S}}\right)$ along Profile HW1 range from about $200 \mathrm{~m} / \mathrm{s}$ (at the surface) to about $490 \mathrm{~m} / \mathrm{s}$ (at about $25-\mathrm{m}$ depth). At shallow depths, $V_{\mathrm{S}}$ is lowest $(\sim 200 \mathrm{~m} / \mathrm{s})$ near meters 80 and between meters 95 and 106, but an abrupt change in $V_{\mathrm{S}}$ is 


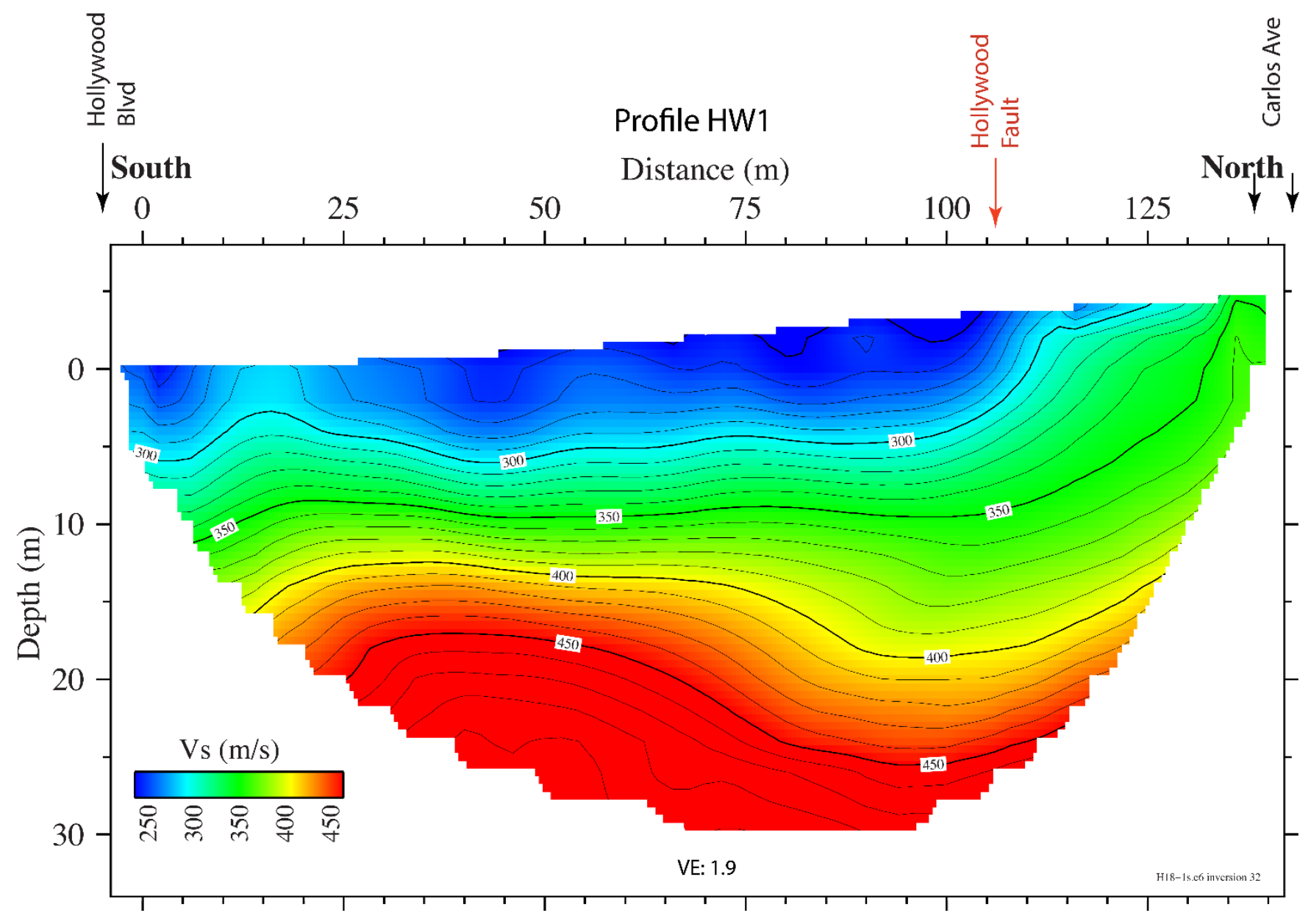

Figure 8. Tomographic S-wave velocity $\left(V_{\mathrm{S}}\right)$ model along Profile HW1, showing locations of nearby streets. Near-surface location of Hollywood Fault at meter 106 (as inferred by guided waves and P-wave velocities) correlates with a sharp change to higher velocities to the north and a relatively low-velocity zone at depths greater than about $15 \mathrm{~m}$. Such near-vertical, S-wave, low-velocity zones are consistent with faulting. Other abbreviations: $\mathrm{m}$, meter(s); s, second(s); VE, vertical exaggeration.

observed at about meter 106, where higher velocities occur at shallower depths to the north. This abrupt change in $V_{\mathrm{S}}$ continues vertically to the base of the velocity model at about $30 \mathrm{~m}$ depth. Zones of abrupt vertical changes in $V_{\mathrm{S}}$ are consistent with faulting because faults cause decreases in $V_{\mathrm{S}}$ owing to shearing. The general low-velocity zone associated with our interpreted fault dips about $79^{\circ}$ to the south.

\section{Profile HW1 $V_{\mathrm{P}} / V_{\mathrm{S}}$ Ratios, Tomography Model}

We developed a model of $V_{\mathrm{P}} / V_{\mathrm{S}}$ ratios (fig. 9) along Profile HW1 by dividing $V_{\mathrm{P}}$ by $V_{\mathrm{S}}$ at each node of the velocity models. $V_{\mathrm{P}} / V_{\mathrm{S}}$ ratios along Profile $\mathrm{HW} 1$ range from about 1 at the surface (in the south and extreme north) to about 4.4 at about $30-\mathrm{m}$ depth (near meter 80 ). In a manner similar to the $V_{\mathrm{P}}$ structure along Profile HW1, we observe a domelike structure for all $V_{\mathrm{P}} / V_{\mathrm{S}}$ values in the vicinity of meters 75 to 106 , but the dome is most pronounced at depths greater than about $15 \mathrm{~m}$. Overall, a slightly southward dip of the structure is observed. Water-saturated faults are expected to have high $V_{\mathrm{P}} / V_{\mathrm{S}}$ ratios because the presence of water causes an increase in $V_{\mathrm{P}}$, and also because shearing causes a larger decrease in $V_{\mathrm{S}}$ than $V_{\mathrm{P}}$, resulting in high values of $V_{\mathrm{P}} / V_{\mathrm{S}}$. Typical hard rocks have $V_{\mathrm{P}} / V_{\mathrm{S}}$ ratios of about 1.72 , but sediments can have $V_{\mathrm{P}} / V_{\mathrm{S}}$ ratios in excess of 3. Furthermore, Catchings and others (2014) showed that faulted sediments have higher $V_{\mathrm{P}} / V_{\mathrm{S}}$ ratios beneath the groundwater table. Accordingly, we 


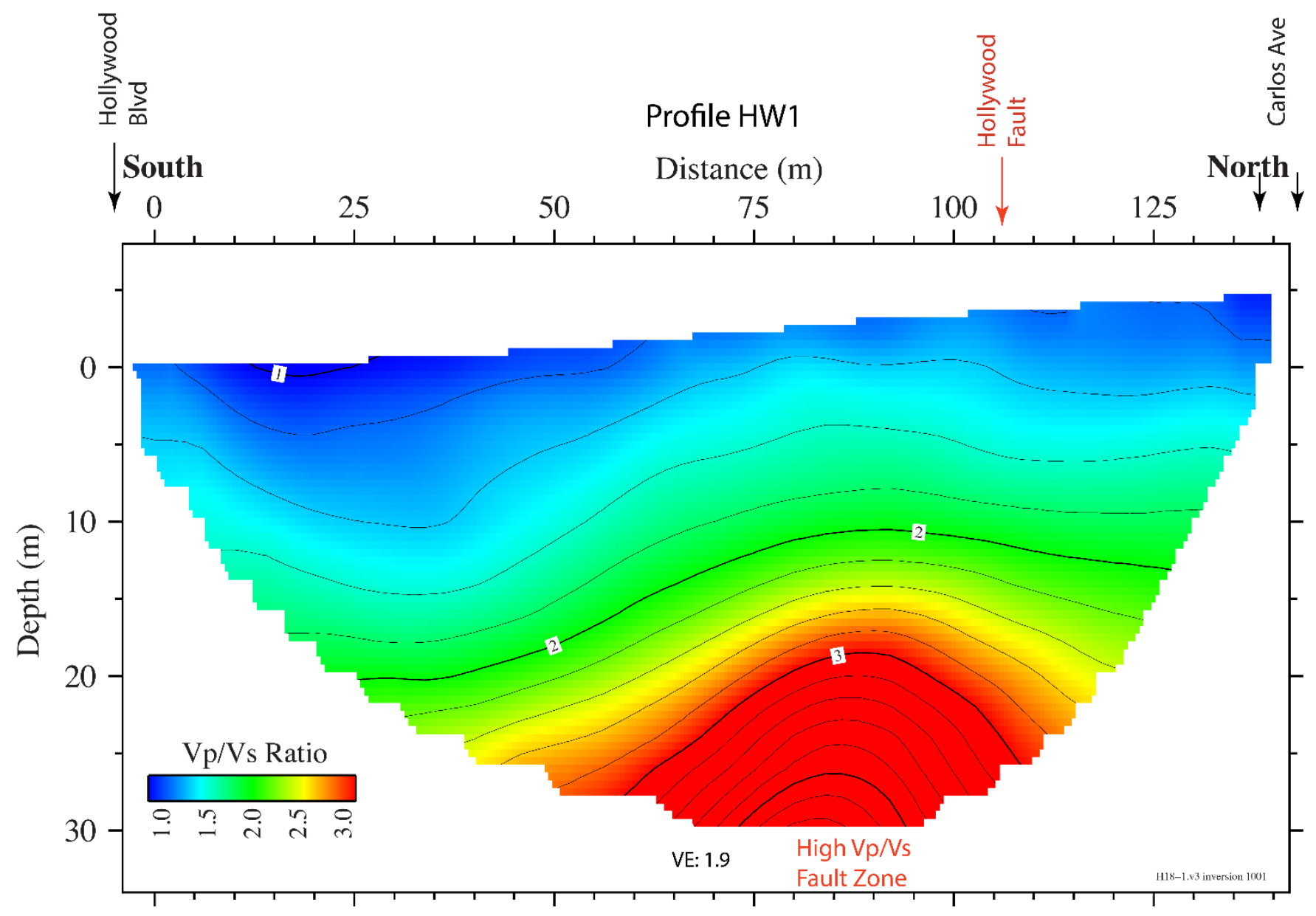

Figure 9. Tomographic $V_{\mathrm{P}} / V_{\mathrm{S}}$ ratio model along Profile HW1, showing locations of nearby streets. Near-surface location of Hollywood Fault at meter 106 (as inferred by guided waves and P- and S-wave velocities) correlates with a shallow-depth zone of high $V_{\mathrm{P}} / V_{\mathrm{S}}$ ratios. Below the inferred $(1,500 \mathrm{~m} / \mathrm{s})$ water table, $V_{\mathrm{P}} / V_{\mathrm{S}}$ ratios are unusually high (as high as 4.6) in upper $30 \mathrm{~m}$; water-saturated fault zones typically have high $V_{\mathrm{P}} / V_{\mathrm{s}}$ ratios. Other abbreviations: m, meter(s); s, second(s); VE, vertical exaggeration.

interpret the relatively high $V_{\mathrm{P}} / V_{\mathrm{S}}$ ratios on Profile $\mathrm{HW} 1$ to be the result of groundwater variations associated with faulting.

\section{Profile HW1 Poisson's Ratios, Tomography Model}

We developed a model of Poisson's ratio (fig. 10) along Profile HW1 using the following relationship between $V_{\mathrm{P}}$ and $V_{\mathrm{S}}$ :

$$
\begin{aligned}
v & =3 \mathrm{~K}-\frac{2 \mu}{6 \mathrm{~K}}+2 \mu \\
& =\frac{\left[\left(\frac{\mathrm{Vp}}{\mathrm{Vs}}\right)^{2}-2\right]}{\left[2\left(\frac{\mathrm{Vp}}{\mathrm{Vs}}\right)^{2}-2\right]}
\end{aligned}
$$

where
$v \quad$ is Poisson's ratio;
$\mathrm{K} \quad$ is the bulk modulus;
$\mu \quad$ is the shear modulus; 
$V_{\mathrm{P}} \quad$ is the $\mathrm{P}$-wave velocity; and

$V_{\mathrm{S}} \quad$ is the $\mathrm{S}$-wave velocity.

The value of $v$ ranges from about 0.05 to about 0.45 along profile HW1. The very low values of $v$ are associated with the shallowest velocity structure (unsaturated zone), and the highest values occur in the deepest materials (below the water table). In the shallow subsurface, $v$ is most strongly influenced by groundwater saturation, but lithology (such as clays) also can have a strong influence. A $v$ value of 0.5 is indicative of a fluid, and, in shallow sediments, a $v$ value above about 0.43 to 0.44 has been associated with the top of the groundwater table (Catchings and others 2007, 2014). Overall, the $v$ structure along Profile HW1 is similar to the $V_{\mathrm{P}} / V_{\mathrm{S}}$ ratio structure, which are both indicative of a water-saturated fault at depth.

\section{Profile HW1 MAS ${ }_{\mathrm{R}}$ Model}

Using Rayleigh waves that were recorded along Profile HW1, we used the MASW method to develop a second $V_{\mathrm{S}}$ model (fig. 11) for Profile HW1. However, the MASW method is inherently a one-

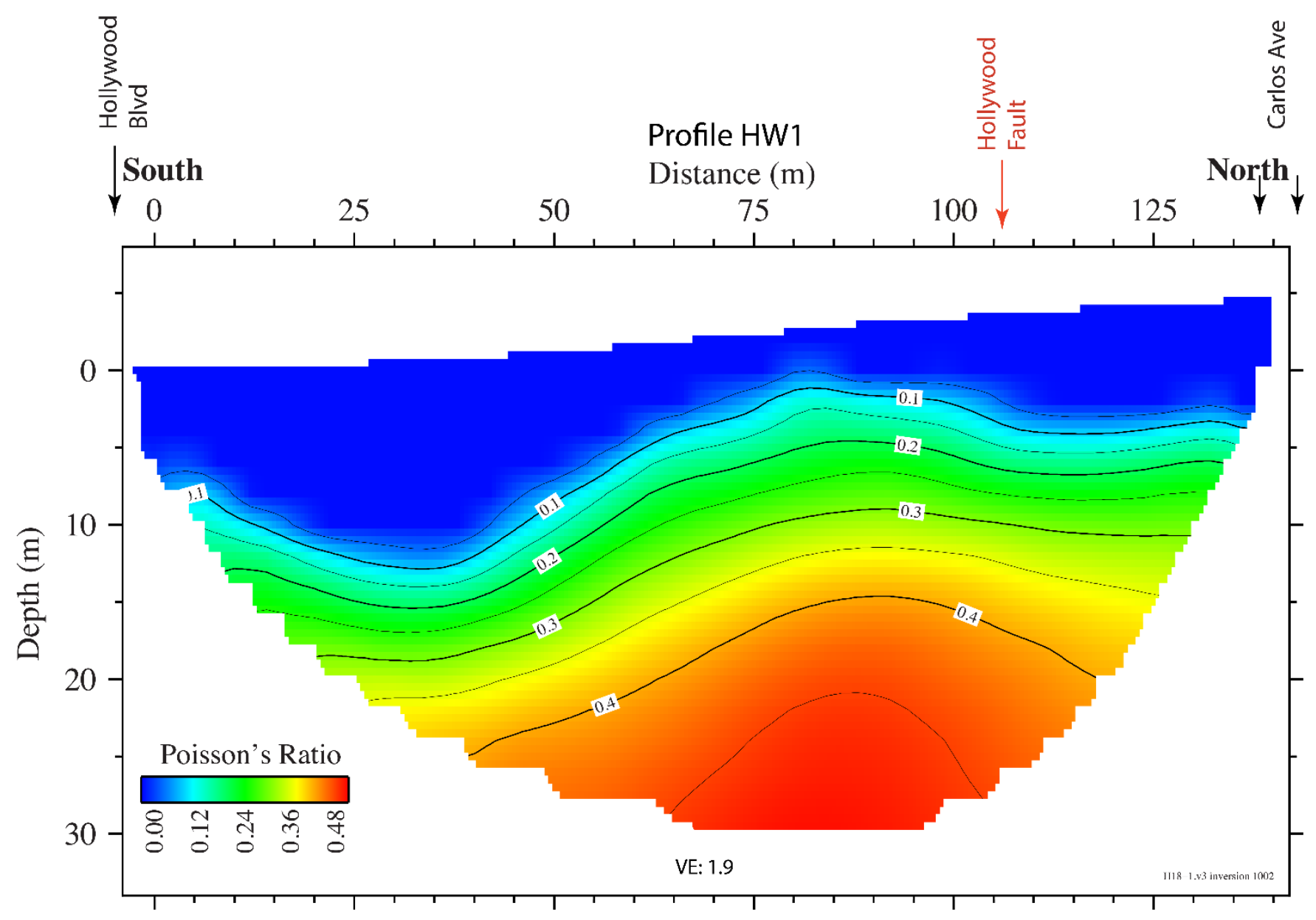

Figure 10. Tomographic Poisson's ratio model along Profile HW1, showing locations of nearby streets. Nearsurface location of Hollywood Fault at meter 106 (as inferred by guided waves, P- and S-wave velocities, and $V_{\mathrm{P}} / V_{\mathrm{S}}$ ratios) correlates with a shallow-depth zone of high Poisson's ratios. At depths of about $20 \mathrm{~m}$, Poisson's ratios are shown to be as high as 0.45 below and slightly southwest of the surface trace of Hollywood Fault. Fluids have a Poisson's ratio of about 0.5 , and Poisson's ratios of about 0.43 have been shown to correlate with groundwater table (Catchings and others, 2008). Water-saturated fault zones typically have high Poisson's ratios. Other abbreviations: $m$, meter(s); s, second(s); VE, vertical exaggeration. 


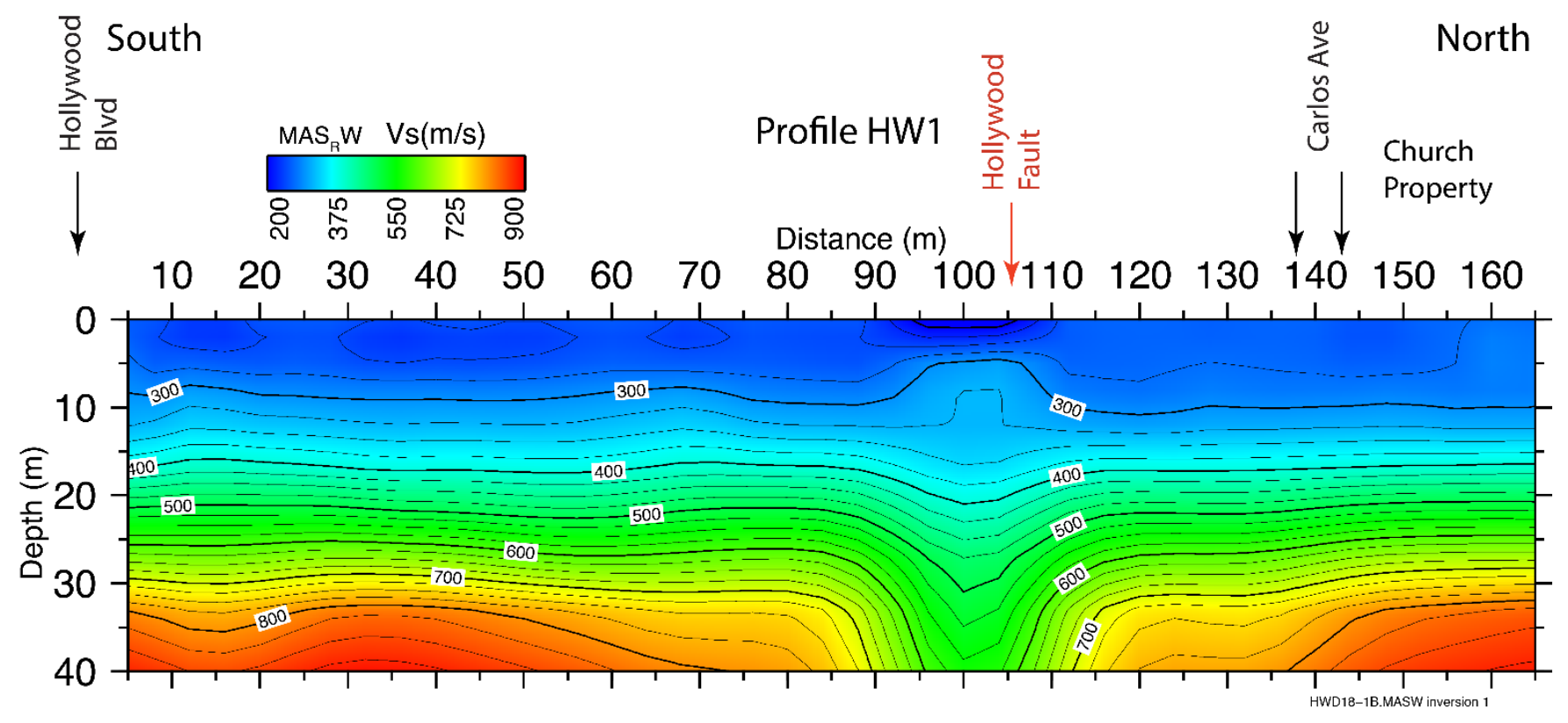

Figure 11. S-wave velocity $(V \mathrm{~s})$ model inferred from Rayleigh waves, using multichannel analysis of surface waves (MASW) method. Near the inferred near-surface Hollywood Fault, our MASRW $V$ s model infers a zone of low $V_{\mathrm{s}}$ in upper few meters, underlain by a zone of high $V_{\mathrm{s}}$ at about $10 \mathrm{~m}$ and also a zone of low $V_{\mathrm{s}}$ to at least $40 \mathrm{~m}$ depth. Such near-vertical low-velocity zones are consistent with near-vertical faulting. Although details of the $V_{S}$ model determined from MASW are slightly different from those of the $V$ s tomography model, both velocity anomalies are similar and are consistent with faulting near meter 106. Locations of nearby streets are shown. Other abbreviations: $\mathrm{m}$, meter(s); s, second(s).

dimensional method, and, as a result, determination of $V_{\mathrm{S}}$ can be affected by lateral variations in structure, velocity, and topography. Nevertheless, the MASW method can provide an indication of lateral variations in $V_{\mathrm{S}}$ along Profile $\mathrm{HW} 1$. Our analysis of Rayleigh waves $\left(\mathrm{MAS}_{\mathrm{R}} \mathrm{W}\right)$ indicates that $V_{\mathrm{S}}$ along Profile HW1 ranges from about $200 \mathrm{~m} / \mathrm{s}$ in the shallow subsurface (meters 95-105) to as much as $875 \mathrm{~m} / \mathrm{s}$ at about 40-m depth. The shallowest $V_{\mathrm{S}}$ values are consistent between the tomography and the MAS $\mathrm{R}_{\mathrm{W}}$ models, with minimum $V_{\mathrm{S}}$ values of about $200 \mathrm{~m} / \mathrm{s}$ near meters 94 to 106 , but MASR $\mathrm{W}$ inferred $V_{\mathrm{S}}$ values are higher at depths greater than about $20 \mathrm{~m}$ in the $\mathrm{MAS}_{\mathrm{R}} \mathrm{W}$ model. In addition, the overall velocity structure is less variable and more linear in the $\mathrm{MAS}_{\mathrm{R}} \mathrm{W}$ model than the tomography model. However, both models suggest the presence of a general near-vertical low-velocity zone near meter 106 that extends to the base of the models. At about meter 106, the MAS $\mathrm{R}$ model indicates a more pronounced near-vertical low-velocity zone, which is highly consistent with a zone of near-vertical faulting (Catchings and others, 2014). Aligning the low-velocity contours in the $\mathrm{MAS}_{\mathrm{R}} \mathrm{W}$ model suggests that the shallow Hollywood Fault dips about $82^{\circ}$ to the south.

\section{Profile HW1 MASLW Model}

Using Love waves recorded along Profile HW1, we developed a $V_{\mathrm{S}}$ model (fig. 12) using the MASW method. Our $\mathrm{MAS}_{\mathrm{L}} \mathrm{W}$ modeling indicates that $V_{\mathrm{S}}$ ranges from about $250 \mathrm{~m} / \mathrm{s}$ at shallow depths to about 675 at about 50-m depth. Although the overall $\mathrm{MAS}_{\mathrm{L}} \mathrm{W}$ model varies from both the $\mathrm{MAS} \mathrm{S}_{\mathrm{R}} \mathrm{W}$ model and the tomography model, $V_{\mathrm{S}}$ and the overall $V_{\mathrm{S}}$ structure have similarities to those of both the tomography and $\mathrm{MAS}_{\mathrm{R}} \mathrm{W}$ models. In particular, the near-vertical low-velocity zone in the vicinity of meters 102 to 120 is seen in all the models and is consistent with a fault in that area. However, whereas the $\mathrm{MAS}_{\mathrm{R}} \mathrm{W}$ and tomography models and the asymmetry of the PGV of guided waves suggest a slight 


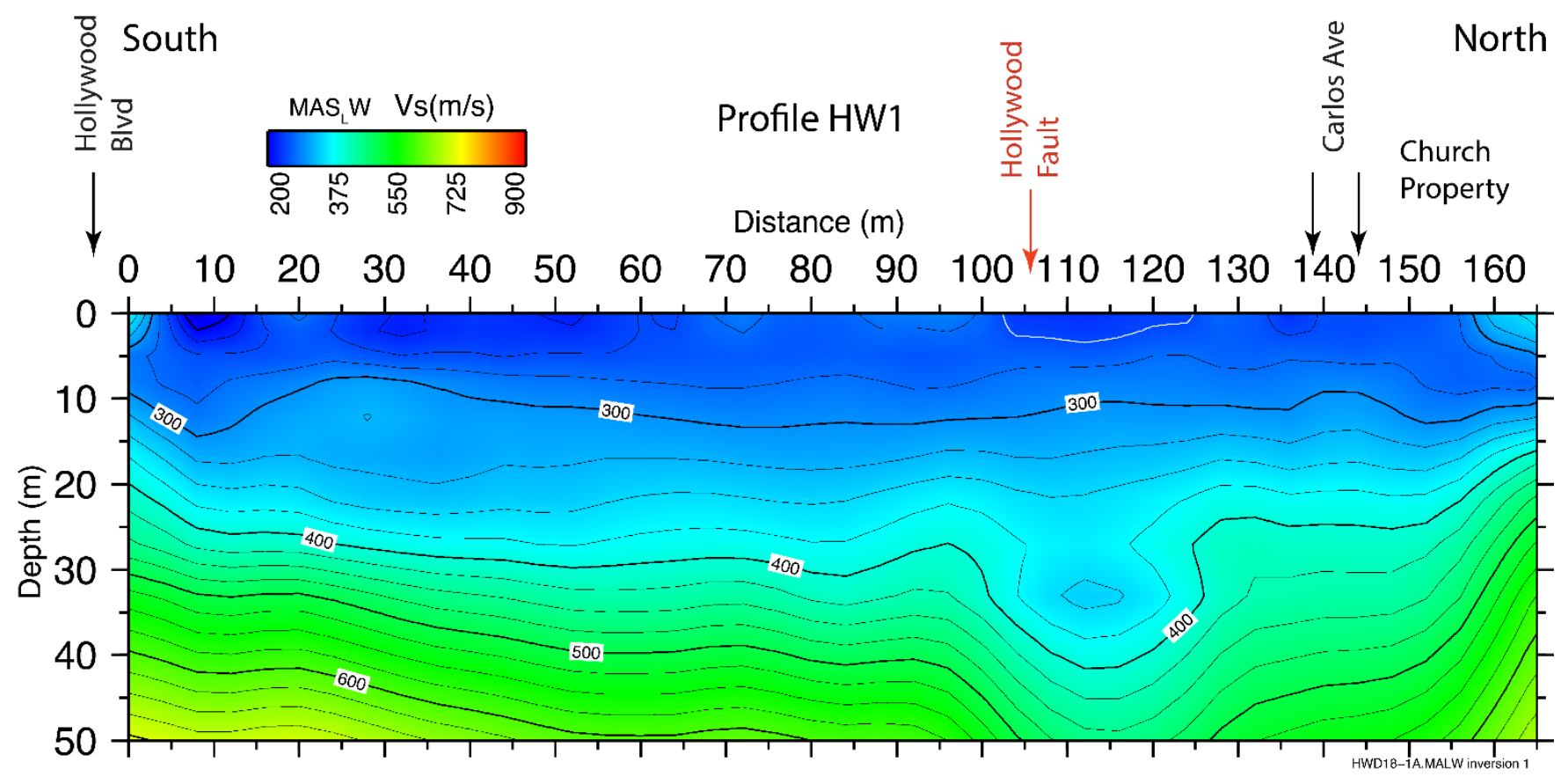

Figure 12. S-wave velocity $\left(V_{\mathrm{S}}\right)$ model inferred from Love waves, using multichannel analysis of surface waves (MASW) method. Near the inferred near-surface Hollywood Fault, our MASLW $V_{\mathrm{S}}$ model infers zones of low $V_{\mathrm{s}}$ in upper few meters and also below about $20 \mathrm{~m}$ depth. Such near-vertical low-velocity zones are consistent with nearvertical faulting. Although details of $V_{S}$ models determined from MASRW, MASLW, and tomography differ in absolute velocity, velocity anomalies determined from all three methods are similar and are consistent with faulting. Locations of nearby streets are shown. Other abbreviations: $m$, meter(s); s, second(s).

southward fault dip at shallow depths, the $\mathrm{MAS}_{\mathrm{L}} \mathrm{W}$ model indicates a slight northward $\left(79^{\circ}\right)$ fault dip at shallow depths, on the basis of the observed low-velocity contours.

\section{Profile HW1 $V_{\mathrm{P}} / V_{\mathrm{S}}\left(V_{\mathrm{P}}\right.$ Tomography and $\left.V_{\mathrm{S}} \mathrm{MAS}_{\mathrm{R}} \mathrm{W}\right)$ Model}

Using $V_{\mathrm{P}}$ from our tomography model (fig. 7) and the $V_{\mathrm{S}}$ from our $\mathrm{MAS} \mathrm{S}_{\mathrm{R}} \mathrm{W}$ model (fig. 11), we developed a hybrid $V_{\mathrm{P}} / V_{\mathrm{S}}$-ratio model (fig. 13) along Profile HW1. Our tomographic/MAS $\mathrm{R}$ W hybrid $V_{\mathrm{P}} / V_{\mathrm{S}}$-ratio model suggests that $V_{\mathrm{P}} / V_{\mathrm{S}}$ ratios range from about 1.2 at the surface to 3.8 at $40-\mathrm{m}$ depth. This range of values in hybrid $V_{\mathrm{P}} / V_{\mathrm{S}}$ ratios is slightly lower than the maximum $V_{\mathrm{P}} / V_{\mathrm{S}}$ ratio value (4.4) indicated by the tomographic $V_{\mathrm{P}} / V_{\mathrm{S}}-$ ratio model (fig. 9); however, the hybrid $V_{\mathrm{P}} / V_{\mathrm{S}}-$ ratio model indicates a pronounced high $V_{\mathrm{P}} / V_{\mathrm{S}}$-ratio (up to 3.8) zone centered at about meters 100 to 105 , similar to the high value (4.4) in the tomographic $V_{\mathrm{P}} / V_{\mathrm{S}}-$ ratio model. Because water-saturated fault zones are expected to cause concentrated high $V_{\mathrm{P}} / V_{\mathrm{S}}-$ ratio zones, we suggest that the relatively wide zone of high $V_{\mathrm{P}} / V_{\mathrm{S}}$ ratios at depth in the hybrid model is likely indicative of a wider fault zone in the upper $40 \mathrm{~m}$ depth of the velocity model. The hybrid $V_{\mathrm{P}} / V_{\mathrm{S}}-$ ratio image indicates an overall near-vertical fault that is centered near meter 100; however, this image is also consistent with the presence of adjacent splay faults.

\section{Profile HW1 $V_{\mathrm{P}} / V_{\mathrm{S}}\left(V_{\mathrm{P}}\right.$ Tomography and $\left.V_{\mathrm{S}} \mathrm{MAS} \mathrm{L}\right)$ Model}

Using $V_{\mathrm{P}}$ from our tomography model (fig. 7) and the $V_{\mathrm{S}}$ from our $\mathrm{MAS}_{\mathrm{L}} \mathrm{W}$ model (fig. 12), we developed a second hybrid $V_{\mathrm{P}} / V_{\mathrm{S}}-$ ratio model (fig. 14) along Profile HW1. Our tomographic/MAS $\mathrm{S}_{\mathrm{L}} \mathrm{W}$ hybrid $V_{\mathrm{P}} / V_{\mathrm{S}}-$ ratio model suggests that $V_{\mathrm{P}} / V_{\mathrm{S}}$ ratios range from about 1.5 at the surface to 6.0 at 40 - to 50-m depth, with pronounced high values being observed beneath the central part of the profile. In the 


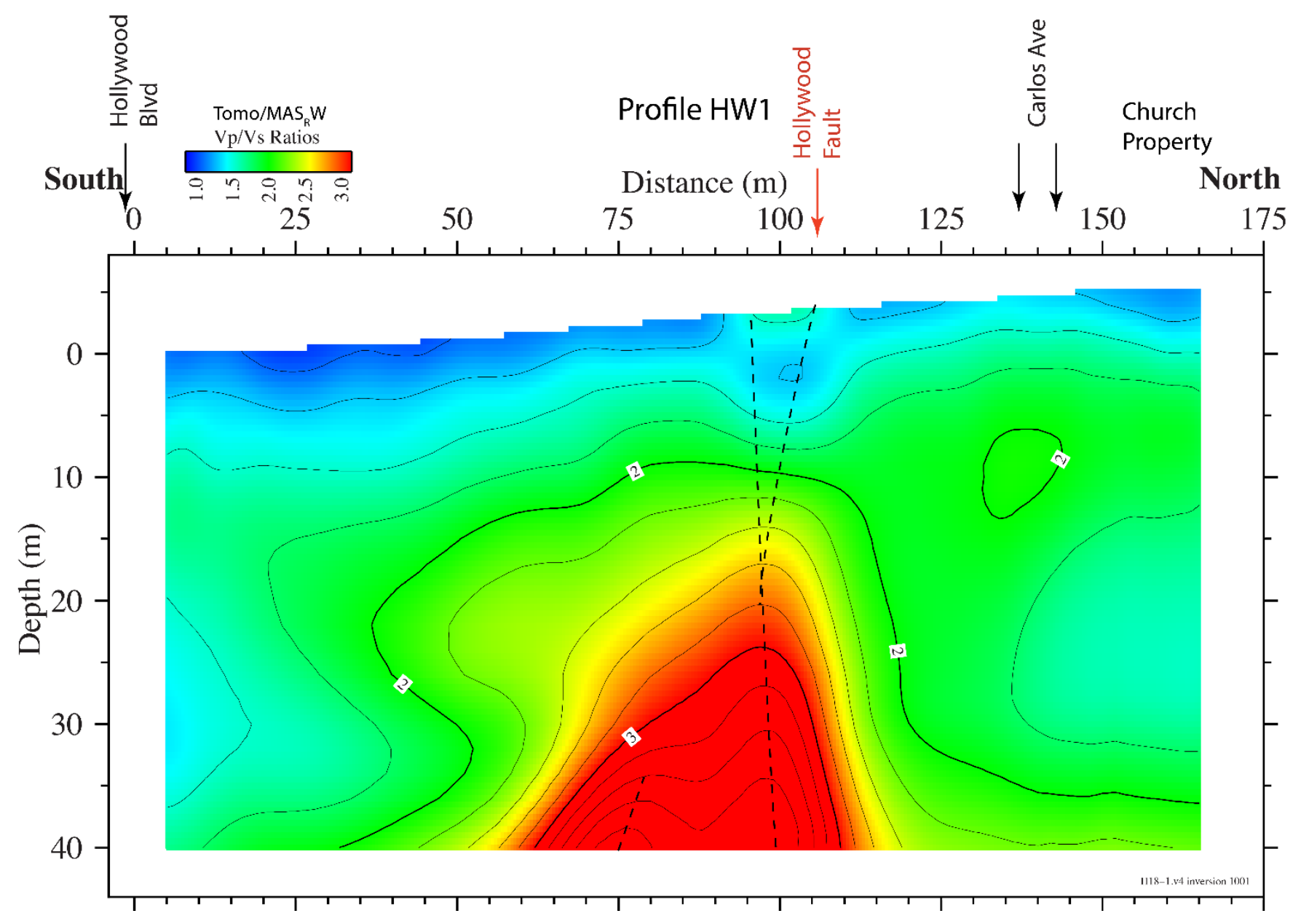

Figure 13. $V_{\mathrm{P}} / V_{\mathrm{S}}$ ratio model along Profile $\mathrm{HW} 1$ derived from a combination of our $V_{\mathrm{P}}$ tomography model and our MAS $\mathrm{R} W V_{\mathrm{S}}$ model. A zone of locally high $V_{\mathrm{P}} / V_{\mathrm{S}}$ ratios occurs near the near-surface trace of Hollywood Fault (dashed lines), as inferred by multiple models in this study. Near-vertical zone of high $V_{\mathrm{P}} / V_{\mathrm{S}}$ ratios is concentrated beneath the near-surface fault trace, as has been seen for other fault zones. Locations of nearby streets are shown. Other abbreviation: $\mathrm{m}$, meter(s).

upper $30 \mathrm{~m}$, all three $V_{\mathrm{P}} / V_{\mathrm{S}}$-ratio models infer similar structures, but the hybrid $V_{\mathrm{P}} / V_{\mathrm{S}}-$ ratio models suggest a wider fault zone at depth and infer possible northward and southward dips.

\section{Profile HW1 P-Wave Reflection Stack}

Using P-wave shot gathers from Profile HW1, we developed a low-resolution P-wave seismic reflection image (stack) of the shallow subsurface (fig. 15). The P-wave reflection stack indicates the presence of predominantly subhorizontal layering in the upper $20 \mathrm{~m}$, with apparent slight folding centered near meter 100 of the profile. This unmigrated image suggests the presence of strong diffractions below about 20-m depth, centered near meter 100. Diffractions are caused by sharp boundaries in the subsurface, and faulting, which vertically offsets layers, is a typical cause of such diffractions, particularly when the diffractions are subvertically aligned, as seen in figure 15 . Thus, the P-wave reflection image is consistent with a near-vertical fault located near meter 100. By aligning the diffractions over depths that range from about 20 to about $120 \mathrm{~m}$, the alignment of diffractions suggests that the fault dips about $87^{\circ}$ northward below 20-m depth (fig. 15). In addition, significant noise or surface waves is seen in the southern part of the reflection image, making it difficult to resolve the 


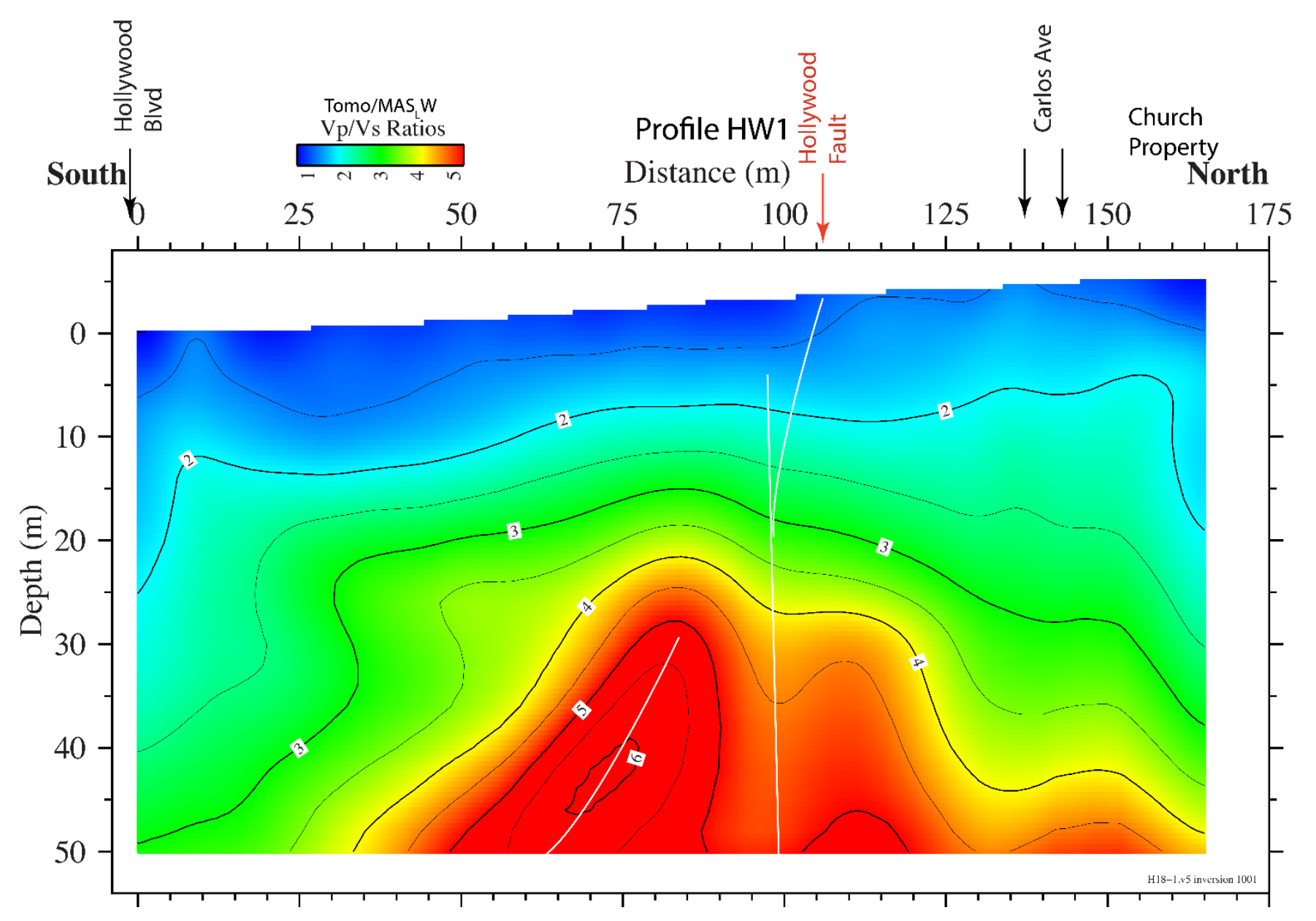

Figure 14. Poisson's ratio model along Profile HW1 derived from combination of our $V_{\mathrm{P}}$ tomography model and our MASLW $V \mathrm{~S}$ model. A zone of locally high Poisson's ratios occurs near the near-surface trace of Hollywood Fault (white lines), as inferred by multiple models in this study. Near-vertical zone of high Poisson's ratios is concentrated near the near-surface trace of Hollywood Fault, as has been seen for other fault zones. Locations of nearby streets are shown. Other abbreviation: $\mathrm{m}$, meter(s).

structure along the south half of Profile HW1. The strong energy likely arises from either the Los Angeles Metro Rail (subway) Redline trains or car traffic along Hollywood Boulevard.

\section{Profile HW1 S-Wave Reflection Stack}

Using S-wave shot gathers from Profile HW1, we developed a low-resolution S-wave seismic reflection image (stack) of the shallow subsurface (fig. 16). The S-wave reflection stack also indicates the presence of predominantly subhorizontal layering and an apparent fold centered near meter 100 . Aligning the apex of the apparent fold - from about 20 to about $125 \mathrm{~m}$ - suggests that the deeper fault dips about 87 degrees northward, with the possibility of a splay fault dipping about $79^{\circ}$ southward near the surface. High noise levels on the south end of the profile interferes with the seismic signal, making it difficult to delineate any possible fault structures.

\section{Summary of Seismic Indicators of Faulting along Profile HW1}

We evaluated 13 different seismic images along Profile HW1, including (1) PGV of guided waves, (2) tomographic $V_{\mathrm{P}}$, (3) tomographic $V_{\mathrm{S}}$, (4) tomographic $V_{\mathrm{P}} / V_{\mathrm{S}}$ ratios, (5) tomographic Poisson's ratios, (6) $\mathrm{MAS}_{\mathrm{R}} \mathrm{W} V_{\mathrm{S}}$, (7) $\mathrm{MAS} \mathrm{S}_{\mathrm{L}} V_{\mathrm{S}}$, (8) hybrid tomography/MAS $\mathrm{MA}_{\mathrm{R}} V_{\mathrm{P}} / V_{\mathrm{S}}$ ratios, (9) hybrid 


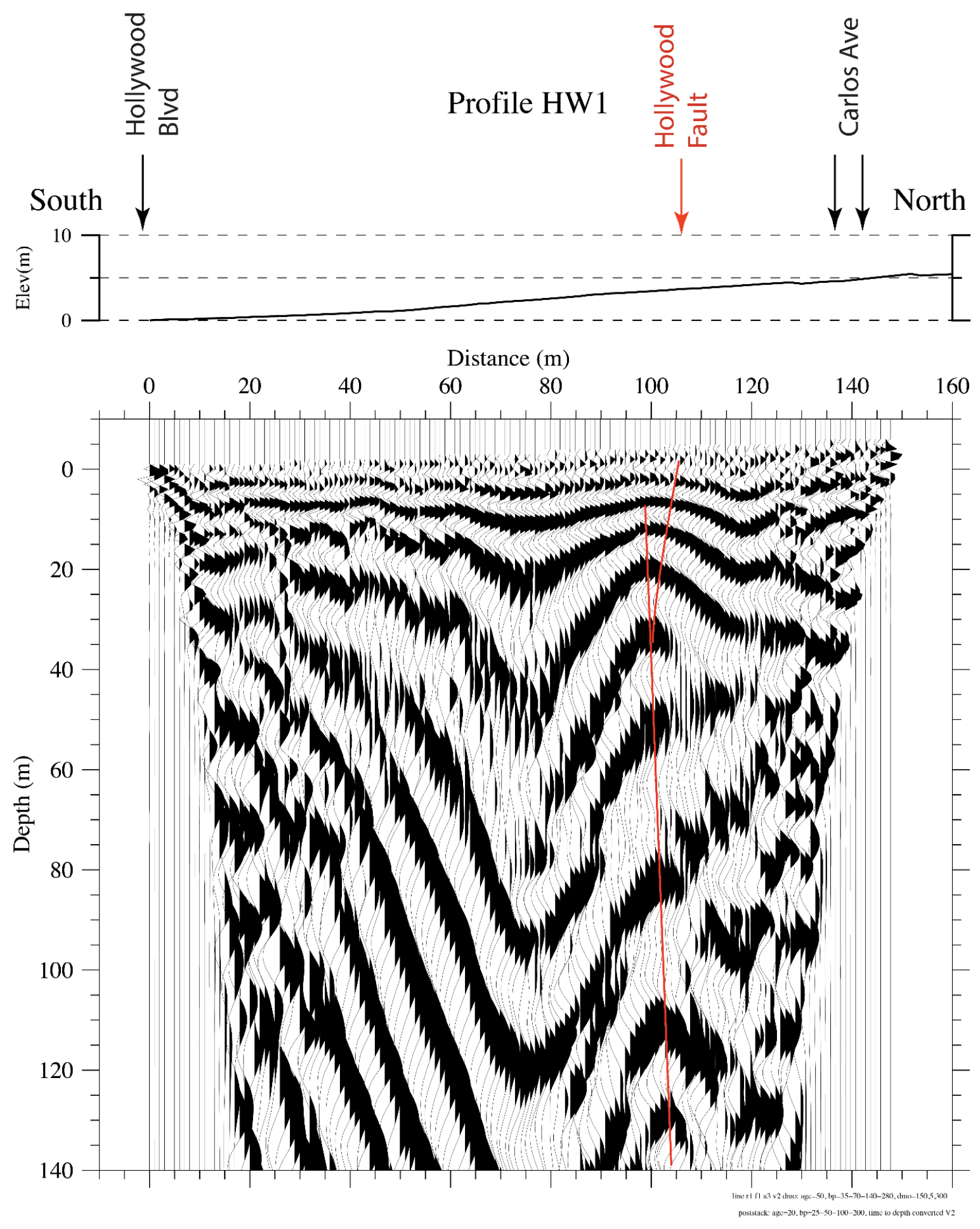

Figure 15. Low-resolution P-wave reflection stack for Profile HW1. Strong diffractions are apparent beneath the inferred location of Hollywood Fault (red lines), beginning at about $10 \mathrm{~m}$ depth and extending to base of reflection image. Such diffractions are typically seen on unmigrated reflection images of faulted strata. Locations of nearby streets are shown. Abbreviation: m, meter(s). 

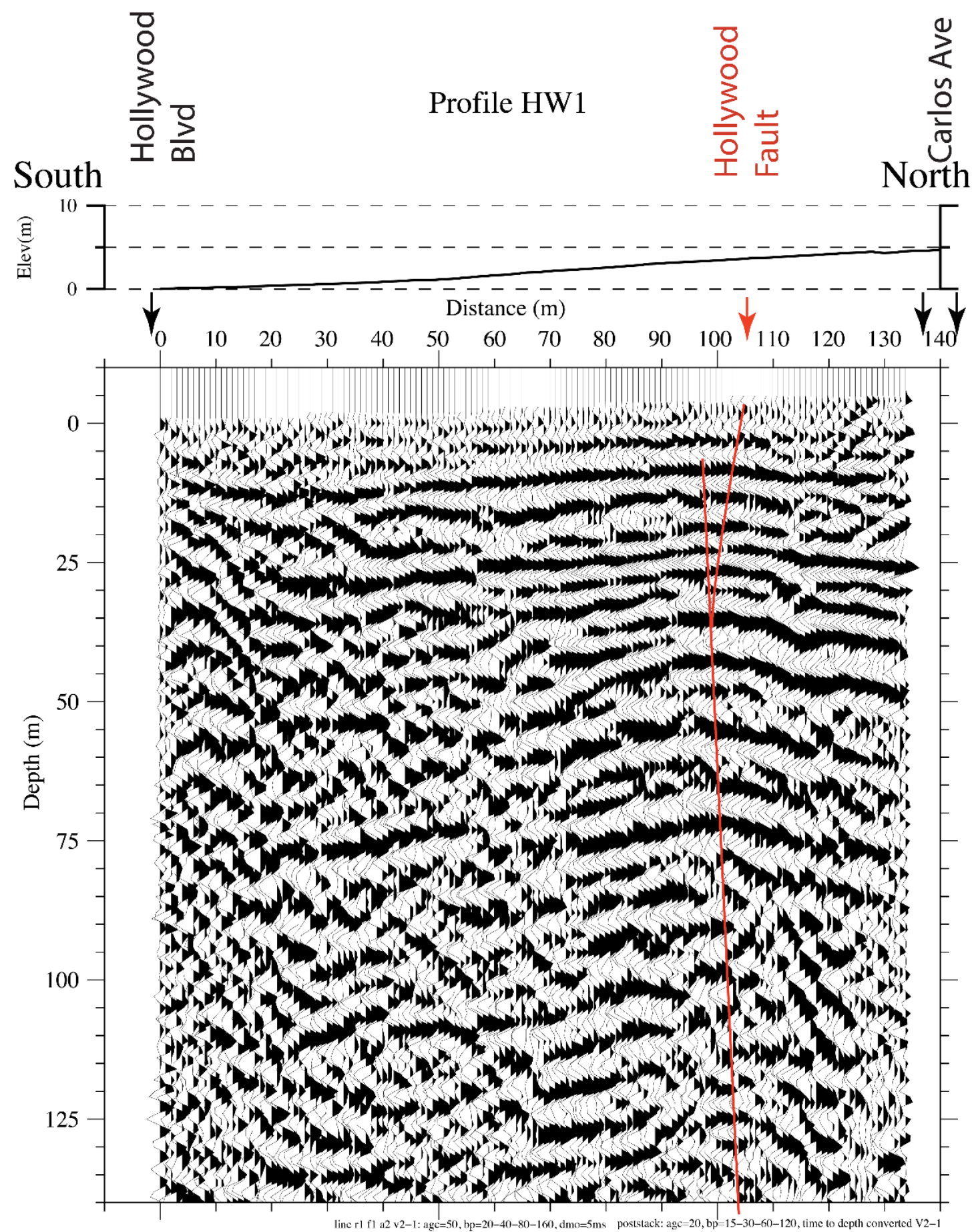

Figure 16. Low-resolution S-wave reflection stack for Profile HW1. Folds and diffractions are apparent beneath the inferred location of Hollywood Fault (red lines), beginning at about $10 \mathrm{~m}$ depth and extending to base of reflection image. Such disrupted layering is typically seen on reflection images of faulted strata. Locations of nearby streets are shown. Abbreviation: m, meter(s).

tomography/MAS $\mathrm{R}_{\mathrm{R}} \mathrm{W}$ Poisson's ratios, (10) hybrid tomography/MAS $\mathrm{L}_{\mathrm{L}} \mathrm{W} V_{\mathrm{P}} / V_{\mathrm{S}}$ ratios, (11) hybrid tomography/MAS $\mathrm{L}_{\mathrm{W}} \mathrm{W}$ Poisson's ratios, (12) P-wave reflection, and (13) S-wave reflection. All 13 images presented here are consistent with a near-vertical fault located near meters 100 to 106 of Profile HW1. We suggest that the guided-wave results are likely most diagnostic of the location of faulting nearest the surface. 


\section{Guided-Wave Results for Profile HW2}

We evaluated two guided-wave seismic datasets recorded along Profile HW2, and both were recorded on the night of May 24, 2018, using the same recording system as was used along Profile HW1. However, the recording array for Profile HW2 was located along North Argyle Avenue, where significant traffic noise occurs. A total of 123 recording stations were surveyed along Profile HW2, but seismographs were not deployed at 11 stations owing to the presence of obstacles such as driveways and buried pipes. Of the stations deployed, six seismographs did not record data.

The first guided-wave survey (HGW2) along Profile HW2 used the same source location (SP1) as was used for the HGW1 guided-wave survey along Profile HW1 (fig. 2). A total of 157 AWD shots were stacked to generate the guided waves for the HGW2 guided-wave survey. The perpendicular distance from SP1 to Profile HW2 was approximately $560 \mathrm{~m}$, with longer distances to the north and to the south of the profile. The seismic sources (shots) for the HGW2 survey began on May 24, 2018, at 20:24:43 (local time) and continued until 20:43:33.

The second guided-wave survey (HGW3) recorded along Profile HW2 used the same recording array as was used in the HGW2 survey; however, the seismic source (SP2) was located near the center of the Profile HW1 recording array (fig. 3), such that SP2 was located at the fault location inferred from an earlier borehole survey. The perpendicular distance from SP2 to Profile HW2 (Argyle Avenue) was approximately $350 \mathrm{~m}$. We used a total of 151 AWD shots (stacked) to generate guided waves for the HGW3 seismic survey. The HGW3 survey shots began on May 24, 2018, at 21:29:37 (local time) and continued until 21:47:09. Ten of the seismographs used during the HGW3 survey did not record data.

\section{Data Analysis for Guided-Wave Survey HGW2}

Guided waves from the HGW2 survey were not easily identified because of high cultural-noise levels along Profile HW2 (North Argyle Avenue). In addition, heavy traffic along the overpass (Highway 101) over North Argyle Avenue, as well as heavy traffic on Hollywood Boulevard and subway trains, appear to be the major sources of noise that significantly reduced the signal-to-noise ratio of the HGW2 data. However, with approximately 157 stacked shots, the S-wave and later arrivals can be identified from data derived from the southern part of the HGW2 survey (fig. 17). From those data, we measured the PGV of the data from about 0.8 to about $2.0 \mathrm{~s}$. The highest PGV values appear to be concentrated near Carlos Avenue and south of Yucca Street (figs. 18A, B) for the HGW2 survey. Although we urge extreme caution in evaluating the PGV of guided waves from such noisy data, the data suggest that guided waves may have been recorded south of Carlos Avenue and south of Yucca Street. The relatively high PGV values near Carlos Avenue and Yucca Street occur at times consistent with those expected for guided waves, traveling at about 50 percent of the apparent $V_{\mathrm{S}}$.

We also evaluated data north of Yucca Street, but the noise levels from the Highway 101 overpass were so high that we did not include those data in this report. We also observed relatively high PGV values between Yucca Street and Highway 101, but owing to the high cultural-noise levels, we have little confidence that the high PGV values are derived from guided waves. Thus, we suggest that the guided waves recorded on the HGW2 survey are indeterminate with respect to faulting and that performing a survey later at night, when cultural and highway noises are less prevalent, might have been more determinate.

\section{Data Analysis for Guided-Wave Survey HGW3}

We acquired the HGW3 survey with the source at SP2 (First Presbyterian Church of Hollywood parking lot) and the recording array located along Profile HW2 (North Argyle Avenue). Data from the HGW3 survey also are very noisy (fig. 18) owing to the same noise sources described above for the HGW2 survey. It appears that those noise sources were even greater than was observed during the 


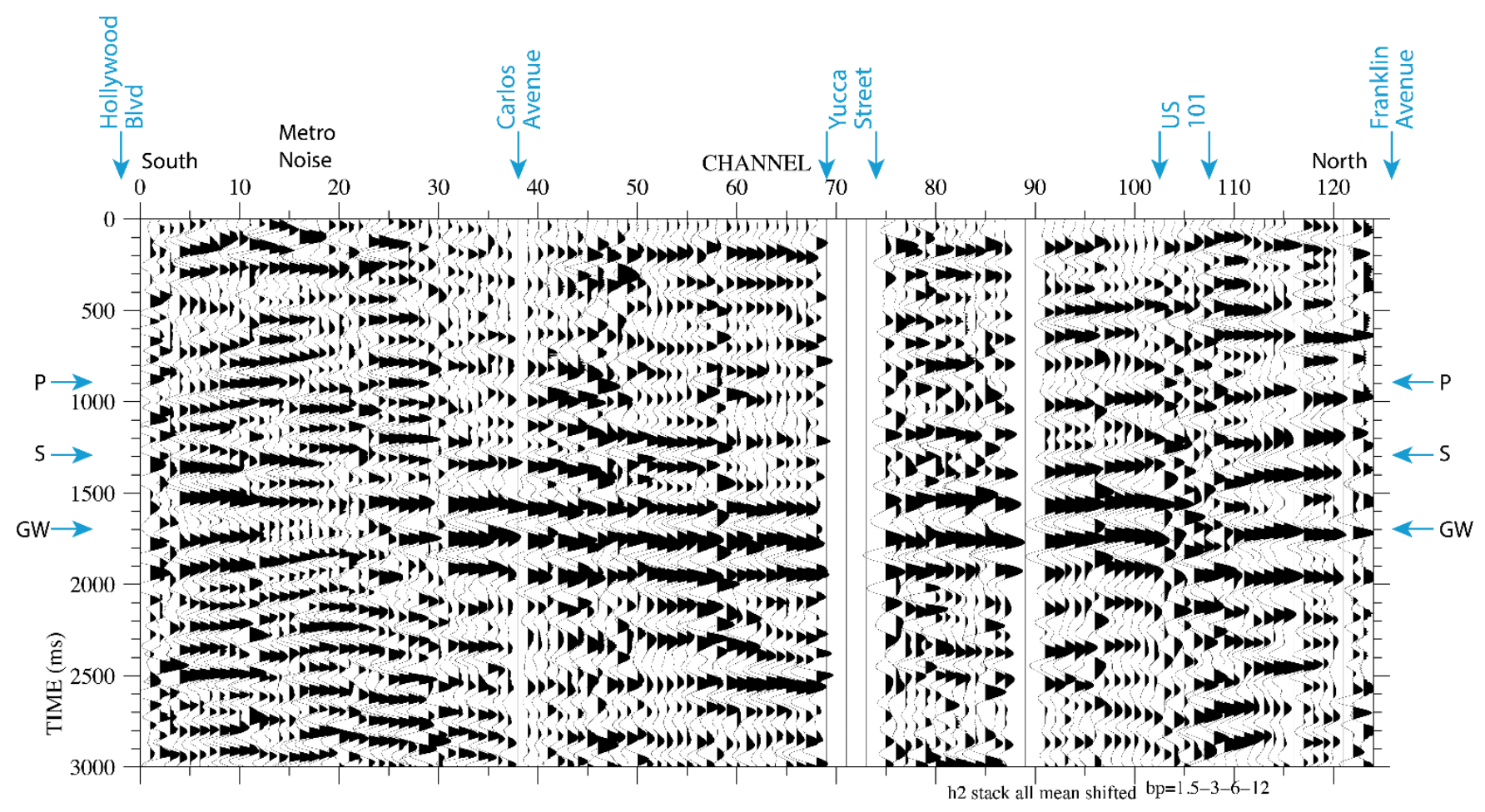

Figure 17. Stacked guided-wave shot gather for Profile HW2 (guided-wave survey HGW2). Source is located at SP1; recording array is located along Profile HW2. Source and recording array are separated by about $560 \mathrm{~m}$. High levels of cultural noise, which are prevalent before the P-wave arrival, are shown on shot gather, especially between channels 1 and 30 and near channel 105. Such high levels of cultural noise make it difficult to evaluate guided waves. $P$ waves $(P)$, S waves $(S)$, and guided waves $(G W)$ are inferred on shot gather. Data were bandpass filtered between 1.5 and $12 \mathrm{~Hz}$. Locations of nearby streets are shown. Other abbreviation: ms, millisecond(s).

HGW1 survey, possibly because there was less traffic during the 21:00 hour time frame, which may have allowed for faster moving vehicles and greater overall noise.

With 151 shots stacked, the main S-wave and apparent guided waves were difficult to identify on the shot gather (fig. 19). However, from the stacked data, we measured PGV values for the part of the survey that was south of Yucca Street (figs. 20A, B, C, D). We observe high PGV values in nearly the same location as seen from the HGW2 seismic survey, particularly south of Carlos Avenue and south of Yucca Street. However, we also observe high PGV values slightly north of Hollywood Boulevard, which are likely attributable to noises from the subway and from traffic on Hollywood Boulevard because the travel times are inconsistent with those expected for guided waves. In contrast, the high PGV values south of Carlos Avenue and south of Yucca Street occur at the approximate time expected for guided waves when the source is located at SP2.

\section{Tomography, MASW, and Reflection Results for Profile HW2}

We acquired an in-line, active-source P-wave seismic survey (HRR3) along Profile HW,2 using P-wave shots and vertical-component sensors that were attached (via refraction cables) to two Geometrics RX-60, multichannel seismographs. Unlike the guided-wave surveys (HGW2 and HGW3), we did not deploy sensors north of Yucca Street owing to the difficulty in deploying cables across Yucca Street; thus, the HRR3 survey was only about $200 \mathrm{~m}$ long. We used 66 vertical-component sensors and 63 AWD shot points for the HRR3 seismic survey. The AWD shots and sensors were colocated ( $1.5 \mathrm{~m}$ lateral offset) and spaced at 3-m intervals. The data were recorded for $2 \mathrm{~s}$ at a sampling 

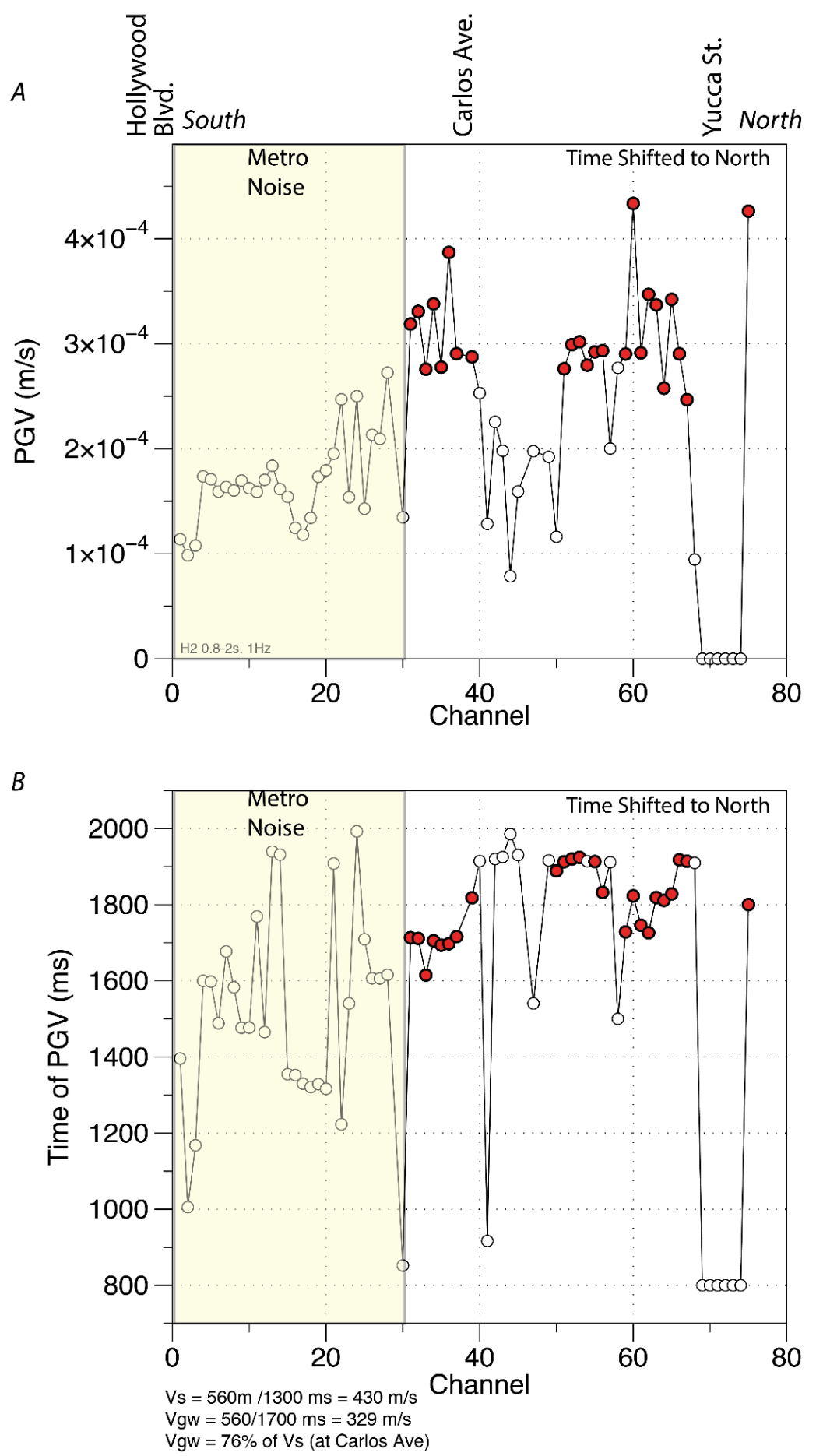

Figure 18. A, Plot of peak ground velocities (PGV) of guided waves for each recording channel along part of Profile HW2 (guided-wave survey HGW2), showing locations of nearby cross streets. Owing to high levels of cultural noise from Highway 101 north of Yucca Street, PGV values for channels north of Yucca Street were deleted from plot. Yellow shading highlights channels that have high levels of cultural noise south of Carlos Avenue (see fig. 17). B, Plot of travel times from SP1 to Profile HW2. Travel times on north end of Profile HW2 were shifted to allow analysis within a limited time window, as higher propagation velocities on north end of profile resulted in shorter travel times. High PGV values on PGV plot correlate with delayed travel times on travel-time plot. Although contaminated with noise, high PGV values (red dots) may infer possible fault locations along profile HW2. Other abbreviations: $\mathrm{m}$, meter(s); $\mathrm{ms}$, millisecond(s); $\mathrm{s}$, second(s). 

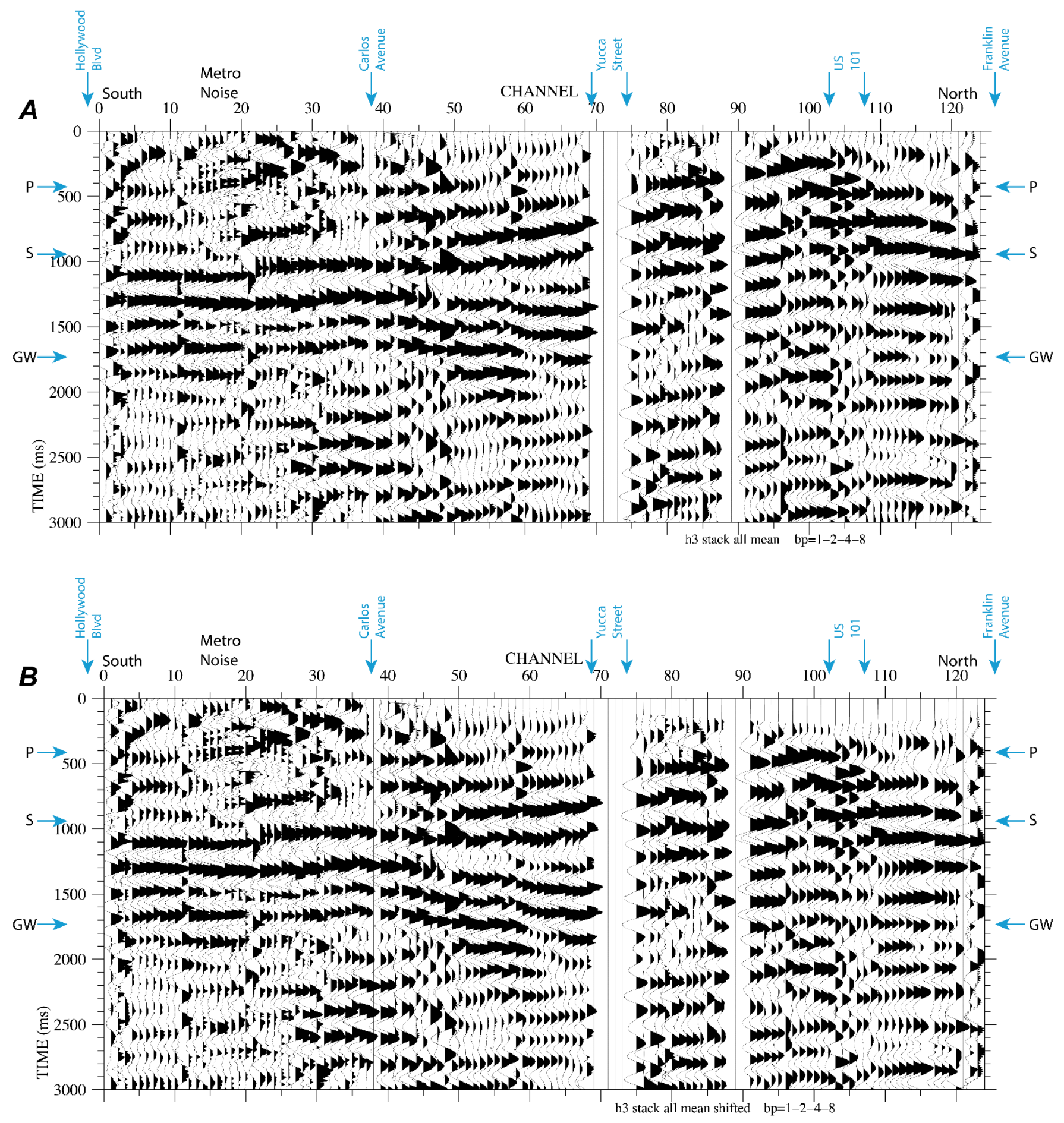

Figure 19. Stacked guided-wave shot gathers for Profile HW2 (guided-wave survey HGW3), showing $(A)$ without time shifts to account for differences in propagation velocities and $(B)$ with time shifts to account for differences in propagation velocities. Source was located at SP2: recording array was located along Profile HW2. There is about $350 \mathrm{~m}$ between the source and the recording array. High levels of cultural noise, which are prevalent before P-wave arrival, are shown on shot gather, especially between channels 1 and 30 and near channel 105. Such high levels of cultural noise make it difficult to evaluate guided waves. P waves (P), S waves (S), and guided waves (GW) are inferred on shot gather. Data were band-pass filtered between 1.5 and $12 \mathrm{~Hz}$. Locations of cross streets are shown. Other abbreviation: ms, millisecond(s). 

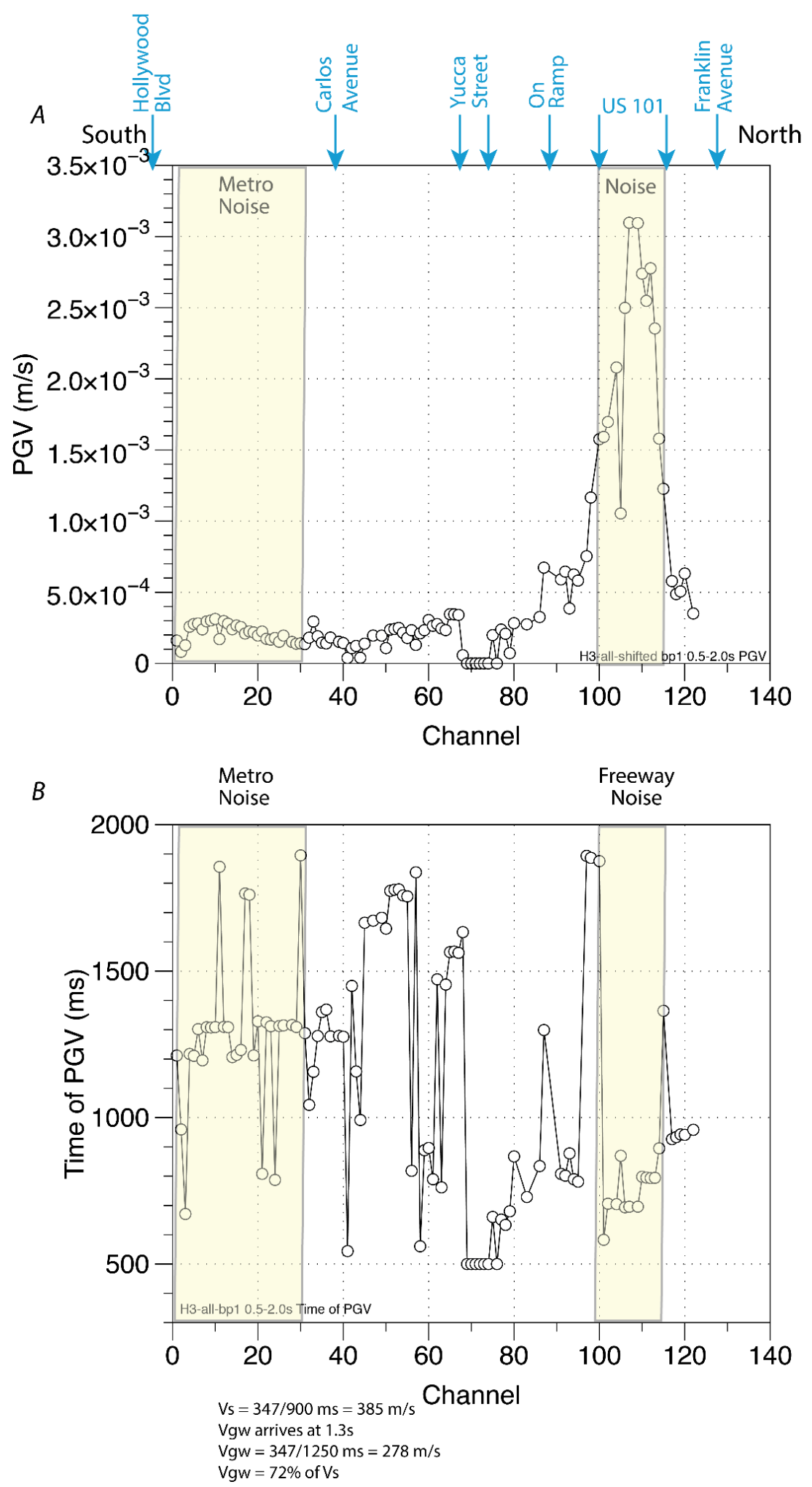

Figure 20. A, Plot of all peak ground velocities (PGV) of guided waves for each recording channel along part of Profile HW2 (guided-wave survey HGW3), showing locations of nearby cross streets. B, Travel times of PGV values shown in $A$. Extremely high PGV values centered near Highway 101 have travel times and velocities that are inconsistent with those expected for guided waves; thus, we suggest that very high PGV values observed for stations near Highway 101 result from freeway noise and not from guided waves; most other PGV values along Profile HW2 are much lower. Slightly higher values are seen on channels 1 to 30, and those higher values may 


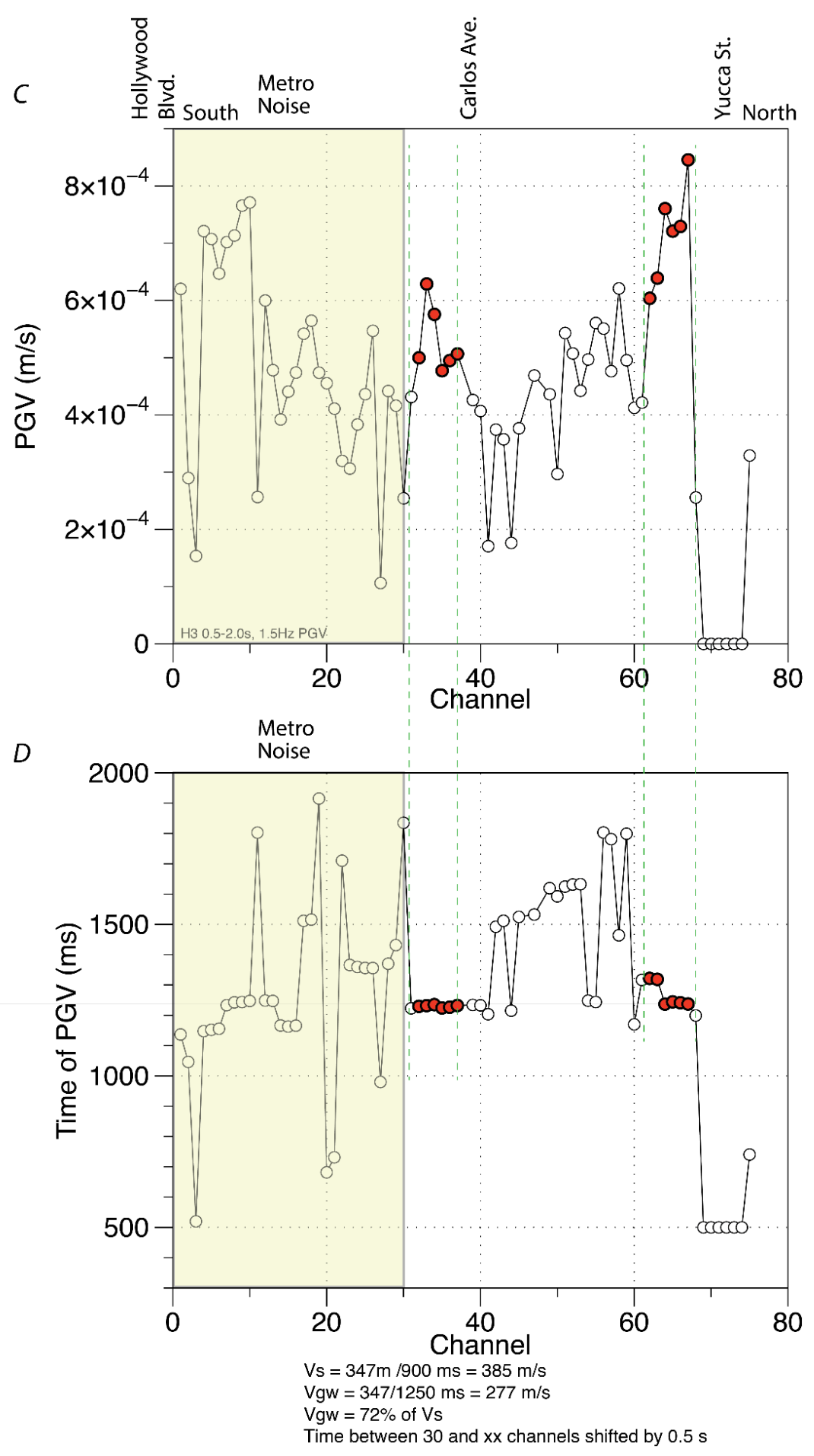

Figure 20 (cont.) result from cultural noises (cars or subway); however, travel times for slightly higher PGV values are generally in time frame expected for guided waves. C, Plot of PGV of guided waves along part of Profile HW2 (guided-wave survey HGW3) south of Yucca Street. High cultural noise is prevalent for channels 1 to 30, making it difficult to determine whether higher PGV values in that range result from guided waves. D, Travel times of PGV values shown in C. Relatively high PGV values (red dots) slightly south of Carlos Avenue and south of Yucca Street have travel times and propagation velocities that are consistent with expectations of guided waves; thus, we suggest possible faulting at those locations (see dashed green lines). Other abbreviations: $m$, meter(s); $\mathrm{ms}$, millisecond(s); s, second(s). 
rate of $0.5 \mathrm{~ms}$. Cultural-noise levels were high along North Argyle Avenue at the time of data acquisition, and the resulting shot gathers were noisy (fig. 21). As a result, we evaluated $V_{\mathrm{S}}$ data that were derived from the surface-wave (Rayleigh wave) data using the MASW technique (fig. 22). Combining the tomographic $V_{\mathrm{P}}$ and the MASW $V_{\mathrm{S}}$ data, we evaluated $V_{\mathrm{P}} / V_{\mathrm{S}}$ ratios and Poisson's ratios along Profile HW2 (figs. 23, 24, respectively).

\section{Profile HW2 $V_{\mathrm{P}}$ Model}

We used the data from the HRR3 survey to develop a $V_{\mathrm{P}}$ model (fig. 22) for Profile HW2. The $V_{\mathrm{P}}$ values range from $400 \mathrm{~m} / \mathrm{s}$ near the surface in the south to about 3,300 m/s at about $70 \mathrm{~m}$ depth near the center of the profile. An abrupt change in shallow velocities $(\sim 400 \mathrm{~m} / \mathrm{s})$ is observed at Carlos Avenue, with higher velocities to the north at shallow depths and progressively thicker lower velocity materials southward toward Hollywood Boulevard. The abrupt change in shallow $V_{\mathrm{P}}$ at Carlos Avenue is similar to the change in $V_{\mathrm{P}}$ seen along Profile HW1 at the apparent Hollywood Fault (fig. 7). The abrupt change in $V_{\mathrm{P}}$ along both Profiles HW1 and HW2 occurs coincident with the zone of apparent high PGV values seen from guided waves. A similar change in $V_{\mathrm{P}}$ also is observed just south of Yucca Street, where PGV of guided waves is locally high. Thus, both guided waves and $V_{\mathrm{P}}$ are suggestive of near-surface faulting slightly south (10-25 m) of the center of Carlos Avenue and about 20 to $35 \mathrm{~m}$ south of the center of Yucca Street.

\section{Profile HW2 $V_{\mathrm{S}}$ Model (from MAS $\mathrm{R}$ )}

From Rayleigh waves generated during the HRR3 seismic survey, we a developed MASW-based $V_{\mathrm{S}}$ model (fig. 23) for Profile HW2. Our $V_{\mathrm{S}}$ model shows that $V_{\mathrm{S}}$ ranges from $200 \mathrm{~m} / \mathrm{s}$ near the surface

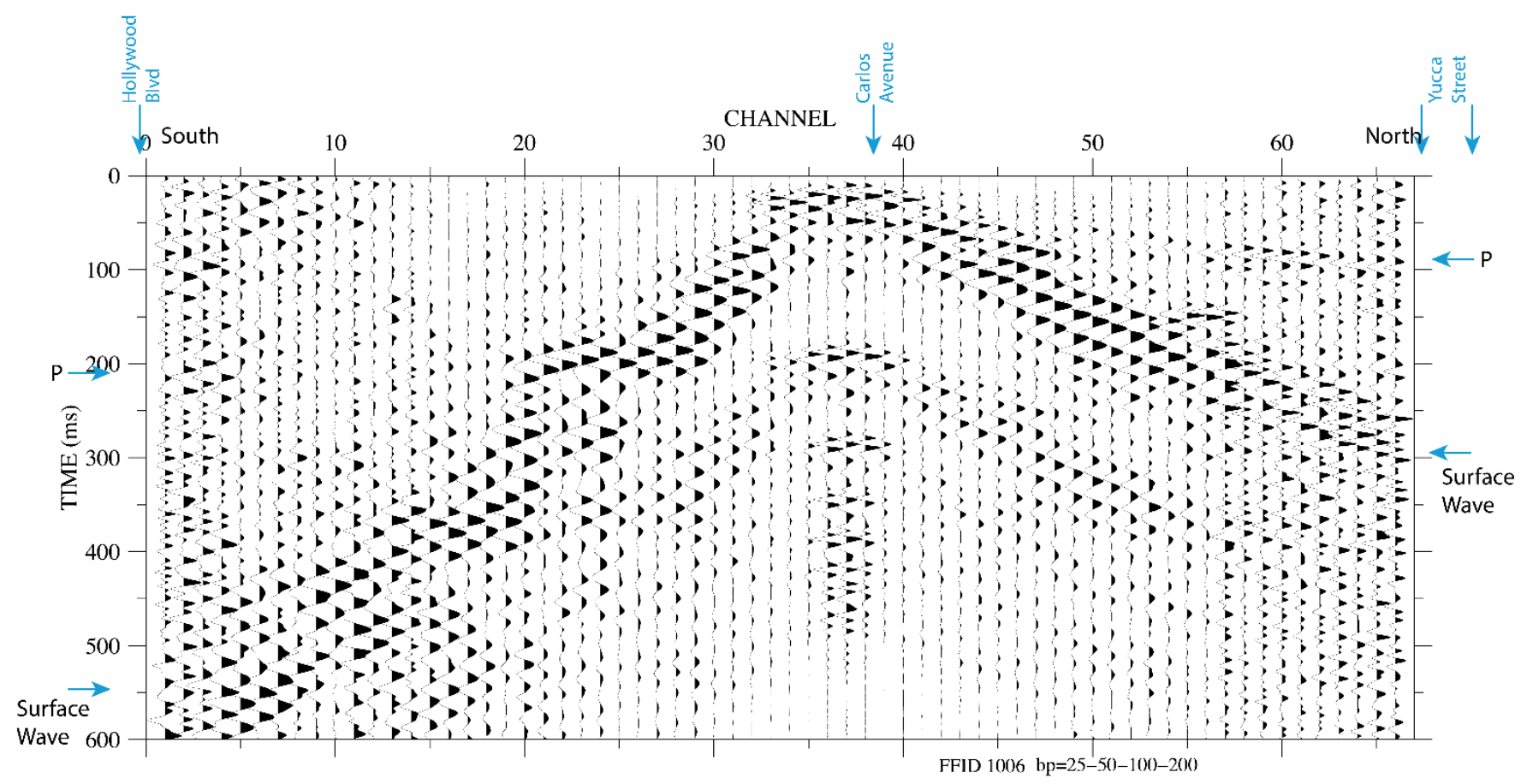

Figure 21. In-line P-wave shot gather along Profile HW2, south of Yucca Street. High cultural noise levels are particularly noticeable for channels 1 to 15 . Multiples, owing to bouncing of seismic source (AWD), are prominent at travel times greater than $200 \mathrm{~ms}$. Zone of asymmetric surface waves and refracted arrivals is present north and south of shot point, demonstrating large differences in structure to south versus to north. Locations of nearby streets are shown. Other abbreviations: $m$, meter(s); ms, millisecond(s); s, second(s). 


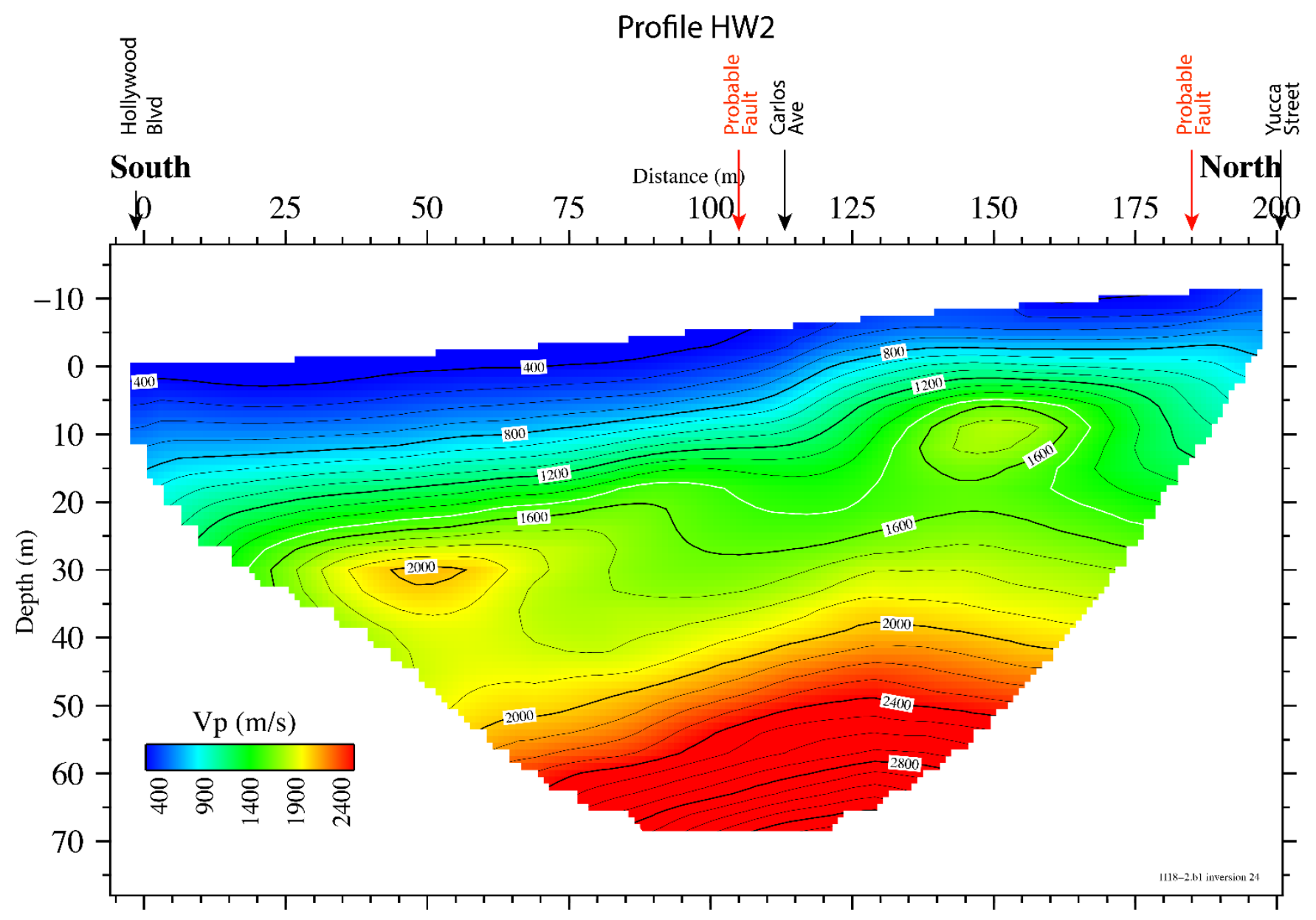

Figure 22. Tomographic P-wave velocity $\left(V_{\mathrm{P}}\right)$ model along Profile HW2, showing locations of cross streets. Prominent $V_{\mathrm{P}}$ anomalies are present along seismic profile, such as abrupt shallowing of $400-\mathrm{m} / \mathrm{s}$ velocity contour near Carlos Avenue. Similar change in velocity is observed at near-surface trace of Hollywood Fault along Profile $\mathrm{HW} 1$. This is also same location that relatively high PGV values are observed on guided-wave PGV plots (see fig. 20). We interpret second change in shallow-depth $V_{\mathrm{P}}$ south of Yucca Street, also consistent with guided-wave PGV values, to infer faulting. Other abbreviations: $m$, meter(s); s, second(s).

on the southern profile to about $675 \mathrm{~m} / \mathrm{s}$ at about 30-m depth south of Carlos Avenue. From the south end of Profile HW2 (at Hollywood Boulevard) to approximately Carlos Avenue, a 7- to 10-m-thick zone of low- $V_{\mathrm{S}}(<300 \mathrm{~m} / \mathrm{s})$ materials is present in the near surface; this layer pinches out at Carlos Avenue in a manner similar to that seen in the tomographic $V_{\mathrm{P}}$ model (fig. 7). Between that 7- to 10-m-thick layer and the base of the model, $V_{\mathrm{S}}$ is high relative to the north end of Profile HW2. A major lateral transition in $V_{\mathrm{S}}$ is observed at all depths of the model, suggesting that a major change in structure is present, likely caused by faulting. Our $V_{\mathrm{S}}$ model also shows that a pronounced, southward-dipping, low-velocity zone is present south of Yucca Street, as was also inferred on the $V_{\mathrm{P}}$ model. This southward-dipping velocity structure may infer a southward-dipping fault south of Yucca Street. Both the $V_{\mathrm{P}}$ and $V_{\mathrm{S}}$ models suggest that an isolated zone of relatively high velocities is present near the surface between meters 130 and 160 .

\section{Profile HW2 $V_{\mathrm{P}} / V_{\mathrm{S}}$ Model ( $V_{\mathrm{P}}$ Tomography and $V_{\mathrm{S}} \mathrm{MAS}_{\mathrm{R}} \mathrm{W}$ )}

Using $V_{\mathrm{P}}$ from the tomography model (fig. 22) and $V_{\mathrm{S}}$ from the MASW-based model (fig. 23), we developed a $V_{\mathrm{P}} / V_{\mathrm{S}}$-ratio model (fig. 24) for Profile HW2. Our model suggests that $V_{\mathrm{P}} / V_{\mathrm{S}}$ ratios range from about 1.5 near the surface south of Carlos Avenue to about 4.8 below $10 \mathrm{~m}$ depth between Carlos 


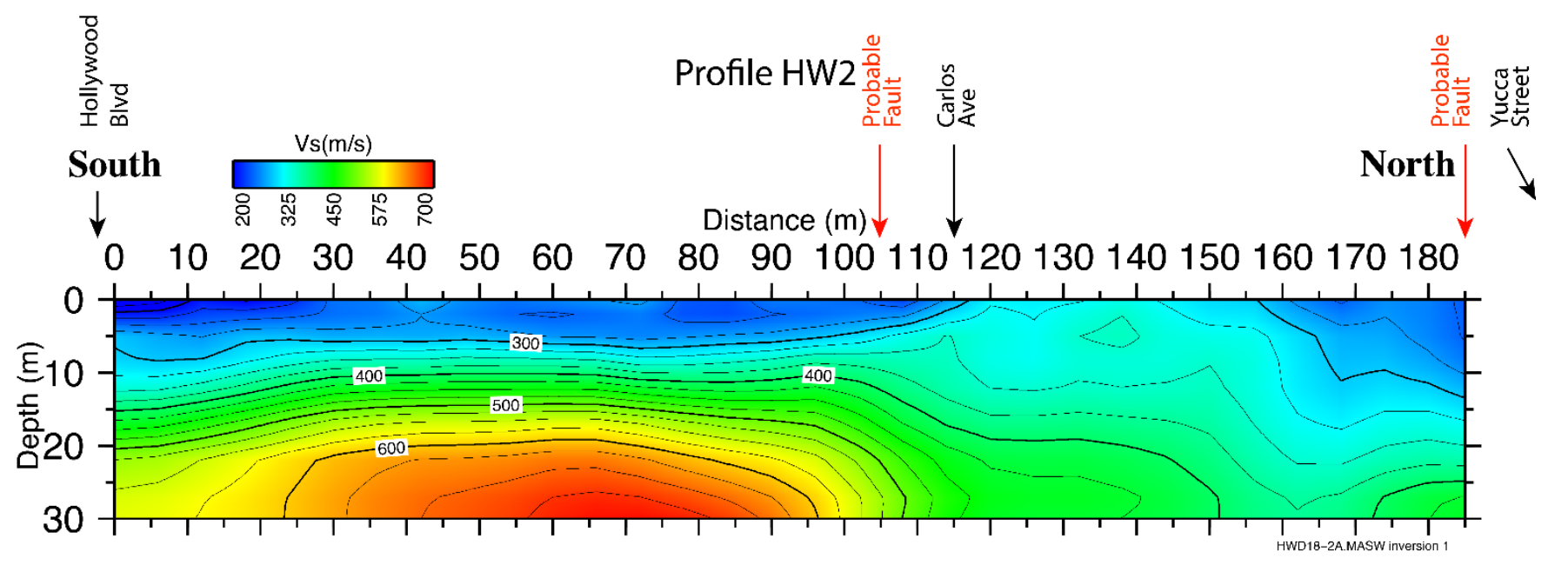

Figure 23. S-wave velocity $(V \mathrm{~s})$ model along Profile HW2, inferred from Rayleigh waves using the multichannel analysis of surface waves (MASW) method. $V_{\mathrm{S}}$ model shows abrupt increase in $V_{\mathrm{S}}$ north of Carlos Avenue, with shallow structure similar to that modeled for $V_{\mathrm{P}}$ model. Higher velocities $(>400 \mathrm{~m} / \mathrm{s})$ are abruptly terminated near Carlos Avenue, suggesting slightly northwestward dip of probable fault. Change in $V \mathrm{~s}$ also is observed south of Yucca Street, with prominent near-vertical low-velocity zone, inferring possible southwestward dip of fault there. Locations of nearby streets are shown. Other abbreviations: $\mathrm{m}$, meter(s); $\mathrm{s}$, second(s).

Avenue and Yucca Street. The zone of highest $V_{\mathrm{P}} / V_{\mathrm{S}}$ ratios is relatively wide near the top and decreases in width with depth, which suggests that two opposing faults join at depth. Thus, on the basis of our $V_{\mathrm{P}}$, $V_{\mathrm{S}}$, and $V_{\mathrm{P}} / V_{\mathrm{S}}$ models, we suggest a northward-dipping fault near Carlos Avenue and a southwarddipping fault south of Yucca Street.

\section{Profile HW2 Poisson's Ratio Model ( $V_{\mathrm{P}}$ Tomography and $V_{\mathrm{S}} \mathrm{MAS} \mathrm{S}_{\mathrm{R}}$ )}

Using the same $V_{\mathrm{P}}$ and $V_{\mathrm{S}}$ models as used to develop our $V_{\mathrm{P}} / V_{\mathrm{S}}-$ ratio model, we developed a Poisson's ratio model for Profile HW2 (fig. 25). The Poisson's ratio model infers a similar structure as that of the $V_{\mathrm{P}} / V_{\mathrm{S}}$-ratio model. Generally, subsurface materials in the upper about $20 \mathrm{~m}$ along Profile HW2 differ markedly from south to north, with the major change occurring at Carlos Avenue. This lateral variation in Poisson's ratio values suggests a significant change in shallow-crustal properties that are likely related to groundwater saturation. Because faults usually act as groundwater barriers, this pronounced lateral change in Poisson's ratio is consistent with the presence of a fault near Carlos Avenue. The highest Poisson's ratio values along our model are confined to a zone between Carlos Avenue and Yucca Street, which would be consistent with bounding faults near Carlos Avenue and slightly south of Yucca Street.

\section{Summary of Seismic Indicators of Faulting along Profile HW2}

We evaluated five seismic models along Profile HW2, including (1) PGV of guided waves from two source locations, (2) tomographic $V_{\mathrm{P}}$, (3) MASW $V_{\mathrm{S}}$, (4) hybrid tomography/MAS $\mathrm{M}_{\mathrm{R}} V_{\mathrm{P}} / V_{\mathrm{S}}$ ratios, and (5) hybrid tomography/MAS $\mathrm{S}_{\mathrm{R}} \mathrm{W}$ Poisson's ratios. All of these models show prominent changes in shallow-depth structure near Carlos Avenue and slightly south of Yucca Street that are consistent with shallow faulting in those locations. We interpret these images as indicating a shallow-depth, northwarddipping fault near Carlos Avenue and a shallow-depth, southward-dipping fault south of Yucca Street, with both faults merging in the shallow subsurface. 


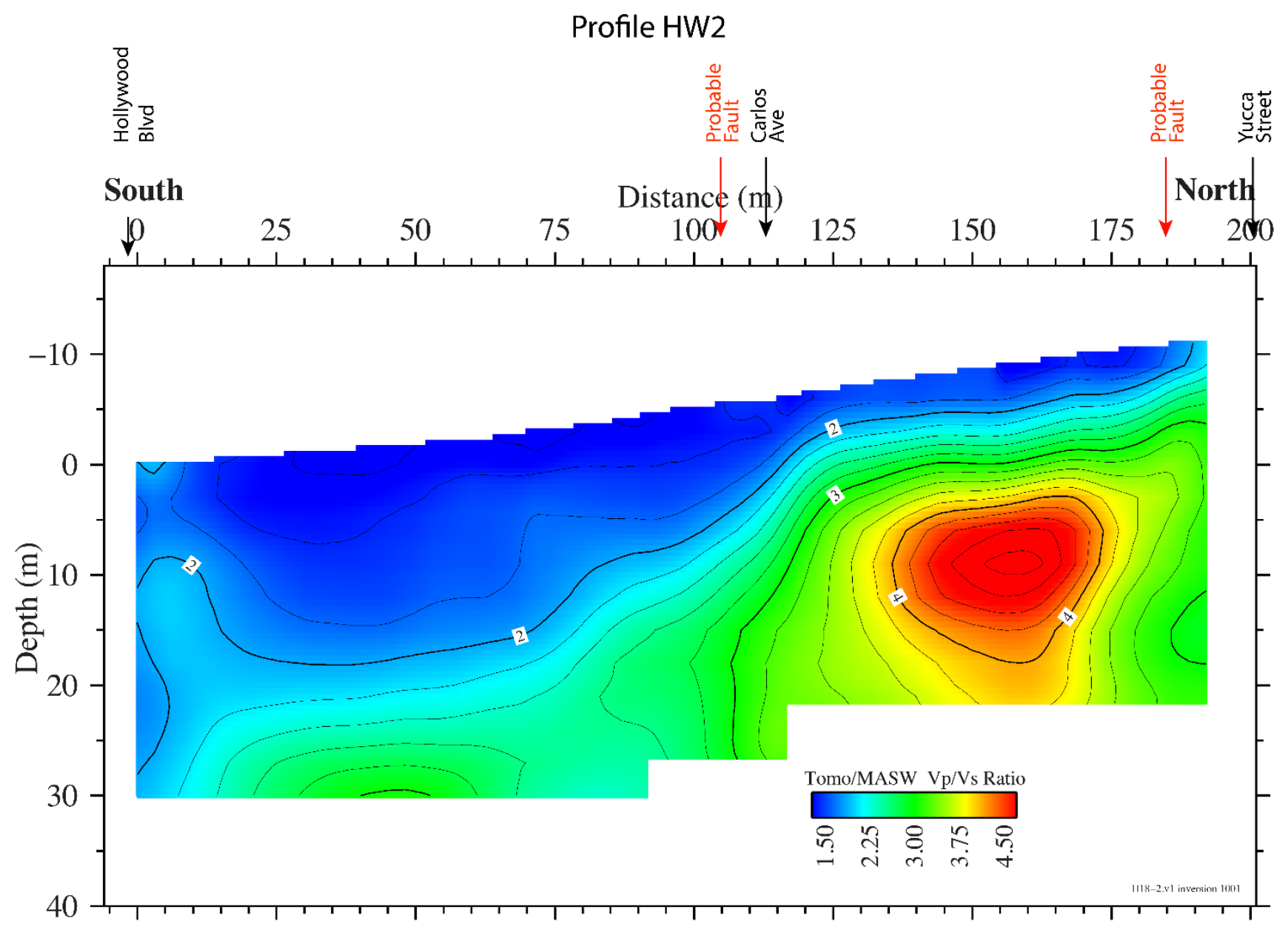

Figure 24. $V_{\mathrm{P}} / V_{\mathrm{s}}$ ratio model along Profile $\mathrm{HW} 2$, derived from combination of our $V_{\mathrm{P}}$ tomography model and our MASRW $V_{\mathrm{S}}$ model. Shallow-depth, abrupt changes in $V_{\mathrm{P}} / V_{\mathrm{S}}$ ratios are present in vicinity of Carlos Avenue and south of Yucca Street. Prominent $V_{\mathrm{P}} / V_{\mathrm{s}}$-ratio high is present at slightly greater depths between two abrupt changes in $V_{\mathrm{P}} / V_{\mathrm{S}}$ ratios. This structure can be interpreted as showing two opposing fault traces. Locations of nearby streets are shown. Abbreviation: $\mathrm{m}$, meter(s).

\section{Summary of Observations, Hollywood Fault}

We evaluated 13 seismic models and data combinations along Profile HW1 at the First Presbyterian Church of Hollywood parking lot (fig. 3). All of those data are consistent with near-surface faulting near meter 106 of Profile HW1, slightly south of Carlos Avenue. On the basis of the combined seismic data, we interpret the fault to slightly splay near the surface, having both northward and southward dips at shallow depths but a northward dip at depth. On the basis of the location of the fault identified in core borings and CPT transects at the Hollywood Courthouse building and our observed location along Profile HW1, we suggest that the fault strikes about N. $87^{\circ} \mathrm{E}$. and has variable dips in the shallow subsurface. However, on the basis of the unmigrated reflection images, we suggest that the fault dips slightly northward at depth.

We evaluated five seismic models and data combinations along Profile HW2 along North Argyle Avenue in Hollywood. All of those data are consistent with, but not definitive of, near-surface faulting slightly south of Carlos Avenue and south of Yucca Street. Furthermore, additional fault traces may be 


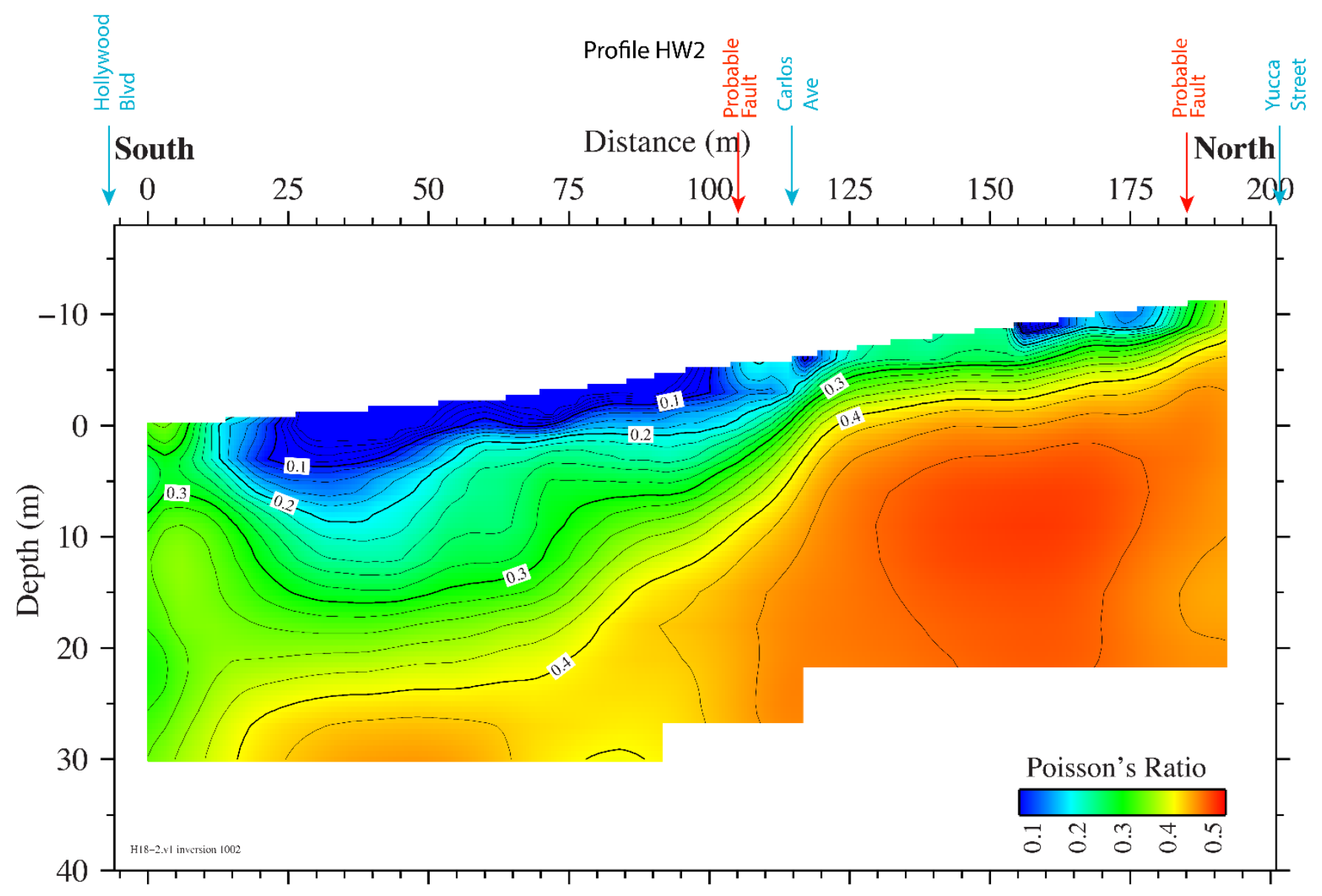

Figure 25. Poisson's ratio model along Profile HW1, derived from combination of our $V_{\mathrm{P}}$ tomography model and our MASRW Vs model. Shallow-depth, abrupt changes in Poisson's ratios are observed in vicinity of Carlos Avenue and south of Yucca Street. Prominent Poisson's-ratio high is present at slightly greater depths between two abrupt changes in near-surface Poisson's ratios, which we interpret as a highly saturated zone between two faults. Locations of nearby streets are shown. Abbreviation: $\mathrm{m}$, meter(s).

present along Profile HW2, but the high levels of cultural noise in our data make it difficult to infer faulting elsewhere along North Argyle Avenue. On the basis of the fault locations along Profiles HW1 and HW2 inferred from our data, we suggest that this strand of the Hollywood Fault strikes almost due east-west between the core boring/CPT transect at the Hollywood Courthouse and our seismic profile along North Argyle Avenue. Although traces of the fault may have variable dips in the shallow subsurface, we suggest that the overall dip is near vertical, with a slightly northward dip at depth.

\section{Santa Monica Fault Data Acquisition (Beverly Hills)}

On May 26, 2018, and on June 6, 2018, we conducted guided-wave seismic surveys across the suspected near-surface trace of the Santa Monica Fault in Beverly Hills, Calif. The recording array for both seismic surveys was located on the east side of Lasky Drive, between Moreno Drive and Santa Monica Boulevard (fig. 26). We refer to this profile as Profile BH1, and we refer to the two individual surveys as BHGW1 and BHGW2.

Survey BHGW1 was about $300 \mathrm{~m}$ long and consisted of approximately 149 recording sites, but six of the sites were not used because they would have blocked driveways. The data from survey BHGW1 were recorded on $4.5-\mathrm{Hz}$ horizontal-component sensors, spaced at 2-m intervals, but data were not recorded at 20 sites owing to instrumental failures. The sampling rate was $2 \mathrm{~ms}$. The seismic source 


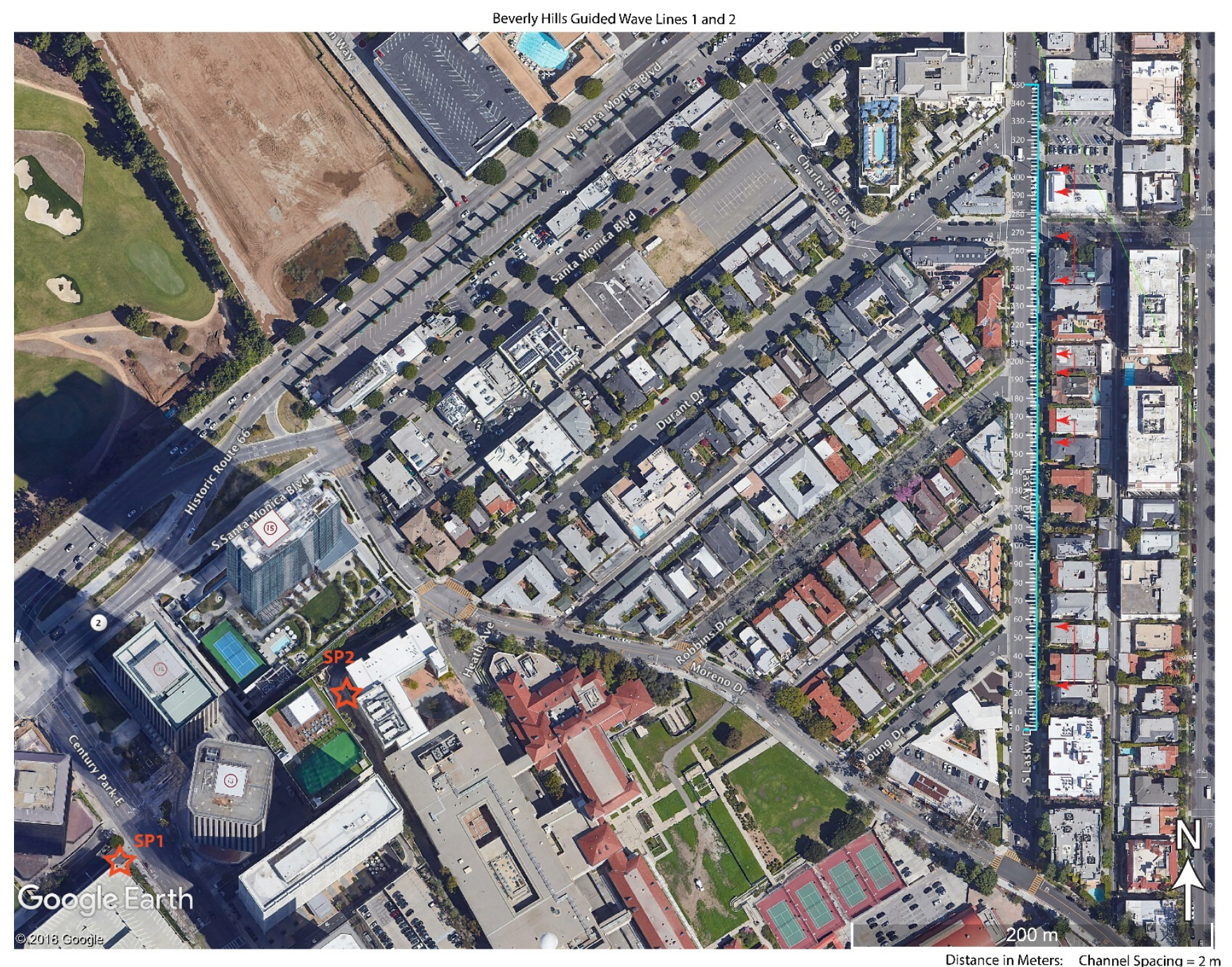

Figure 26. Google Earth image of Santa Monica Fault in our study area in Beverly Hills, showing locations of seismic surveys (BHGW1, BHGW2) recorded along Profile BH1 (cyan line). Scale (in meters [m]) is included along Profile BH1. Seismic sources were generated at SP1 and SP2 (red stars) at the near-surface trace of Santa Monica Fault, as inferred from geologic mapping. Recording arrays for BHGW1 and BHGW2 surveys were located in same place, except that BHGW2 survey extended farther north by about $50 \mathrm{~m}$. Red arrows show zones where high PGV values (that have travel times consistent with guided waves) were recorded.

(227-kg AWD) used to generate guided waves was located approximately $30 \mathrm{~m}$ southwest of Century Park East and about $100 \mathrm{~m}$ southeast of Santa Monica Blvd, within an alley northwest of a parking garage. The first AWD shot started on May 26, 2018, at 21:42:05 (local time; 04:42:05 UTC), and the last shot was completed at 22:24:46 (local time; 05:24:46 UTC) on the same day. We stacked a total of 198 individual shots to form a guided-wave shot gather.

We decided to acquire a second seismic guided-wave survey (BHGW2) along Laskey Drive on June 6, 2018, when we discovered that the expected fault crossing was at the approximate north end of the BHGW1 survey, near the intersection of Lasky Drive and Charleville Boulevard. The recording stations for the BHGW2 survey were in the same locations as that of the BHGW1 survey, but the length $(350 \mathrm{~m})$ of the recording array for BHGW2 was slightly longer (fig. 26). Profile BH2 consisted of 174 recording stations, but recorders were not deployed at 13 stations because they would have blocked driveways. We used the same sensors $(4.5-\mathrm{Hz})$, station spacing $(2 \mathrm{~m})$, and sampling rate $(2 \mathrm{~ms})$ for the 
BHGW2 survey as was used for the BHGW1 survey. However, the seismic source (SP2) for the BHGW2 survey was located at SP2, about $80 \mathrm{~m}$ southwest of Heath Avenue and about $130 \mathrm{~m}$ southeast of Santa Monica Boulevard (fig. 26). The first shot started on June 6, 2018, at 22:05:42:36 (local time; 05:42:36 UTC), and the last shot was completed at 23:01:37 (local time; 06:01:37 UTC). A total of about 198 AWD shots were generated. Owing to instrumental failures, we did not obtain data from 19 of the 174 seismic recorders.

\section{Santa Monica Fault Data Analysis}

The seismic sources for the BHGW1 seismic survey were located about 500 and $647 \mathrm{~m}$ southwest of the southernmost and northernmost ends of Profile BH1, respectively (fig. 27). We chose this site (SP1) to generate seismic sources because it was the location of a previous coring and CPT transect, in which an active trace of the Santa Monica Fault was identified. Because the source was not centered with respect to the recording array, a difference in travel time from the south end to the north end of the array was observed. To evaluate the PGV of the guided waves within the same time window, the "moveout" of the travel time was removed by shifting the time of the more distant arrivals on the north end of the profile. Thus, the actual travel time of the guided waves on the north end of the recording array was greater by about $500 \mathrm{~ms}$ than what is shown in figure 27 .

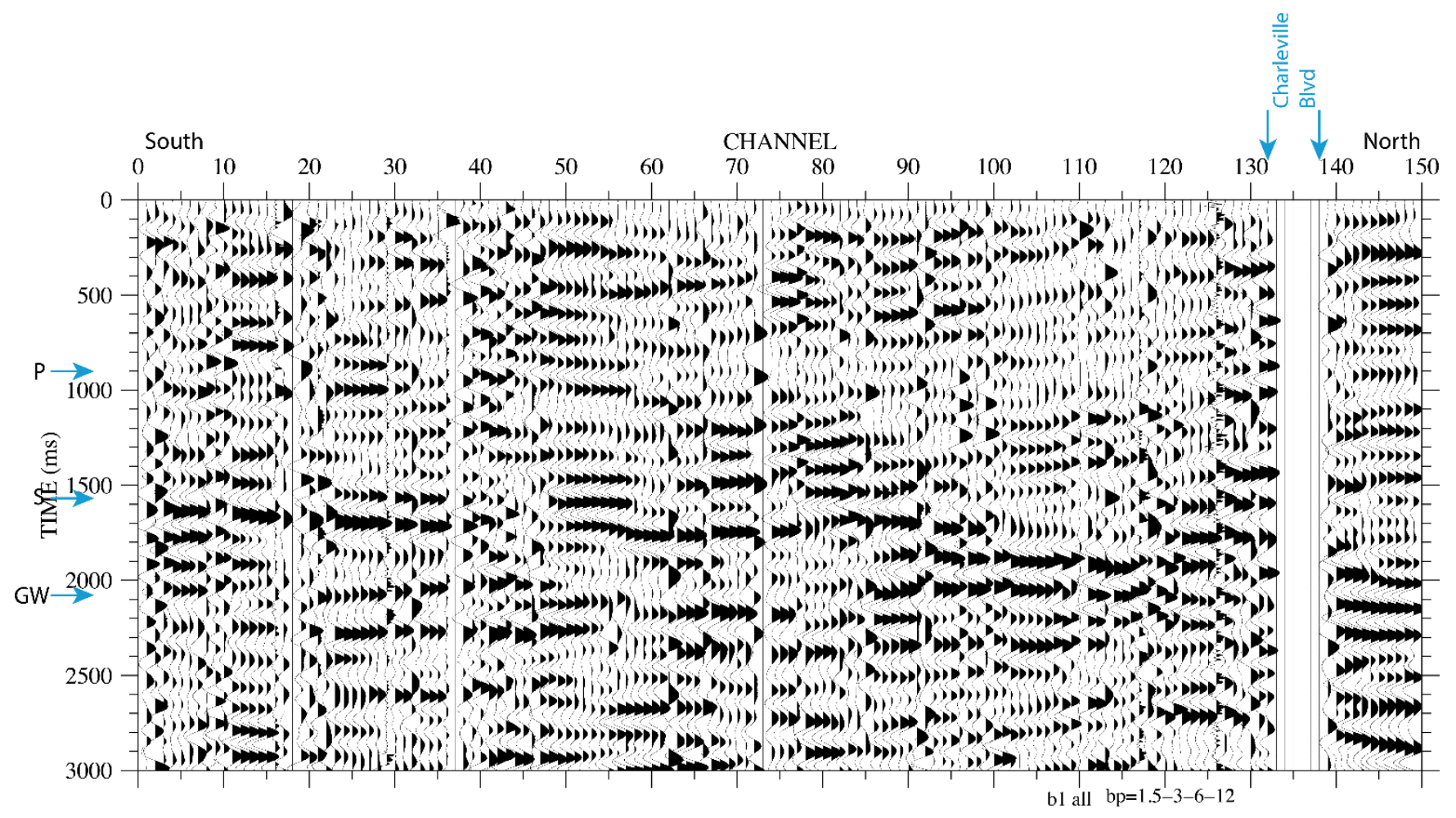

Figure 27. Stacked guided-wave shot gather for BHGW1 seismic survey. Source is located at SP1; recording array is located along Profile $\mathrm{BH} 1$ (distance between source and recording array ranges from about 500 to about $650 \mathrm{~m}$ ). Long propagation distance and high level of cultural noise resulted in poor signal-to-noise ratios. $P$ waves $(\mathrm{P})$, S waves (S), and guided waves (GW) are inferred on shot gather. Data were band-pass filtered between 1.5 and $12 \mathrm{~Hz}$. Location of Charleville Boulevard is shown. Other abbreviation: ms, millisecond(s). 


\section{Guided-Wave Data Analysis for Profile BH1}

The signal-to-noise ratio of the data acquired during the BHGW1 seismic survey was low (fig. 27 ) owing to excessively high cultural-noise levels during the $\sim 21: 00$ - to $\sim 22: 00$-hour local time frame on May 26, 2018, which was a Saturday evening. However, even with the low signal-to-noise ratios, we were able to evaluate PGV of guided waves (fig. 28) within the time frame ( $>1.5$ to $3 \mathrm{~s}$ ) expected for shear-wave and guided-wave arrivals. On the basis of travel time and amplitude, we infer the presence of low-velocity guided waves south and north of Charleville Boulevard and possibly near the south end of Profile BH1. The observed high values of guided-wave PGV (fig. 28A) correlate with the expected guided-wave travel times (fig. 28B). Our data show that the highest PGV values arrived at the recording array at about $2,500 \mathrm{~ms}(2.5 \mathrm{~s} ; \sim 0.5 \mathrm{~s}$ added to arrivals on the north end of the profile shown in fig. $28 B)$, and because the source was approximately $650 \mathrm{~m}$ from apparent fault zone, this suggests that the guided waves traveled at about $250 \mathrm{~m} / \mathrm{s}$. The earliest shear waves arrived at the recording array at about 1,500 ms $(1.5 \mathrm{~s})$, suggesting an average $V_{\mathrm{S}}$ of about $330 \mathrm{~m} / \mathrm{s}$. These velocities suggest that the guided waves travel at about 75 percent of the velocity of the shear wave. Along Profile BH1, the most prominent high values of PGV are observed between channels 60 and 150 (between meters 118 and 298) of the recording array, which extends from slightly south to slightly north of Charleville Boulevard (fig. 28).

\section{Beverly Hills Profile BH2 Guided-Waves}

The signal-to-noise ratios of the data from the BHGW2 seismic survey (fig. 29) were higher than those of the data recorded for the BHGW1 survey. As a result, the shear-wave and guided-wave arrivals are more apparent on the BHGW2 data. The higher signal-to-noise ratios may have resulted from stronger signals because the seismic source (SP2) was closer to the recording array, but the higher ratios may also have resulted from lower cultural-noise levels present later in the evening ( 22:00 to $\sim 23: 00$ local time). Lower noise levels also were likely on a Wednesday evening (June 6, 2018) than on a Saturday evening.

From the data obtained during the BHGW2 seismic survey, we evaluated PGV values of guided waves from the time of the shear-wave arrival $(\sim 1 \mathrm{~s})$ to about $3.2 \mathrm{~s}$ (includes a 0.5 -s time shift on the north end of the profile; see fig. 30). Our PGV values are averaged over three consecutive arrivals to limit large variations from a single arrival. On the basis of travel time and amplitude, the low-velocity guided waves appear easy to identify. High-PGV values (fig. 30A) correlate with the expected guidedwave travel times (and velocities) along Profile BH2 (fig. 30B). Our data show that the highest PGV values arrived at the recording array at 2,000 to 2,500 $\mathrm{ms}(2.0-2.5 \mathrm{~s}$; includes the time shift), and, using distance from the source $(368-510 \mathrm{~m})$ to the fault traces, we found that the guided waves traveled at about 185 to $200 \mathrm{~m} / \mathrm{s}$. These guided-wave velocities are lower than those estimated for the BHGW1 survey because of the greater distance and deeper propagation depth of guided waves between SP1 and the BHGW1 recording array. The earliest shear wave for the BHGW2 survey arrived at the recording array at about 1,500 to $2,000 \mathrm{~ms}(1.5-2.0 \mathrm{~s})$, suggesting an average $V_{\mathrm{S}}$ of about 245 to $255 \mathrm{~m} / \mathrm{s}$. This suggests that the guided wave travels at about 75 to 78 percent of the velocity of the shear wave.

Along Profile $\mathrm{BH} 2$, the most prominent late-arriving, high-PGV values are seen at stations (channels) 120 to 135 (meters 238-268) and 145 to 152 (meters 288-302) of the recording array; these stations were located in the vicinity of Charleville Boulevard, suggesting that prominent fault traces are present in that area. However, late-arriving, locally high PGV values also were observed near stations 11 to 28,78 to 82 , and 95 to 102 . The high-PGV values observed at these stations also coincide with late arrivals that are consistent with guided waves. Similarly PGV-value zones also were seen on the BHGW1 survey, which were contaminated with cultural noise. Because of the consistent travel-time delays and high amplitudes, we suggest that each of the high-PGV values listed above likely are fault related. Because of the prominent PGV peaks and observed travel times (velocities) near Charleville Boulevard, we suggest that those probable faults are the ones most directly connected to the fault trace at 
$A$

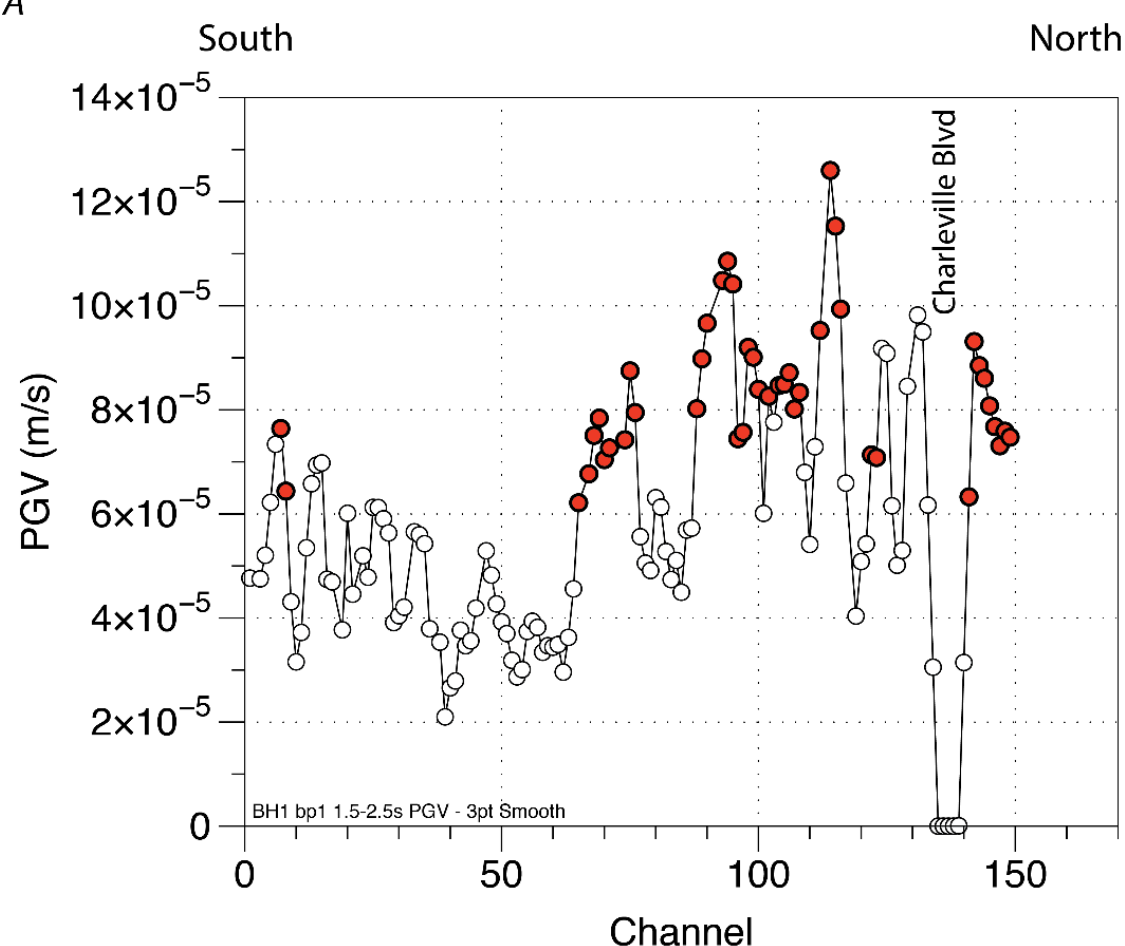

$B$

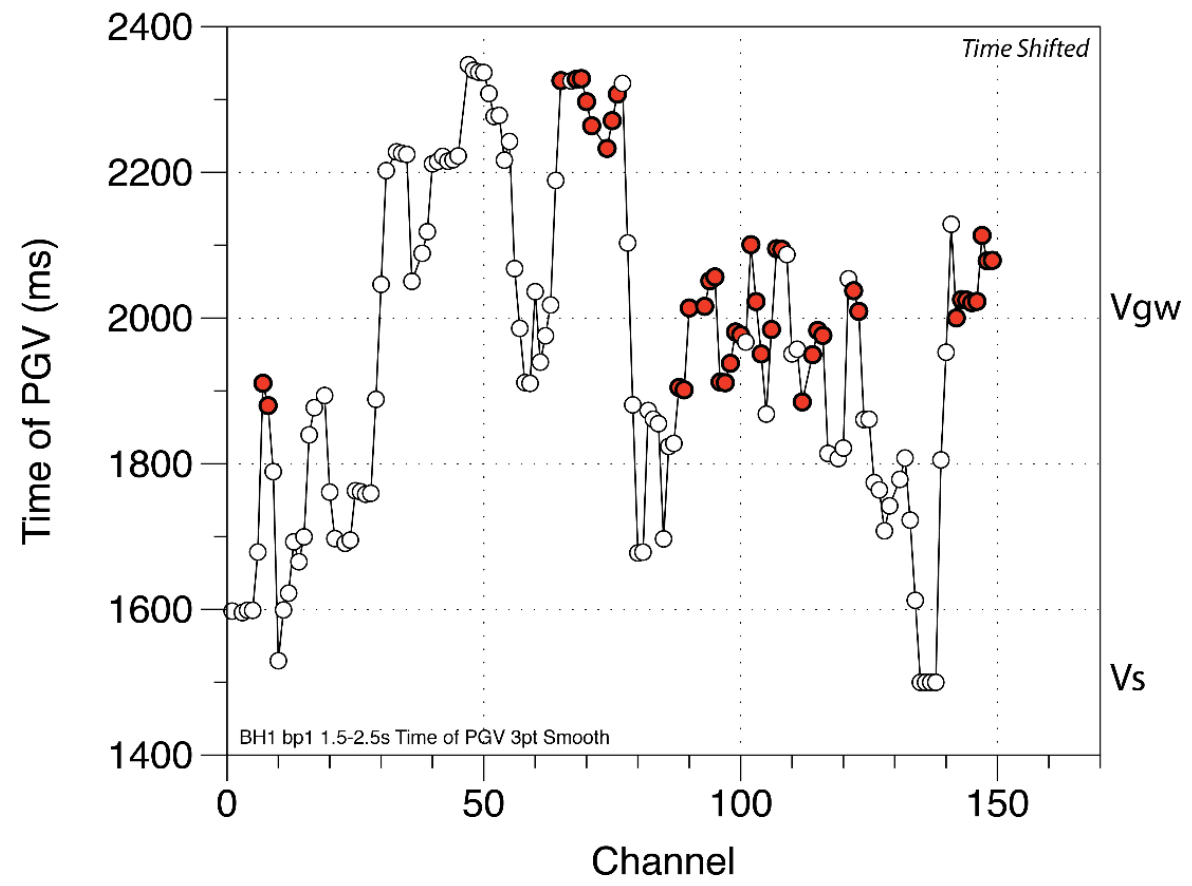

Figure 28. A, Plot of peak ground velocity (PGV) of guided waves for each recording channel along BHGW1 survey. Highest PGV values (red dots) were concentrated on north end of recording array, both north and south of Charleville Boulevard; indications of relatively high values also are present at several locations along Lasky Drive. $B$, Plot of time of arrival of corresponding PGV values shown in A. Note that highest PGV values coincide with delayed phases that arrive at about 1.9 to 2.1 seconds (s) or more (after 0.5-s time shift applied). Arrival times have been shifted downward on north end of profile by about $0.5 \mathrm{~s}$ relative to south end of profile. Owing to low signal-tonoise ratios for BHGW1 survey, uncertainty is high in possible fault traces. Location of Charleville Boulevard is shown. Other abbreviations: $m$, meter(s); ms, millisecond(s); s, second(s). 


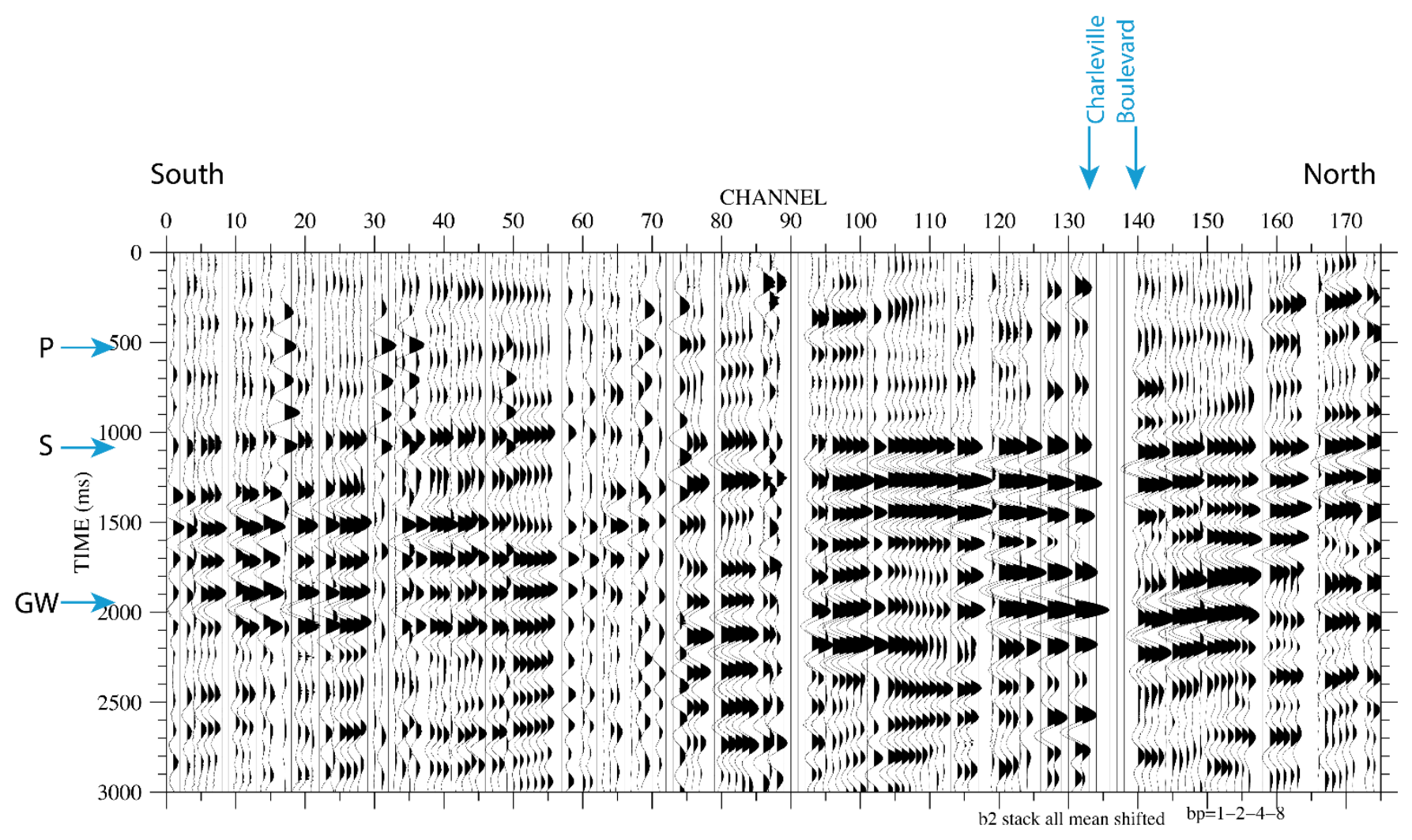

Figure 29. Stacked guided-wave shot gather for Profile BH2. Source is located at SP2; recording array is located along Profile $\mathrm{BH} 1$ (distance between source and recording array ranges from about 370 to about $510 \mathrm{~m}$ ). Shorter propagation distance and lower cultural-noise levels resulted in higher signal-to-noise ratios than recorded for BHGW1 survey. $P$ waves $(P)$, S waves (S), and guided waves $(G W)$ are inferred on shot gather. Data were bandpass filtered between 1 and $8 \mathrm{~Hz}$. Location of Charleville Boulevard is shown. Other abbreviation: ms, millisecond(s).

the seismic source (SP2). The probable fault traces near Charleville Boulevard also are likely to be nearsurface traces. Because multiple high-PGV zones are present along the BHGW2 survey, we suggest that the near-surface Santa Monica Fault is distributed along several traces along Lasky Drive.

\section{Summary of Observations, Santa Monica Fault, Beverly Hills}

We acquired only guided-wave data along Lasky Drive in Beverly Hills because we did not have the requisite permission to conduct in-line, active-source surveys. Additionally, we had little direct knowledge of the location of traces of the Santa Monica Fault where we could place our seismic sources. As a result, we conducted two guided-wave seismic surveys along Lasky Drive. Before conducting the first survey (BHGW1), we did not realize that one of the main traces of the Santa Monica Fault may have been located near the intersection of Charleville Boulevard and Lasky Drive, which was the north end of the BHGW1 survey. Upon learning of this possible location of the fault trace, we chose to conduct a second survey (BHGW2) that extended northward of the possible fault trace.

The signal-to-noise ratios of data from the BHGW1 survey were low, but the data from that survey appear to be consistent with probable faulting north and south of Charleville Boulevard. In addition, the data indicate that additional distributed faulting may be present along Profile BH1, particularly south of Charleville Boulevard. However, because of the low signal-to-noise ratios of the data, we have lower confidence in the data from the BHGW1 survey. 


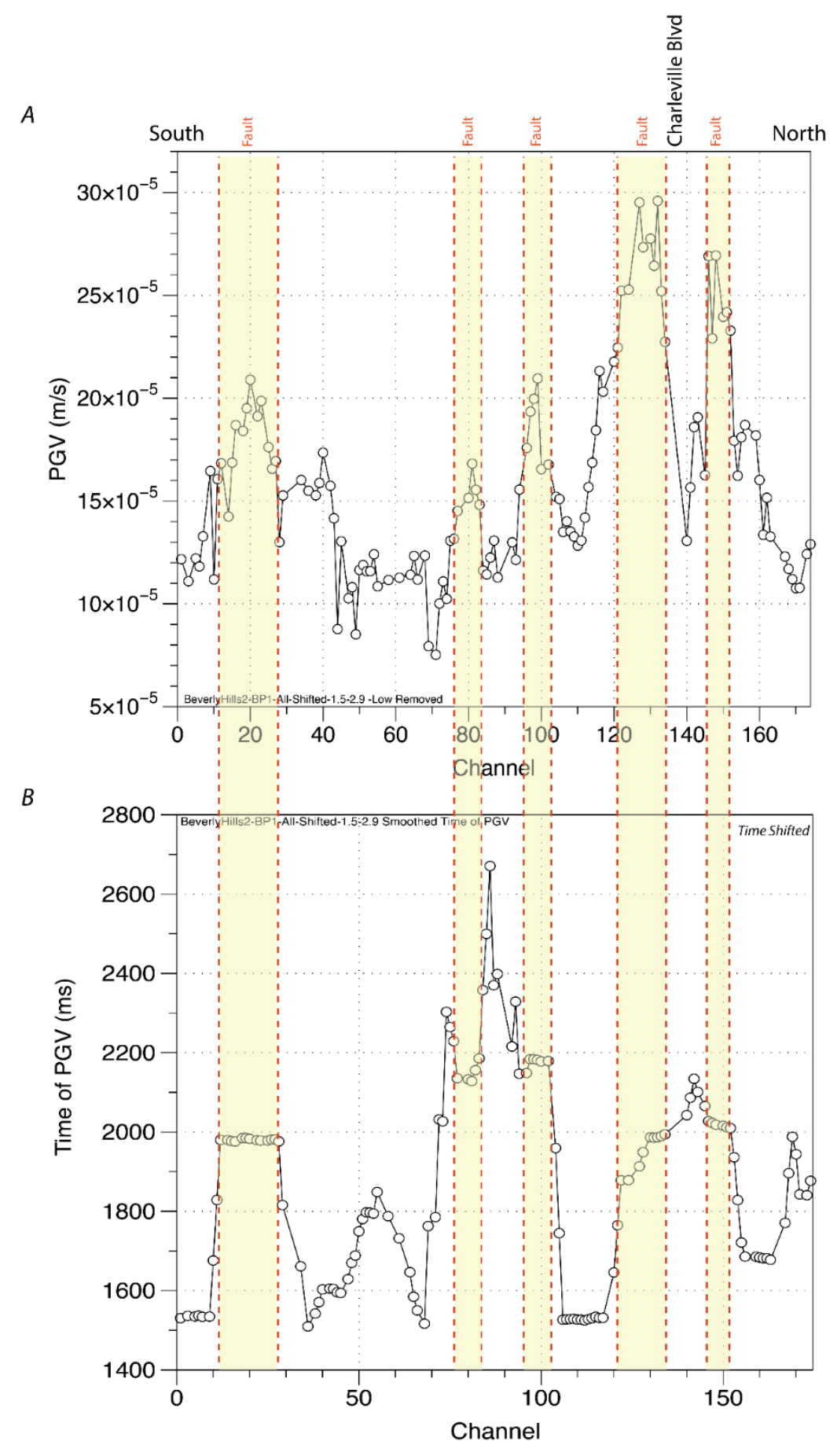

Figure 30. A, Plot of peak ground velocity (PGV) of guided waves for recording channels along BHGW2 survey. Because data were not recorded for some stations and because some sensors were not leveled when deployed, we opted to average each PGV value relative to the two closest PGV values to obtain a more stable result. HighPGV values (yellow shading) were concentrated along several locations along Lasky Drive; highest PGV values are near Charleville Boulevard. B, Plot of time of arrival of corresponding PGV values shown in A. Arrival times have been shifted downward on north end of profile by about 0.5 second (s) relative to south end of profile. Highest PGV values coincide with delayed phases that arrive at about $2 \mathrm{~s}$ or more (shifted time), consistent with guided waves, suggesting prominent faulting near Charleville Boulevard, but additional faulting appears to be present at areas along the profile (yellow shading). Location of Charleville Boulevard is shown. Other abbreviations: $m$, meter(s); ms, millisecond(s); s, second(s). 
Data from the BHGW2 survey contained much higher signal-to-noise ratios, and the BHGW2 data also are indicative of faulting near the intersection of Charleville Boulevard and Lasky Drive. In addition, the BHGW2 data also are consistent with the presence of as many as three other fault traces along Lasky Drive. Importantly, all five of these high-PGV zones can be inferred on both the BHGW1 and BHGW2 data (figs. 28, 30). Thus, we suggest that distributed shallow-depth faulting likely is present at several locations along Lasky Drive.

\section{References Cited}

Aki, K., and Lee, W.H.K., 1976, Determination of three-dimensional velocity anomalies under a seismic array using P-arrival times from location earthquakes-1. A homogeneous initial model: Journal of Geophysical Research, v. 81, p. 4381-4399.

Ben-Zion, Y., 1998, Properties of seismic fault zone waves and their utility for imaging low-velocity structure: Journal of Geophysical Research, v. 103, p. 12,567-12,585.

Ben-Zion, Y., Peng, Z., Okaya, D., Seeber, L., Armbruster, J.G., Ozer, N., Michael, A.J., Baris, S., and Aktar, M., 2003, A shallow fault zone structure illuminated by trapped waves in the Karadere-Duzce branch of the North Anatolian fault, Western Turkey: Geophysical Journal International, v. 152, p. 699-717.

Boness, N.L., and Zoback, M.D., 2004, Stress-induced seismic velocity anisotropy and physical properties in the SAFOD Pilot Hole in Parkfield, CA: Geophysical Research Letters, v. 32, L15S17, https://doi.org/10.1029/2003GL019020.

Brouwer, J., and Helbig, K., 1998, Shallow high-resolution reflection seismics, in Helbig, K., and Treitel, S., eds., Handbook of Geophysical Exploration, vol. 19: Oxford, United Kingdom, Elsevier, $391 \mathrm{p}$.

Catchings, R.D., 1999, Regional $V_{\mathrm{P}}, V_{\mathrm{S}}, V_{\mathrm{P}} / V_{\mathrm{S}}$, and Poisson's ratios across earthquake source zones from Memphis, Tennessee to St. Louis, Missouri: Bulletin of the Seismological Society America, v. 89, p. 1591-1605.

Catchings, R.D., Gandhok, G., Goldman, M.R, Okaya, D., Rymer, M.J., and Bawden, G.W., 2008, Near-surface location, geometry, and velocities of the Santa Monica fault zone, Los Angeles, California: Bulletin of the Seismological Society of America, v. 98, p. 124-138.

Catchings, R.D., Gandhok, G., Goldman, M.R., and Steedman, C., 2007, Near-surface structure and velocities of the northeastern Santa Cruz Mountains and the western Santa Clara Valley, California, from seismic imaging: U.S. Geological Survey Open-File Report 2007-1039, 70 p., https://pubs.usgs.gov/of/2007/1039/.

Catchings, R.D., Goldman, M.R., Lee, W.H.K., Rymer, M.J., and Ponti, D.J., 1998, Thrust faults apparently related to and possible coseismic origin of surface cracks in Potrero Canyon, Los Angeles County, California, following the 1994 Northridge, California, earthquake: Bulletin of the Seismological Society of America, v. 88, p. 1379-1391.

Catchings, R.D., Goldman, M.R., Li, Y.G., and Chan, J.H., 2016, Continuity of the West Napa-Franklin fault zone inferred from guided waves generated by earthquake following the 24 August $2014 \mathrm{Mw} 6.0$ South Napa Earthquake: Bulletin of the Seismological Society of America, v.106, p. 2721-2746, https://doi.org/10.1785/0120160154.

Catchings, R.D., Goldman, M.R., Trench, D., Buga, M., Chan, J.H., Criley, C.J., and Strayer, L.M., 2017, Shallow-depth location and geometry of the Piedmont Reverse splay of the Hayward Fault, Oakland, California: U.S. Geological Survey Open-File Report 2016-1123, 22 p., https://doi.org/10.3133/ofr20161123.

Catchings, R.D., Rymer, M.J., Goldman, M.R., and Gandhok, G., 2009, San Andreas fault geometry at Desert Hot Springs, California, and its effects on earthquake hazards and groundwater: Bulletin of the Seismological Society of America, v. 99, p. 2190-2207. 
Catchings, R.D., Rymer, M.J., Goldman, M.R., Hole, J.A., Huggins, R., and Lippus, C., 2002, Highresolution seismic velocities and shallow structure of the San Andreas fault zone at Middle Mountain, Parkfield, California: Bulletin of the Seismological Society of America, v. 92, p. 2493-2503.

Catchings, R.D., Rymer, M J., Goldman, M.R., Prentice, C.S., and Sickler, R.R., 2013, Fine-scale delineation of the location of and relative ground shaking within the San Andreas fault zone at San Andreas Lake, San Mateo County, California: U.S. Geological Survey Open-File Report 2013-1041, 58 p., https://pubs.usgs.gov/of/2013/1041/.

Catchings, R.D., Rymer, M.J., Goldman, M.R., Sickler, R.R., and Criley, C.J., 2014, A method and example of seismically imaging near-surface fault zones in geologically complex areas using $V_{\mathrm{P}}, V_{\mathrm{S}}$, and their ratios: Bulletin of the Seismological Society of America, v. 104, p. 1989-2006, https://doi.org/10.1785/0120130294.

Cormier, V.F., and Spudich, P., 1984, Amplification of ground motion and waveform complexity in fault zones-Examples from the San Andreas and Calaveras faults: Geophysical Journal of the Royal Astronomical Society, v. 79, p. 135-152.

Eberhart-Phillips, D., 1990, Three-dimensional P and S velocity structure in the Coalinga region, California: Journal of Geophysical Research, v. 95, p. 15,343-15,363.

Eberhart-Phillips, D., and Michael, A.J., 1998, Seismotectonics of the Loma Prieta, California, region determined from three-dimensional $V_{\mathrm{P}}, V_{\mathrm{P}} / V_{\mathrm{S}}$, and seismicity: Journal of Geophysical Research, $\mathrm{v}$. 103, p. 21,099-21,120.

Ellsworth, W.L., and Malin, P.E., 2011, Deep rock damage in the San Andreas Fault revealed by P- and S-type fault-zone-guided waves: Geological Society of London Special Publications, v. 359, p. 39-53, https://doi.org/10.1144/SP359.3.

Fohrmann, M., Ingel, H., Jahnke, G., and Ben-Zion, Y., 2004, Guided waves from sources outside faults-An indication for shallow fault zone structure?: Pure and Applied Geophysics, v. 161, p. 2125-2137, https://doi.org/10.1007/s00024-004-2553.

Group Delta, 2015, Fault Activity Report, 6044 Carlos Avenue, Hollywood district, City of Los Angeles, California: GDC Project No. LA-1230, 99 p.

Hayashi, K., 2008, Development of surface wave methods and its application to site investigations: Kyoto, Japan, Kyoto University, Ph.D. dissertation, 304 p., https://doi.org/10.14989/doctor.k13774.

Hayashi, K., and Suzuki, H., 2004, CMP cross-correlation analysis of multichannel surface-wave data: Exploration Geophysics, v. 35, p. 7-13, https://doi.org/10.1071/EG04007.

Healy, J., and Peake, L., 1975, Seismic velocity structure along a section of the San Andreas fault near Bear Valley, California: Bulletin of the Seismological Society of America, v. 65, p. 1177-1197.

Hole, J.A., 1992, Nonlinear high-resolution three-dimensional seismic traveltime tomography: Journal of Geophysical Research, v. 97, p. 6553-6562.

Hough, S.E., Ben-Zion, Y., and Leary, P.C., 1994, Fault-zone waves observed at the southern Joshua Tree earthquake rupture zone: Bulletin of the Seismological Society of America, v. 84, p. 761-767. Huang, B.S., Teng, T.L., and Yeh, Y.T., 1995, Numerical modeling of fault-zone trapped wavesAcoustic case: Bulletin of the Seismological Society of America, v. 85, p. 1711-1717.

Ingel, H., Jahnke, G., and Ben-Zion, Y., 2002, Numerical simulation of fault zone guide wavesAccuracy and 3-D effects: Pure Applied Geophysics, v. 159, p. 2067-2083.

Jahnke, G., Ingel, H., and Ben-Zion, Y., 2002, Three-dimensional calculations of fault-zone-guided waves in various irregular structures: Geophysical Journal International, v. 151, p. 416-426.

Jarchow, C.M., Catchings, R.D., and Lutter, W.J., 1994, Large-explosive source, wide-recording aperture, seismic profiling on the Columbia Plateau, Washington: Geophysics, v. 59, p. 259-271.

Korneev, V.A., Nadeau, R.M., and McEvilly, T.V., 2003, Seismological studies at Parkfield IX-Fault zone imaging using guided wave attenuation: Bulletin of the Seismological Society of America, v. 93, p. 1415-1426. 
Leary, P.C., Li, Y.-G., and Aki, K., 1987, Observation and modelling of fault-zone fracture seismic anisotropy. I. P, SV and SH travel times: Geophysical Journal of the Royal Astronomical Society, v. 91, p. 461-484.

Li, Y.-G., Catchings, R.D., and Goldman, M.R., 2016, Subsurface fault damage zone of the $2014 \mathrm{Mw}$ 6.0 South Napa, California, earthquake viewed from fault-zone trapped waves: Bulletin of the Seismological Society of America, v. 106, p. 2747-2763, https://doi.org/10.1785/0120160039.

Li, Y.-G., De Pascale, G.P., Quigley, M.C., and Gravley, D.M., 2014, Fault damage zones of the M7.1 Darfield and M6.3 Christchurch earthquakes characterized by fault-zone trapped waves: Tectonophysics, v. 618, p. 79-101.

Li, Y.-G., Ellsworth, W.L., Thurber, C.H., Malin, P.E., and Aki, K., 1997, Fault zone guided waves from explosions in the San Andreas fault at Parkfield and Cienega Valley, California: Bulletin of the Seismological Society of America, v. 87, p. 210-221.

Li, Y.-G., and Leary, P.C., 1990, Fault zone trapped seismic waves: Bulletin of the Seismological Society of America, v. 80, p. 1245-1271.

Li, Y.-G., Leary, P.C., Aki, K., and Malin, P.E., 1990, Seismic trapped modes in the Oroville and 577 San Andreas fault zones: Science, v. 249, p. 763-766.

Li, Y.-G., Malin, P.E., and Vidale, J.E., 2007, Low-velocity damage zone on the San Andreas fault at depth near SAFOD site at Parkfield delineated by fault-zone trapped waves: Scientific Drilling, v. 1, p. 73-77, https://doi.org/10.2204/iodp.sd.s01.09.2007.

Li, Y.-G., and Vidale, J.E., 1996, Low-velocity fault-zone guided waves-Numerical investigations of trapping efficiency: Bulletin of the Seismological Society of America, v. 86, p. 371-378.

Li, Y.-G., Vidale, J.E., Aki, K., and Xu, F., 2000, Depth-dependent structure of the Landers fault zone from trapped waves generated by aftershocks: Journal of Geophysical Research, v. 105, p. 6237-6254.

Malin, P.E., Lou, M., and Rial, J.A., 1996, FR waves-A second fault-guided mode with implications for fault property studies: Geophysical Research Letters, v. 23, p. 3547-3550.

Malin, P.M., Shalev, E., Balven, H., and Lewis-Kenedi, C., 2006, Structure of the San Andreas fault at SAFOD from P-wave tomography and fault-guided wave mapping: Geophysical Research Letters, v. 33, L13314, https://doi.org/10.1029/2006GL025973.

Mayer-Rosa, D., 1973, Travel time anomalies and distribution of earthquakes along the Calaveras fault zone, California: Bulletin of the Seismological Society of America, v. 72, p. 901-910.

Mooney, W.D., and Ginzburg, A., 1986, Seismic measurements of the internal properties of fault zones: Pure and Applied Geophysics, v. 124, p. 141-157.

Mooney, W.D., and Luetgert, J.H., 1982, A seismic refraction study of the Santa Clara Valley and southern Santa Cruz Mountains, west-central California: Bulletin of the Seismological Society of America, v. 72, p. 901-909.

Ninyo and Moore, 2015a, Fault rupture hazard evaluation, Hollywood Courthouse, Los Angeles, California: Ninyo and Moore, Project No. 402132007, February 24, 2015.

Ninyo and Moore, 2015b, Supplemental Fault rupture hazard evaluation, Hollywood Courthouse, Los Angeles, California, Project No. 402132007, June 15, 2015.

Park, C.B., Miller, R.D., and Xia, J., 1999, Multichannel analysis of surface waves: Geophysics, v. 64, p. 800-808.

Rovelli, A., Caserta, A., Marra, F., and Ruggiero, V., 2002, Can seismic waves be trapped inside an inactive fault zone? The case study of Nocera Umbra, Central Italy: Bulletin of the Seismological Society of America, v. 92, p. 2217-2332.

Spudich, P., and Olsen, K.B., 2001, Fault zone amplified waves as a possible seismic hazard along the Calaveras fault in central California: Geophysical Research Letters, v. 28, p. 2533-2536. 
Thurber, C.H., 1983, Earthquake locations and three-dimensional crustal structure in the Coyote Lake area, central California: Journal of Geophysical Research, v. 88, p. 8226-8236, https://doi.org/10.1029/JB088iB10p08226.

Thurber, C.H., and Atre, S.R., 1993, Three-dimensional $V_{\mathrm{P}} / V_{\mathrm{S}}$ variations along the Loma Prieta rupture zone: Bulletin of the Seismological Society of America, v. 83, p. 717-736.

Thurber, C.H., Atre, S.R., and Eberhart-Phillips, D., 1995, Three-dimensional $V_{\mathrm{P}}$ and $V_{\mathrm{P}} / V_{\mathrm{S}}$ structure at Loma Prieta, California, from local earthquake tomography: Geophysical Research Letters, v. 22, p. 3079-3082.

Wang, C.Y., Lin, W., and Wu, F.T., 1978, Constitution of the San Andreas fault zone at depth: Geophysical Research Letters, v. 5, p. 741-744.

Xia, J., Miller, R.D., and Park, C.B., 1999, Estimation of near-surface shear-wave velocity by inversion of Rayleigh waves: Geophysics, v. 64, p. 691-700.

Xia, J., Xu, Y., Lou, Y., Miller, R.D., Cakir, R., and Zeng, C., 2012, Advantages of using multichannel analysis of Love waves (MALW) to estimate near-surface shear-wave velocity: Surveys in Geophysics, v. 33, p. 841-860.

Yong, A., Martin, A., Stokoe, K., and Diehl, J., 2013, ARRA-funded $V_{\text {S30 }}$ measurements using multitechnique approach at strong-motion stations in California and central-eastern United States: U.S. Geological Survey Open-File Report 2013-1102, 60 p. and data files, accessed December 18, 2018, at https://pubs.usgs.gov/of/2013/1102/.

Yuan, J., 2011, Field studies comparing SASW, beamforming, and MASW test methods and characterization of geotechnical materials based on $V_{\mathrm{S}}$ : Austin, University of Texas at Austin, Ph.D. dissertation, $296 \mathrm{p}$. 